ANDRÉ LUIZ NUNIS DA SILVA

DINÂMICA E CONTROLE DE UM SISTEMA DE CRISTALIZAÇÃO POR EVAPORAÇÃO MÚLTIPLO-EFEITO

São Paulo, 2012 
ANDRÉ LUIZ NUNIS DA SILVA

\title{
DINÂMICA E CONTROLE DE UM SISTEMA DE CRISTALIZAÇÃO POR EVAPORAÇÃO MÚLTIPLO-EFEITO
}

\author{
Dissertação apresentada à Escola \\ Politécnica da Universidade de São \\ Paulo para obtenção do título de \\ Mestre em Engenharia.
}

São Paulo, 2012 
ANDRÉ LUIZ NUNIS DA SILVA

\title{
DINÂMICA E CONTROLE DE UM SISTEMA DE CRISTALIZAÇÃO POR EVAPORAÇÃO MÚLTIPLO-EFEITO
}

\author{
Dissertação apresentada à Escola \\ Politécnica da Universidade de São \\ Paulo para obtenção do título de \\ Mestre em Engenharia.
}

Área de Concentração: Engenharia Química

Orientador: Prof. Dr. Marcelo Martins Seckler

São Paulo, 2012 
Este exemplar foi revisado e alterado em relação à versão original, sob responsabilidade única do autor e com a anuência de seu orientador.

São Paulo, de novembro de 2012.

Assinatura do autor

Assinatura do orientador

Silva, André Luiz Nunis da

Dinâmica e controle de um sistema de cristalização por evaporação múltiplo-efeito / A.L.N. da Silva. -- ed.rev. -- São Paulo, 2012.

$126 \mathrm{p}$.

Dissertação (Mestrado) - Escola Politécnica da Universidade de São Paulo. Departamento de Engenharia Química.

1.Controle de processos 2.Cristalização 3.Evaporação multiplo-efeito I.Universidade de São Paulo. Escola Politécnica.

Departamento de Engenharia Química II.t. 


\section{AGRADECIMENTOS}

Agradeço

Aos professores Darci Odloak e Marcelo Martins Seckler pela orientação e principalmente pela paciência e crédito depositados em mim.

A minha mãe Izaura e a meus irmãos Otávio, Ricardo e Ana pelo apoio incondicional na realização deste trabalho.

Aos meus amigos Alexandre e Cezar pelos papos jogados fora.

Pelos momentos de distração e descanso mental proporcionados pelos amigos da UNICAMP Thiago, Gabriel, Natália, Marcia, Luís (Tio Lu) e Roberto.

Aos Brunos pela gentileza em ceder seus computadores em momentos de necessidade de inclusão digital no LSCP.

Ao Marquito pelo incentivo da escolha desse tema.

Ao IPT e os colegas do LPP por acreditarem em mim. 
"O silêncio vai salvar-me de estar errado (e de ser idiota), mas que também irá privarme da possibilidade de estar certo"

Igor Stravinsky 


\section{RESUMO}

O desenvolvimento de métodos que aumentem a eficiência de controle de processos de cristalização ganhou importância devido à necessidade de melhoras nas taxas de produção, minimizando os custos de energia e mantendo a qualidade das partículas. Neste trabalho os autores estudaram a aplicação de um controlador preditivo (MPC) a um processo de cristalização de cloreto de sódio por evaporação múltiplo-efeito, com alimentação paralela, permitindo que a planta busque, em tempo real, o melhor ponto de operação respeitando os limites definidos. Primeiramente, foi criado um modelo fenomenológico não linear através de balanços de massa, energia e momento considerando a cinética de cristalização, de forma que se possa simular a dinâmica de operação dos cinco efeitos operando dependentemente. O modelo físico possibilitou a aplicação de um controlador do tipo MPC com zona de controle permitindo que as principais variáveis de saída encontrem, dentro de uma faixa de operação aceitável, o ponto ótimo do processo nas condições atuais. Ao mesmo sistema foi aplicado um controlador clássico do tipo PID para avaliação dos ganhos adquiridos pela técnica de controle por predição do estado futuro da planta, observando uma melhor estabilidade e queda no consumo energético.

Palavras-chave: Cristalização, Evaporação Múltiplo-efeito, Controle Preditivo. 


\begin{abstract}
The development of methods to increase the efficiency of the crystallization process control has gained importance due to the need to improve production rates, to minimize energy costs and to improve the quality of particulate products. In this work the author has applied a model predictive control (MPC) to a continuous forced circulation five-stage evaporative sodium chloride crystallizer with parallel feed, providing the real time search of the best operating point inside the defined set of constraints. First, a non-linear phenomenological model was developed by mass, energy and moment balances coupled to the crystallization kinetics, to simulate the dynamic operation of the five effects working dependently. The physical model enabled the study of the implementation of a model predictive control MPC with zone control that allows the main output variables to be controlled in acceptable operating ranges and the detection of the optimum operating point of the process corresponding to current economic conditions. To evaluate the benefits of the advanced control strategy, a classical PID control system was also implemented in the crystallization system and the two strategies were compared to evaluate the benefit of the model based predictive strategy that provides a better stability and a decrease in the energy consumption.
\end{abstract}

Keywords: Crystallization, multiple-effect evaporation, model predictive control. 


\section{LISTA DE ILUSTRAÇÕES}

Figura 1 - Curva de Solubilidade para uma substância típica (adaptado de Jancic e Grootscholten, 1984) ...................................................... 24

Figura 2 - Evaporador por simples efeito - adaptado de Geankoplis, (2003) ... 33

Figura 3 - Evaporador Múltiplo-efeito com alimentação co-corrente - adaptado de Geankoplis, (2003)

Figura 4 - Evaporador Múltiplo-efeito com alimentação contracorremte adaptado de Geankoplis, (2003) ............................................ 34

Figura 5 - Evaporador Múltiplo-efeito com alimentação paralela....................... 35

Figura 6 - Diagrama de blocos para o controle preditivo (Adaptado de Seborg et

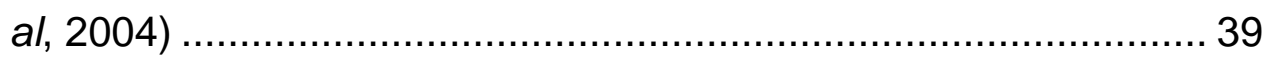

Figura 7 - Estrutura de controle (adaptado de González e Odloak (2009)) ...... 45

Figura 8 - Fluxograma Simplificado do Processo ............................................. 51

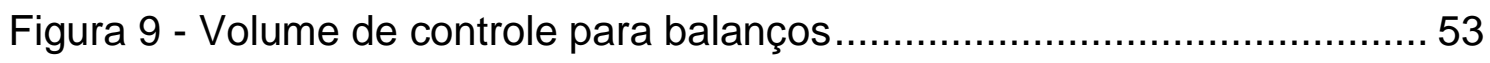

Figura 10 - Esquema simplificado de simulação do processo.......................... 77

Figura 11 - Dependência de variáveis entre os efeitos. .................................. 79

Figura 12 - Esquema de aplicação do controlador PID .................................. 81

Figura 13 - Temperatura do primeiro efeito ao longo do tempo...................... 84

Figura 14 - Fração de sólidos do primeiro efeito ao longo do tempo................. 84

Figura 15 - Temperatura do segundo efeito ao longo do tempo....................... 85

Figura 16 - Fração de sólidos do segundo efeito ao longo do tempo ................ 85

Figura 17 - Temperatura do terceiro efeito ao longo do tempo ........................ 86

Figura 18 - Fração de sólidos do terceiro efeito ao longo do tempo.................. 86

Figura 19 - Temperatura do quarto efeito ao longo do tempo ......................... 87

Figura 20 - Fração de sólidos do quarto efeito ao longo do tempo …............... 87

Figura 21 - Temperatura do quinto efeito ao longo do tempo ........................ 88

Figura 22 - Fração de sólidos do quinto efeito ao longo do tempo .................... 88

Figura 23 - Fração de sólidos e temperatura no primeiro efeito após perturbação na vazão de alimentação do terceiro efeito ................ 89

Figura 24 - Fração de sólidos e temperatura no segundo efeito após perturbação na vazão de alimentação do terceiro efeito ................ 90

Figura 25 - Fração de sólidos e temperatura no terceiro efeito após perturbação na vazão de alimentação do terceiro efeito ................................... 90 
Figura 26 - Fração de sólidos e temperatura no quarto efeito após perturbação na vazão de alimentação do terceiro efeito

Figura 27 - Fração de sólidos e temperatura no quinto efeito após perturbação na vazão de alimentação do terceiro efeito

Figura 28 - Concentração de sólidos nos efeitos (a) 1, (b) 2, (c) 3, (d) 4, (e) 5 frente a uma duplicação na vazão de alimentação $A c$ de todos os efeitos.

Figura 29 - Mudanças na variável manipulada para identificação do sistema . 94

Figura 30 - Modelos lineares identificados a partir da resposta ao degrau na corrente de alimentação do terceiro estágio. .95

Figura 31 - Fração mássica de cristais no primeiro efeito para controle PID ... 99

Figura 32 - Fração mássica de cristais no segundo efeito para controle PID. 100 Figura 33 - Fração mássica de cristais no terceiro efeito para controle PID .. 100 Figura 34 - Fração mássica de cristais no quarto efeito para controle PID .... 101 Figura 35 - Fração mássica de cristais no quinto efeito para controle PID .... 101 Figura 36 - Variação de temperatura no primeiro efeito para controle PID .... 102 Figura 37 - Fração mássica de cristais no quinto efeito para controle PID .... 102 Figura 38 - supersaturação no quarto efeito para controle PID...................... 104

Figura 39 - Consumo energético da unidade para controle PID .................... 105

Figura 40 - Fração mássica de cristais no primeiro efeito para controle IHMPC 107

Figura 41 - Fração mássica de cristais no segundo efeito para controle IHMPC 107

Figura 42 - Fração mássica de cristais no terceiro efeito para controle IHMPC 108

Figura 43 - Fração mássica de cristais no quarto efeito para controle IHMPC 108

Figura 44 - Fração mássica de cristais no quinto efeito para controle IHMPC109

Figura 45 - Temperatura no primeiro efeito para controle IHMPC................... 109

Figura 46 - Temperatura no quinto efeito para controle IHMPC..................... 110

Figura 47 - Consumo energético da unidade para controle IHMPC ................ 111

Figura 48 - Supersaturação no quarto efeito para controle IHMPC................. 112

Figura 49 - Fração mássica de cristais para o primeiro efeito: a) IHMPC b) PID 
Figura 50 - Fração mássica de cristais para o segundo efeito: a) IHMPC b) PID

Figura 51 - Fração mássica de cristais para o terceiro efeito: a) IHMPC b) PID 113

Figura 52 - Fração mássica de cristais para o quarto efeito: a) IHMPC b) PID 114

Figura 53 - Fração mássica de cristais para o quinto efeito: a) IHMPC b) PID 114

Figura 54 - Consumo energético da planta: a) IHMPC b) PID........................ 114

Figura 55 - Consumo energético da planta: a) IHMPC b) PID......................... 116 


\section{LISTA DE TABELAS}

Tabela 1 - Condições iniciais de processo para operação ............................... 83

Tabela 2 - Modelos discretos identificados a partir da resposta da fração mássica ao degrau nas vazões de alimentação

Tabela 3 - Ajustes do controlador PID, para controle das concentrações $x_{1}, x_{2}$, $\mathrm{x}_{3}, \mathrm{x}_{4}$ e $\mathrm{x}_{5}$ para as temperaturas do primeiro e quinto efeito. 98

Tabela 4 - Valores de Set-points para controlador PID .................................. 98

Tabela 5 - Valores iniciais para simulação do controlador ............................... 99

Tabela 6 - Ponto ótimo calculado pelo RTO ................................................. 106

\section{ANEXOS}

Tabela A. 1- Coeficientes para a equação de Antoine para salmoura saturada e água pura (Kaufmann, 1960)

Tabela A. 2 - Poder calorífico de soluções saturadas de $\mathrm{NaCl}$ (Kaufmann, 1960).

Tabela A. 3 - Solubilidade da salmoura em função da temperatura (Kaufmann, 1960). 124

Tabela A. 4 - Densidade de Salmoura saturada (Mullin, 2001) 124

Tabela A. 5 - Propriedades do cristal de $\mathrm{NaCl}$ 125

Tabela A. 6 - Propriedades da água pura (Incropera e Witt, 1992). 125

Tabela A. 7- Constantes e expoentes da taxa de crescimento e nucleação .. 125

Figura A. 1 - Comparação entre o modelo com massa total do cristalizador constante e massa do cristalizador variável com a densidade.. 126 


\section{LISTA DE ABREVIAÇÔES}

ARX Autoregressive with Exogenous Input

CSD Crystal Size Distribution

EDO Equação Diferencial Ordinária

GSPI Gain-Schedule Proportional Integral

IHMPC Infinite Horizon Model Predictive Control

ITAE Integral of the Time-Weighted Absolute Error

MIMO Multiple Input, Multiple Output

MPC Model Predictive Control

NLPI Nonlinear Proportional and Integral

NMPC Nonlinear Model Predictive Control

PI Controlador Proporcional e Integral

PID Controlador Proporcional, Integral e Derivativo

RTO Real Time Optimization

SISO Single Input, Single Output 


\section{LISTA DE SÍMBOLOS}

A Matriz de estado para as variáveis de controle

A Área de troca térmica no modelo fenomenológico $\left[\mathrm{m}^{2}\right]$

$\overline{\mathrm{A}} \quad$ Matriz utilizada para cálculo de variáveis otimizadas

$\mathrm{Ac}_{\mathrm{i}} \quad$ Vazão mássica de alimentação na circulação $[\mathrm{kg} / \mathrm{h}]$

$A p_{i} \quad$ Vazão mássica de alimentação na perna elutriadora [kg/h]

$A_{p} \quad$ Constante da equação de Antoine

B Matriz de entradas para as variáveis de controle

$\overline{\mathrm{B}} \quad$ Matriz utilizada para cálculo de variáveis otimizadas

Bo Taxa de nascimento de partículas [\#/s]

$B_{p} \quad$ Constante da equação de Antoine

C Matriz de saída para as variáveis de controle

$\mathrm{C}_{\mathrm{p}} \quad$ Constante da equação de Antoine

$\mathrm{Cp}_{\mathrm{i}}$ Potencial calorífico da suspensão no estágio $i\left[\mathrm{~kJ} / \mathrm{kg}^{\circ} \mathrm{C}\right]$

$\mathrm{Cp}_{\mathrm{ap}}$ Potencial calorífico da vazão de entrada pela perna elutriadora $\left[\mathrm{kJ} / \mathrm{kg}^{\circ} \mathrm{C}\right]$

c Concentração de soluto na saturação $\left[\mathrm{kg} / \mathrm{m}^{3}\right.$ de suspensão]

$\mathrm{c}_{\mathrm{i}} \quad$ Concentração de soluto no efeito $i\left[\mathrm{~kg} / \mathrm{m}^{3}\right.$ de suspensão]

D Taxa de destruição de partículas [\#/s]

$d^{0}, d_{i}^{d}$ Matrizes obtidos pela expansão parcial do modelo $G_{i, j}$

Fu Matriz utilizada para cálculo de variáveis otimizadas

Fx Matriz utilizada para cálculo de variáveis otimizadas

Go Velocidade de crescimento de partículas [m/s] 
$\mathrm{G}_{\mathrm{i}, \mathrm{j}} \quad$ Função transferência representativa do modelo

$\mathrm{H}_{\mathrm{v}} \quad$ Entalpia de vapor $[\mathrm{kJ} / \mathrm{kg}]$

$\Delta \mathrm{H}_{\mathrm{cr}} \quad$ Entalpia de cristalização

I Matriz identidade

$\bar{I} \quad$ Conjunto de matrizes identidade

k Instante do tempo

$\mathrm{K}_{\mathrm{ob}} \quad$ Matriz de ganho do observador.

$\mathrm{K}_{\mathrm{d}} \quad$ Ganho derivativo do controlador PID

$\mathrm{K}_{\mathrm{i}} \quad$ Ganho integral do controlador PID

$\mathrm{K}_{\mathrm{p}} \quad$ Ganho proporcional do controlador PID

L Tamanho da partícula

$\mathrm{L}_{s} \quad$ Massa da solução

$\mathrm{M}_{\mathrm{i}} \quad$ Massa total de suspensão no evaporador $i$

m Horizonte de controle para definição do controlador

$\mathrm{m}_{\mathrm{j}} \quad$ j-ésimo momento para definição do modelo

n Densidade populacional $\left[\# / \mathrm{m}^{\mathrm{m}} \mathrm{m}^{3}\right]$

nu Número de variáveis manipuladas

ny Número de variáveis controladas

p Horizontes de predição para o controlador

$P_{\mid} \quad$ Vazão de produto em suspensão para o modelo

Pv Pressão de vapor

Qi Calor trocado nos condensadores

Q Matriz de fatores de atenuação das variáveis controladas 
Q Matriz obtida pela solução da equação de Lyapunov

$q^{-1} \quad$ Operador de atraso

$Q_{u} \quad$ Pesos para variáveis entrada

$\overline{\mathrm{Q}}_{u} \quad$ Matriz diagonal das variáveis de peso $\mathrm{Q}_{u}$

$Q_{y} \quad$ Pesos para variáveis entrada

$\overline{\mathrm{Q}}_{\mathrm{y}} \quad$ Matriz diagonal das variáveis de peso $\mathrm{Q}_{\mathrm{y}}$

R Matriz de fatores de atenuação das variáveis manipuladas

$\overline{\mathrm{R}} \quad$ Matriz diagonal das variáveis de peso $\mathrm{R}$

$r_{1} \quad$ Polos do sistema

S Massa de sólidos em suspensão [kg]

$\mathrm{S}(\mathrm{t}) \quad$ Resposta a perturbação degrau do modelo

$\mathrm{S}_{u} \quad$ Pesos para as variáveis de folga das variáveis de saída

Sy Pesos para as variáveis de folga das variáveis de entrada

T Temperatura do cristalizador $\left[{ }^{\circ} \mathrm{C}\right]$

$t_{a} \quad$ Tempo amostral [s]

$\mathrm{T}_{\mathrm{ap}}$ Temperatura de alimentação na perna elutriadora $\left[{ }^{\circ} \mathrm{C}\right]$

$\mathrm{T}_{\mathrm{s}} \quad$ Temperatura do vapor saturado $\left[{ }^{\circ} \mathrm{C}\right]$

$\mathrm{T}_{\text {cei }} \quad$ Temperatura da suspensão em recirculação $\left[{ }^{\circ} \mathrm{C}\right]$

$\mathrm{U} \quad$ Coeficiente global de troca térmica $\left[\mathrm{W} / \mathrm{m}^{2} \mathrm{~K}\right]$

u Variável manipulada

$\Delta \mathrm{u}$ Incremento das entradas

$u_{\text {des }} \quad$ Valor ótimo da variável manipulada 
$\dot{V} \quad$ Vazão volumétrica para a corrente $\left[\mathrm{m}^{3} / \mathrm{h}\right]$

$V_{i} \quad$ Vazão de vapor de cada efeito $[\mathrm{kg} / \mathrm{h}]$

$\mathrm{v}(\mathrm{k}) \quad$ Ruido branco no instante $\mathrm{k}$

$V_{0} \quad$ Vazão mássica de vapor vivo $[\mathrm{kg} / \mathrm{h}]$

$V_{k, u} \quad$ Função objetivo a ser minimizada para o controlador

$V_{t} \quad$ Volume total de suspensão no cristalizador [m³]

X Matriz de variáveis otimizadas

$x(k)$ Vetor variável de estado para a definição do controlador

$\tilde{x} \quad$ Variável de estado estimado

x Fração mássica de partículas [kg/kg de suspensão]

$x^{d} \quad$ Estado dos modos do sistema

y(k) Variável de saída no instante $k$

$\mathrm{y}_{\mathrm{sp}} \quad$ Valor de "set-point" das variáveis controladas.

w Fração mássica de soluto de cloreto de sódio na saturação

z Variável de atraso

\section{Subscritos}

c Relativo à circulação forçada

e Relativo à entrada do cristalizador pela circulação forçada

i Índice representativo do número do efeito da planta

j I Índice de j-ésimo momento

$\mathrm{P} \quad$ Relativo à perna elutriadora

S Relativo à saída do cristalizador pela circulação forçada 


\section{Alfabeto grego}

$\delta_{\mathrm{u}} \quad$ Variáveis de folga para as entradas do sistema

$\delta_{\mathrm{y}} \quad$ Variáveis de folga para as entradas do sistema

$\lambda\left(T_{i}\right) \quad$ Calor latente de vaporização a temperatura $\mathrm{Ti}[\mathrm{kJ} / \mathrm{kg}]$

$\Pi_{n u} \quad$ Matriz utilizada para cálculo de variáveis otimizadas

$\rho_{\mathrm{L}} \quad$ Densidade da solução $\left[\mathrm{kg} / \mathrm{m}^{3}\right]$

ps Densidade dos sólidos em suspensão $\left[\mathrm{kg} / \mathrm{m}^{3}\right]$ 


\section{SUMÁRIO}

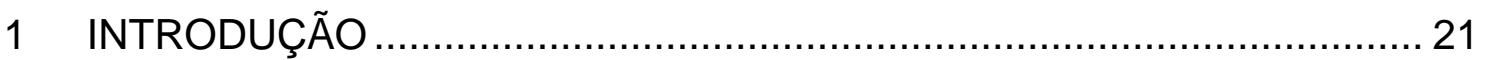

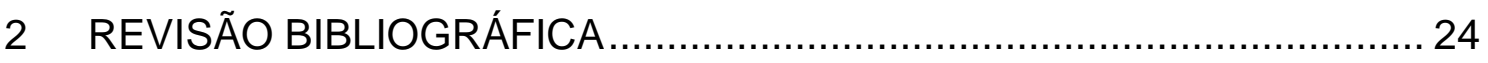

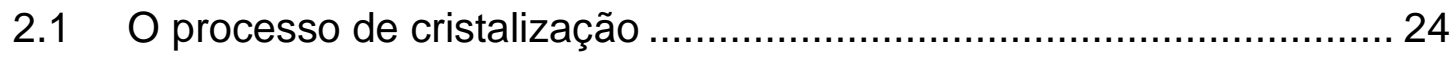

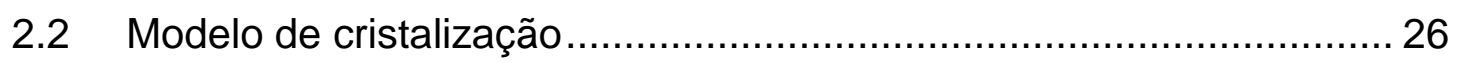

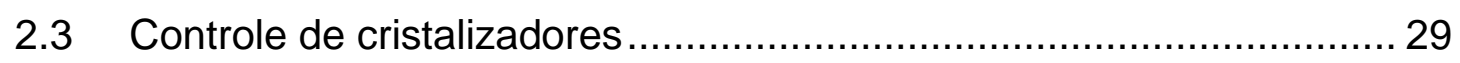

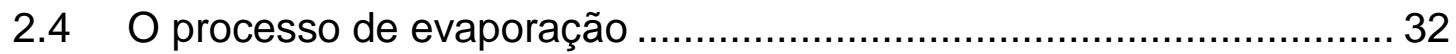

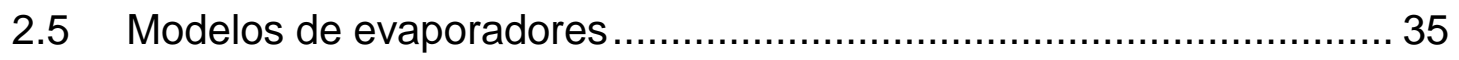

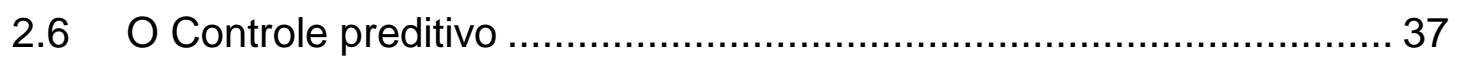

2.7 Aplicação de controle preditivo ………….................................... 46

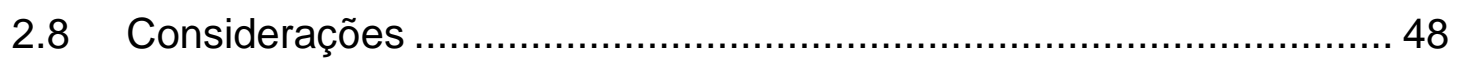

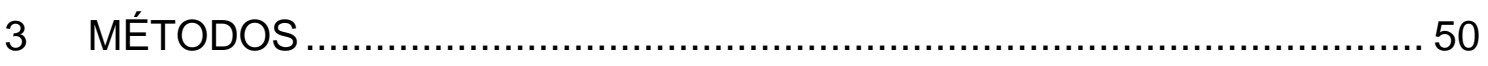

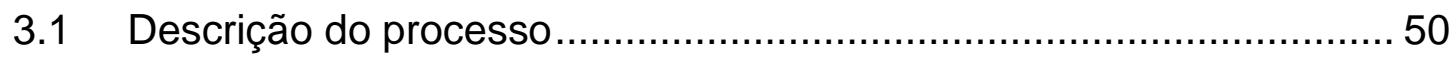

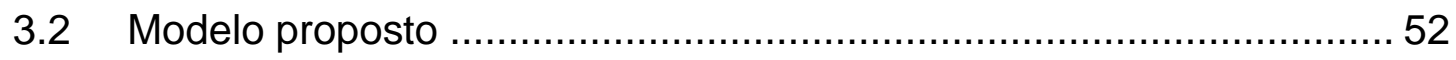

3.3 Identificação do sistema - Modelo auto-regressivo com entradas

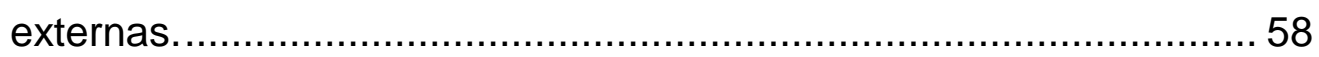

3.4 Controlador Proporcional, Integral e Derivativo................................... 60

3.5 Controlador preditivo de horizonte infinito com controle por faixas ..... 61

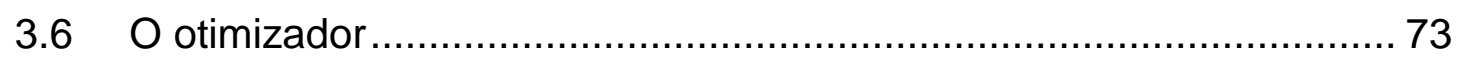

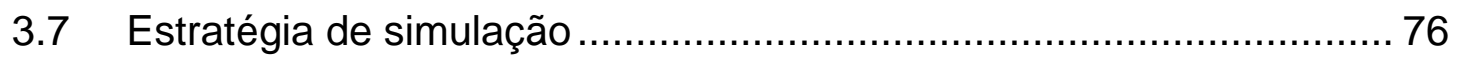

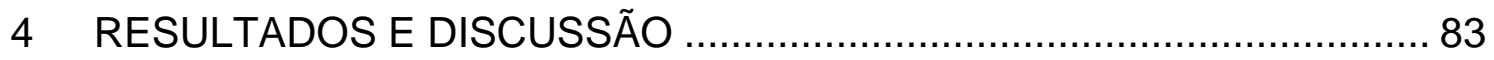

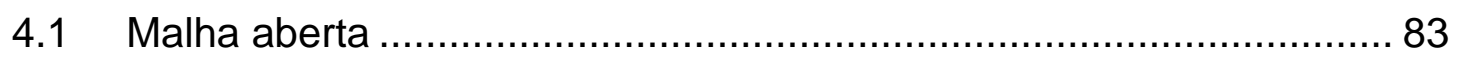

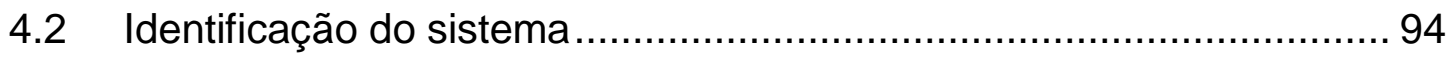




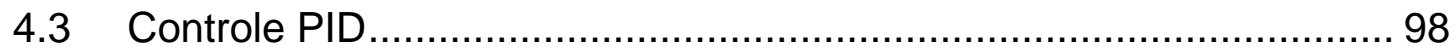

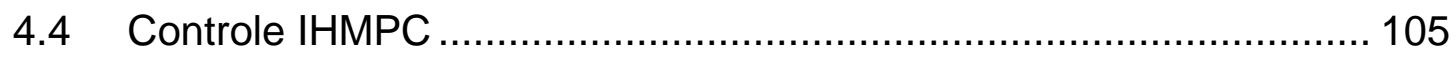

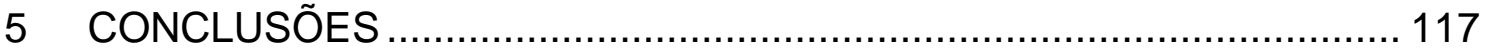

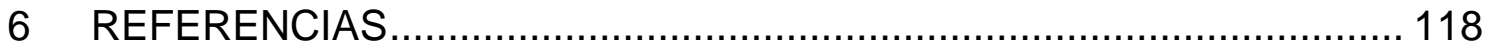

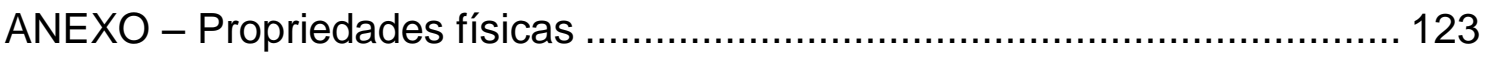




\section{INTRODUÇÃO}

Cristalização por evaporação é uma das operações unitárias mais utilizadas na indústria, largamente aplicada para purificação e separação. O processo de cristalização possui importância econômica na fabricação de produtos como açúcar, cloreto de sódio, ácido bórico, alumina, além de outros.

Para que esse tipo de cristalização ocorra, é necessário que seja disponível energia suficiente para a evaporação do solvente. $O$ consumo de energia de um processo evaporativo pode representar $70 \%$ do consumo total da unidade produtiva (Runyon et al., 1991).

Devido aos altos custos econômicos e ambientais associados ao consumo de energia, engenheiros buscam constantemente meios para minimizá-la, ajustando a configuração dos equipamentos e especificando a melhor condição de operação. Por exemplo, a configuração de evaporadores em múltiplo-efeito permite minimizar os gastos de energia por volume de produção, já que o calor latente do vapor gerado pela evaporação de um efeito pode ser reaproveitado no efeito seguinte (Billet, 1989).

É difícil manter um processo operando continuamente dentro das condições especificadas. Perturbações que venham acontecer nas variáveis como vazão e temperatura podem levar a uma condição em que haja um consumo de energia maior ou comprometer a segurança de operação ao se atingir determinados limites dos equipamentos de processo. Controladores foram desenvolvidos de modo a manter automaticamente essas especificações e proteger o processo de perturbações.

Com o desenvolvimento da computação, os métodos de controle se aperfeiçoaram, ampliando o escopo do controle. Assim, busca-se não somente manter a unidade operando em uma determinada condição pré-estabelecida, mas também encontrar condições ótimas adaptáveis frente às mudanças físicas devidas aos desgastes ou mudanças das variáveis como alimentação ou influências externas que venham a alterar o processo. Pode-se citar 0 desenvolvimento dos algoritmos para controle preditivo como o MPC (Model 
Predictive Control), que têm a capacidade de manter as restrições operacionais e ao mesmo tempo otimizar em tempo real o sistema controlado (Patra et al., 2007).

O controle preditivo MPC se refere a uma classe de algoritmos de controle capaz de predizer a resposta futura da planta a partir de um modelo matemático representativo do processo (Qin e Badgwell, 2003), otimizando a cada momento a trajetória futura do processo a partir de cálculos de uma sequência de ajustes futuros das variáveis manipuladas. Esse controlador geralmente utiliza para a predição, modelos lineares discretos que representem a dinâmica do sistema, sejam eles obtidos por modelagem fenomenológica ou por métodos de identificação.

O uso do controle preditivo em processos de cristalização se mostrou mais vantajoso com relação a outros algoritmos clássicos como o controlador proporcional-integral-derivativo (PID). O método preditivo permite que determinadas restrições inerentes ao processo sejam respeitadas pelo controlador. Para processos de cristalização pode-se citar como restrições a concentração máxima de cristais numa solução, a supersaturação, que influenciará a cristalização e o tamanho médio de partículas, além de outras variáveis que podem comprometer a qualidade dos cristais produzidos, como a morfologia, que é alterada por temperaturas excessivas de operação.

Alguns exemplos de aplicação de controle preditivo para esse tipo de processo foram descritos por Bunin et al (2010), Christofides et al (2008), Corriou et al (2008). Todos eles reportaram melhorias tanto no consumo energético quanto na qualidade do produto ao se utilizar dessa técnica frente a algoritmos convencionais.

As aplicações de controlador avançado são descritas para cristalização em batelada, contínua para um simples efeito ou para processos evaporativos por múltiplo-efeito que não envolva cristalização (Rohani et al, 1999a; b; Cadet et al,1999; Shi et al, 2006; Liu et al, 2008; Suarez et al, 2009; Atuonwu et al, 2009; Damour et al, 2010). Informações com relação ao uso dessas técnicas de controle que envolva cristalização em evaporadores do tipo múltiplo-efeito 
são escassas e oferecem grande oportunidade de estudo, visando a otimização energética sem comprometer a qualidade do produto.

Neste trabalho propõe-se desenvolver um modelo dinâmico para um sistema de cristalização por evaporação múltiplo-efeito. Propõe-se também usar 0 modelo desenvolvido para a identificação de modelos lineares discretos. Finalmente, propõe-se aplicar os modelos lineares discretos em um controlador preditivo (MPC), com a finalidade de estudar a vantagem desse tipo de controlador em comparação com um controle PID clássico. Os resultados poderão ser utilizados para diminuir custos operacionais. 


\section{REVISÃO BIBLIOGRÁFICA}

\subsection{O processo de cristalização}

A cristalização de um soluto a partir de uma solução ocorre quando a solução está supersaturada, isto é, quando a concentração do soluto é maior que aquela prescrita pelo equilíbrio termodinâmico (Jancic e Grootscholten, 1984), representado na Figura 1 pela curva de solubilidade (curva $b-\mathrm{S}$ ).

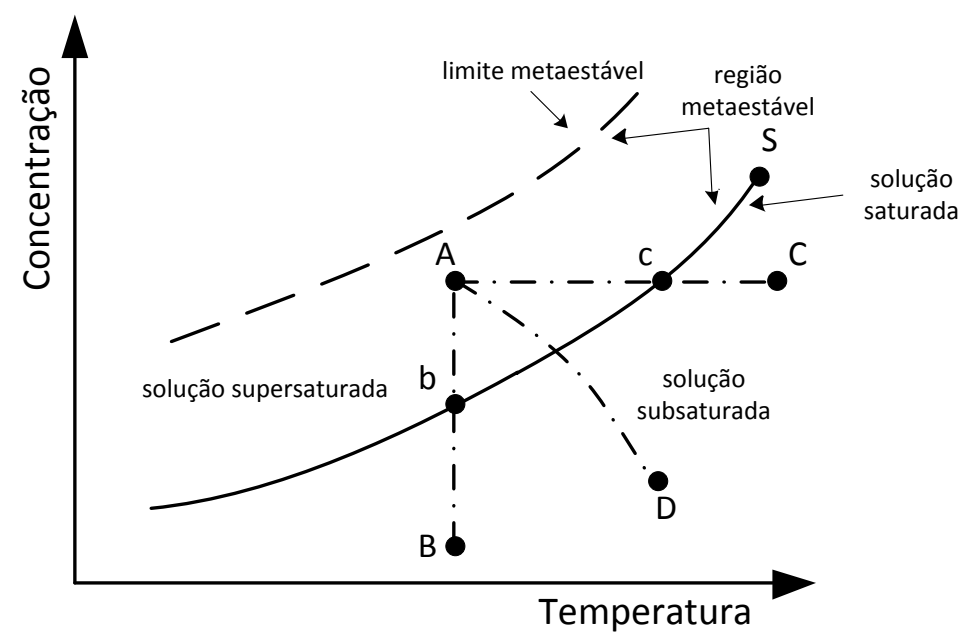

Figura 1 - Curva de Solubilidade para uma substância típica (adaptado de Jancic e Grootscholten, 1984)

A solução supersaturada tende a retornar para o equilíbrio, liberando o soluto em excesso pela formação de novos cristais. O nível de supersaturação é expresso pela diferença $\left(T_{A}-T_{C}\right)$ (Figura 1$)$ ou pela diferença $\left(C_{A}-C_{b}\right)$. Para cristalização evaporativa é preferível se empregar a segunda expressão.

Cristais presentes em uma solução supersaturada aumentam de tamanho. A taxa de crescimento molecular $(\mathrm{G}$, em $\mathrm{m} / \mathrm{s}$ ) é usualmente expressa como a seguinte função da supersaturação:

$G o=k_{g}\left(C_{A}-C_{B}\right)^{g}(1-a L)$

Onde

- $\mathrm{kg}$ é a constante da taxa de crescimento 
- g é o expoente da taxa de crescimento.

- L é o tamanho do cristal

- a é uma constante empírica que relaciona a dependência da taxa de crescimento com o tamanho $L$ de cristais.

A formação de novos cristais, denominada nucleação primária, é um processo mais difícil de acontecer se comparado à deposição de soluto em cristais já existentes, ocorrendo espontaneamente apenas quando a concentração do soluto supera o limite metaestável da solução, indicado pela linha pontilhada na Figura 1. Se a solução já contiver cristais, como é o caso de processos contínuos, ocorre a nucleação secundária, que é o aparecimento de novos núcleos de cristal a partir de fragmentos dos cristais existentes. A taxa de nucleação secundária (B) depende diretamente da supersaturação, da concentração de sólidos do meio $\left(\mathrm{C}_{\mathrm{so}}\right)$ e da energia de agitação dispendida $\varepsilon$. É usual se escrever para a nucleação a seguinte expressão.

$$
B o=k_{b}\left(C_{A}-C_{B}\right)^{b} C_{s o l}^{S} \varepsilon^{e}
$$

Onde

- $k_{b}$ é a constante da taxa de nucleação

- $b$ é o expoente da taxa de nucleação

A supersaturação pode ser atingida por resfriamento da solução ou concentrando a solução por evaporação. A evaporação pode ser isotérmica ou a vácuo. Há ainda dois outros métodos, a precipitação e a cristalização por anti-solventes.

A precipitação é um processo isotérmico no qual se altera a solubilidade do soluto a partir de uma reação química. Na cristalização por anti-solvente, o soluto apresenta uma baixa solubilidade na mistura de solvente e anti-solvente. A cristalização é conduzida adicionando-se o anti-solvente a uma mistura soluto-solvente. 
Num cristalizador evaporativo contínuo, uma população com um grande número de cristais coexiste em uma solução. A solução torna-se supersaturada pela evaporação do solvente. Nesta situação, há formação contínua de novos cristais e o crescimento dos cristais existentes a partir de transferência de soluto da fase líquida para a fase sólida. O processo é mantido à custa de troca de calor de uma fonte externa para a suspensão.

Processos que operam continuamente podem apresentar vantagens quanto a custos operacionais em relação a processos em batelada (Laerson et al, 2006). Esses permitem que ajustes nas condições operacionais sejam feitos com maior acuidade para se obter os melhores resultados em termos de consumo energético e produtividade. Isso permite um menor número de operadores e uma menor demanda de utilidades, minimizando o tamanho de outros equipamentos que participam do processo como refervedores, torre de resfriamento e geradores de energia. Também tem como vantagem um menor investimento de capital não somente no equipamento cristalizador em si, mas também no estoque de matéria-prima e produtos. Porém, quando a taxa de produção é pequena, passa a ser mais interessante se utilizar equipamentos que operam em batelada (Felder e Rousseau, 2005). Outras situações requerem o uso de cristalizadores em batelada, como em casos em que 0 produto possui alto valor agregado e devem-se minimizar as perdas, ou quando a cristalização exige uma queda brusca de temperatura para se atingir a supersaturação desejada, ou ainda para produzir diversos produtos no mesmo equipamento que exijam maior flexibilidade (Laerson et al, 2006).

\subsection{Modelo de cristalização}

A modelagem matemática responde à necessidade de se compreender os processos industriais e sua dinâmica. Isso é feito pela combinação de modelos teóricos e simulações computacionais que auxiliam no entendimento tanto de princípios básicos quanto do comportamento de processos complexos. No caso de processos de cristalização, os modelos permitem simular as características dos produtos, como tamanho e quantidade de partículas. A cristalização a partir de uma solução é caracterizada pela formação de um 
espectro de cristais de diferentes tamanhos (Wolf, 1990). Esse espectro, denominado Distribuição de Tamanho de Cristais (CSD do inglês Crystal Size Distribution) é importante para o comportamento do produto em operações que sucedem a cristalização como filtração, secagem, estocagem e transporte bem como para o desempenho do produto em sua aplicação final.

\subsubsection{Balanço populacional}

A dinâmica de processos particulados foi estudada por alguns autores com 0 objetivo de conhecer como perturbações poderiam afetar a produção. Para entender a variação de um sistema particulado frente a processos de nascimento, crescimento, aglomeração e quebra de cristais, foi desenvolvido na década de 60 o balanço populacional (Equação 3). Esse recurso tem sido muito utilizado por aqueles que estudam, além de outros aspectos, a dinâmica em cristalizadores operando em batelada ou continuamente (Wolf, 1990; Shi et al., 2006; Christofides et al., 2007; Lakatos et al., 2007; Christofides et al., 2008; Nagy et al., 2008).

$$
\frac{\partial n}{\partial t}+\frac{\partial(G n)}{\partial L}+D-B+n \frac{d\left(\log V_{t}\right)}{d t}=-\sum_{k} \frac{n_{k} \dot{V}_{k}}{V_{t}}
$$

Onde

- $n(L, t)$ é a densidade populacional, definida como o número de cristais de com tamanho entre $L$ e $L+d L$ de uma população, num instante $t$, dividido pela largura da faixa de tamanhos $\mathrm{dL}$, por unidade de volume de cristalizador, \#/m/m

- $G$ a taxa de crescimento de partículas, $\mathrm{m} / \mathrm{s}$

- Lo tamanho da partícula, m

- $D$ a taxa de destruição de partículas na faixa $\mathrm{dL}, \# / \mathrm{m} / \mathrm{m}^{3} / \mathrm{s}$

- $B$ a taxa de nascimento de partículas na faixa $\mathrm{dL}, \# / \mathrm{m} / \mathrm{m}^{3} / \mathrm{s}$

- $V_{t}$ o volume da suspensão, $\mathrm{m}^{3}$

- $\dot{V}_{k}$ a vazão volumétrica para a corrente $k, \mathrm{~m}^{3} / \mathrm{s}$ 


\subsubsection{Método de momentos}

A resolução de um problema de balanço populacional não é trivial, levando muitos a desenvolverem técnicas para simplificar a solução (Ramkrishna, 2000; $\mathrm{Hu}$ et al., 2005). Entre essas técnicas a mais adotada quando não há a necessidade de se obter a distribuição de partículas detalhada é o balanço de momentos, onde $m_{j}$ é j-ésimo momento de uma distribuição, definido pela Equação 4 (Jones, 2002).

$m_{j}(t)=\int_{0}^{\infty} n L^{j} d L$

Fisicamente, o momento de ordem zero é o número total de cristais de uma população, o momento de ordem 1 é o comprimento total, o momento 2 é proporcional à superfície dos cristais e o momento 3 é proporcional ao seu volume. Ao se substituir a variável $n$ por $m_{j}$ na equação de balanço populacional, a variável independente $L$ desaparece, resultando uma equação diferencial ordinária. Assim sendo, na abordagem de momentos, uma equação diferencial parcial (PDE) em $n$ é substituída por um conjunto finito de $j$ equações diferenciais ordinárias (ODE) em $m_{j}$. Em seu trabalho, Shi et al (2006) mostram que a resolução de problemas desse tipo utilizando balanço de momento tem pouca diferença se comparado à resolução por balanço populacional.

\subsubsection{Métodos alternativos para resolução de balanço populacional}

$\mathrm{Na}$ literatura é possível encontrar outros métodos para simulação de sistemas de cristalização e resolução do balanço populacional. Em seu livro, Ramkrishna (2000) apresenta alguns métodos de resolução do balanço populacional, dentre eles o método de aproximação sucessiva e geração sucessiva, que consistem na solução da Equação 3 por somas sucessivas das contribuições das variáveis dependentes, sendo um método de resolução numérica semelhante ao método de Picard.

Ramkrishna (2000) cita também uma resolução analítica do problema via transformada de Laplace, que consiste na transformação de um problema de valor inicial em uma equação algébrica, de forma a obter a solução de uma 
equação diferencial de uma forma indireta sem a necessidade de resolver integrais complexas.

Outro método numérico citado pelo autor foi a resolução da Equação 3 pelo Método Monte Carlo, um método estatístico utilizado em simulações estocásticas. Esse método utiliza de observações de distribuição de probabilidade e de amostragens para aproximar a função balanço populacional.

Com o desenvolvimento dos recursos computacionais, foi possível criar ferramentas que fazem uma análise microscópica de um volume de controle, possibilitando uma análise heterogênea num processo de cristalização. Muitos parâmetros do modelo de cristalização podem ser calculados a partir de detalhes mais precisos de modelos de dissipação de energia por turbulências e campos de fluxos, que podem ser obtidas por técnicas de fluidodinâmica computacional (Yu et al, 2007).

Um trabalho que utiliza dessa técnica desenvolvido por Kramer et al (2000), que com apoio de ferramentas de fluidodinâmica computacional simularam toda a hidrodinâmica dentro do equipamento, para então obter um perfil de cristalização ao longo de todo o volume de um cristalizador de circulação forçada, e o tamanho médio de cristais na saída do cristalizador.

O uso das diferentes técnicas para a resolução do balanço populacional dependerá da aplicação que se faça durante o estudo, para casos em que não é necessário conhecer detalhes como a distribuição de tamanho de partículas e pode-se considerar que o sistema de cristalização é homogêneo, o balanço de momento trás uma solução satisfatória para o problema (Shi et al, 2006).

\subsection{Controle de cristalizadores}

Alguns autores utilizam as técnicas de modelagem e identificação de sistemas para projetos de controladores para processos de cristalização a partir de soluções. Na maioria das vezes, o objetivo é manter um determinado padrão de qualidade do produto, mantendo a distribuição de tamanho dos cristais 
numa faixa controlada, manter um máximo de produção aceitável ou minimizar o consumo de energia.

As principais estratégias de controle de processos de cristalização envolvem controlar a temperatura ou a concentração. O estudo do controle de temperatura foi a primeira técnica desenvolvida para esse tipo de processo, devido a uma maior facilidade de se medir "inline" essa variável. O controle da concentração em cristalizadores foi aperfeiçoado mais recentemente devido aos avanços na técnica de medição "inline" de concentração, que no passado eram inviáveis devido às limitações tecnológicas (Wolf, 1991; Yu et al, 2007).

Myerson (2002) descreveu outras variáveis controladas para cristalização em batelada como taxa de alteração de pressão, rotação do agitador ou da bomba e tempo de batelada. Essa estratégia foi aplicada em outros trabalhos realizados por Rawlings et al (1992; 1993).

\subsubsection{Controle de temperatura}

Essa técnica é mais comumente utilizada para cristalizadores por resfriamento operando em batelada (Christofides et al., 2007; Yu et al., 2007), pois permite controlar os níveis de supersaturação da solução, e consequentemente o perfil de cristais formados. Há trabalhos publicados em que se estudaram o controle de cristalizadores pela temperatura como nos exemplos a seguir.

Mathews e Rawlings (1998) modelaram um cristalizador em batelada por resfriamento, descrevendo o crescimento e nucleação de cristais por modelos empíricos obtidos a partir de dados medidos online como a supersaturação. Esses modelos identificados "online" foram utilizados para otimizar um perfil de temperaturas ao longo do tempo e consequentemente um perfil de distribuição de tamanho de partículas para melhorar a qualidade da filtração da suspensão após a batelada. Da mesma maneira Corriou et al (2008) desenvolveram um controlador para um cristalizador em batelada cuja variável manipulada era a temperatura do cristalizador, utilizando um modelo preditivo para otimização dinâmica do perfil de temperatura ao longo do tempo. 


\subsubsection{Controle de concentração}

O controle de concentração em cristalizadores é mais comum para processos contínuos, onde as variáveis manipuladas são, em geral, temperatura de operação, pressão absoluta, tempo de residência de produto, tamanho de cristais (por destruição de finos ou classificação do produto removido), nível de líquido, temperatura e concentração de alimentação e densidade de suspensão (Myerson, 2002).

A preferência pelo controle da concentração de cristais é devida à dificuldade de se medir a distribuição de tamanho de cristais online para suspensões pouco diluídas (Wolf, 1990), sendo possível medir a densidade da suspensão na saída do produto, que pode ser diretamente relacionada com a concentração de cristais, pela relação (Mullin, 2001):

$$
\rho_{\text {susp }}=\frac{L_{s}+S}{\frac{L_{s}}{\rho_{L}}+\frac{S}{\rho_{S}}}
$$

Onde

- $\quad L_{s}$ é a massa da solução.

- S é a massa de sólidos em suspensão

- $\rho L$ é a densidade da solução.

- $\rho_{S}$ é a densidade dos sólidos em suspensão

Aproveitando-se desse potencial, Wolf (1990) desenvolveu para cristalizadores contínuos uma estratégia de controle em que monitora a densidade de cristais, manipulando variáveis como vazão de alimentação de solução, vazão de remoção de finos e o calor fornecido. Sendo que o controle do tamanho médio de cristais foi realizado pelo monitoramento da densidade da suspensão, inferindo com o auxilio do balanço de momento o tamanho médio das partículas. O objetivo de Wolf foi obter um modelo dinâmico validado experimentalmente que pudesse ser aplicado para projeto de controladores. 
O controle de cristalizadores batelada pela concentração é mais recente se comparado ao controle por temperatura, isso se deve às limitações dos medidores "inline" disponíveis nas décadas de 1980 e 1990. A medição "inline" da concentração se tornou mais viável com o desenvolvimento de técnicas de medição, tais como espectrometria de infravermelho, espectrometria Raman e espectrometria ultra-violeta (Yu et al, 2007).

Nagy et al (2008) aplicaram o controle de concentração de cristais para cristalizadores em batelada, trazendo como vantagem a redução na sensibilidade da qualidade dos produtos a determinados distúrbios do processo. Porém, Hermanto et al (2009) identificaram como desvantagem nesta estratégia o maior tempo de batelada.

O uso de novas técnicas de medição "inline" trás novas oportunidades às estratégias de controle disponíveis, diferentes da estratégia de controle de temperatura e concentração mais comumente aplicadas. Como exemplo podese citar Mesbah et al (2010), que desenvolveram um modelo a partir do balanço populacional para controle de um processo de cristalização evaporativa, manipulando a quantidade de energia fornecida ao sistema para controlar a taxa de crescimento dos cristais através da supersaturação criada pela evaporação do solvente, enquanto que se media "inline" a distribuição de tamanho de partículas por difratometria laser.

\subsection{O processo de evaporação}

O processo evaporativo caracteriza-se pela evaporação de um solvente (Sinnot, 2005) para produção de líquidos concentrados, sólidos secos ou para cristalização. Para que a evaporação ocorra, é necessário que uma determinada quantidade de energia seja adicionada ao sistema. A energia requerida para o processo governa os aspectos econômicos da operação (Billet, 1989).

Um exemplo simples de um processo evaporativo é representado na Figura 2. Um evaporador por simples efeito recebe pela corrente de vapor $V_{o}$ a energia necessária para evaporar e concentrar a solução. 


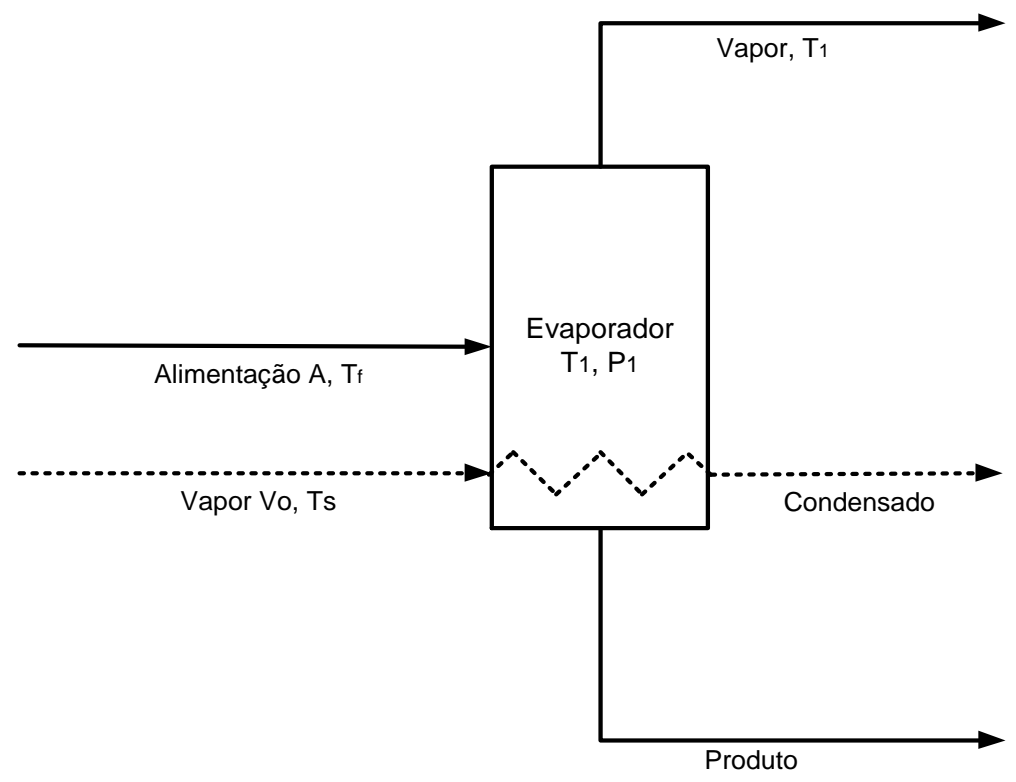

Figura 2 - Evaporador por simples efeito - adaptado de Geankoplis, (2003)

A solução a ser concentrada (corrente A) é alimentada e aquecida até a temperatura $T_{1}$ pelo vapor $V_{0}$. Assumindo que a solução está completamente misturada e homogênea, sendo $T_{1}$ a temperatura de ebulição da solução à pressão de operação, o solvente irá evaporar a uma mesma temperatura $T_{1}$. $O$ vapor gerado é superaquecido, devido às propriedades coligativas da solução, ou seja, a temperatura $T_{1}$ é maior que a temperatura $T_{s}$ de saturação do solvente puro.

Evaporadores por simples efeito são geralmente usados quando a capacidade de operação requerida é pequena ou quando o custo de vapor é relativamente baixo se comparado aos custos de um evaporador. Esses evaporadores costumam aproveitar pouco a energia, já que o calor latente do vapor gerado é descartado. Muito desse calor latente pode ser recuperado e reutilizado, empregando-se evaporadores de múltiplo-efeito.

A Figura 3 mostra um diagrama simplificado de um sistema de evaporação por triplo-efeito. A alimentação do primeiro efeito é aquecida pelo vapor fornecido $V_{0}$. O vapor gerado no primeiro efeito é suficiente para aquecer a solução do segundo efeito, reaproveitando seu calor latente a uma temperatura e pressão inferiores às do efeito anterior, já que a sua temperatura de condensação é $T_{s}$ $<T_{1}$. No segundo efeito, o processo se repete com a evaporação da solução, 
cujo vapor gerado é enviado até o sistema de troca térmica do terceiro efeito. É possível utilizar mais de três efeitos, decisão que dependerá dos custos de implantação de cada efeito (Geankoplis, 2003).

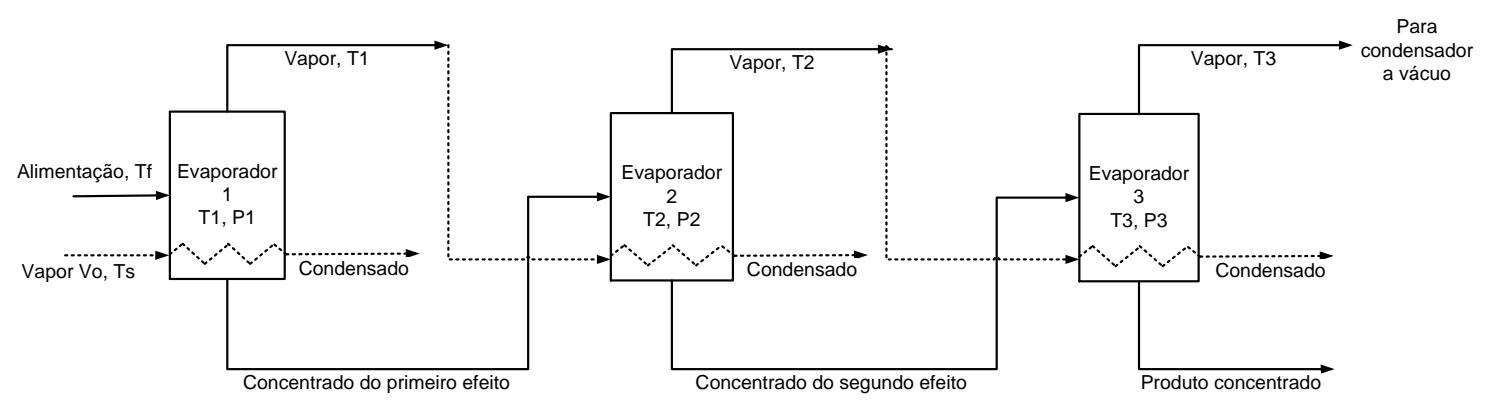

Figura 3 - Evaporador Múltiplo-efeito com alimentação co-corrente - adaptado de Geankoplis, (2003)

A alimentação do sistema da Figura 3 é em série e co-corrente, pois a solução fresca A é alimentada no primeiro efeito e flui para os próximos efeitos no mesmo sentido da corrente de vapor. Essa configuração é geralmente usada quando a solução alimentada A está a uma temperatura elevada, próxima à temperatura de operação do primeiro efeito, ou quando a solução concentrada ao final pode ser danificada a alta temperatura, considerando que o ponto de ebulição decresce a cada efeito.

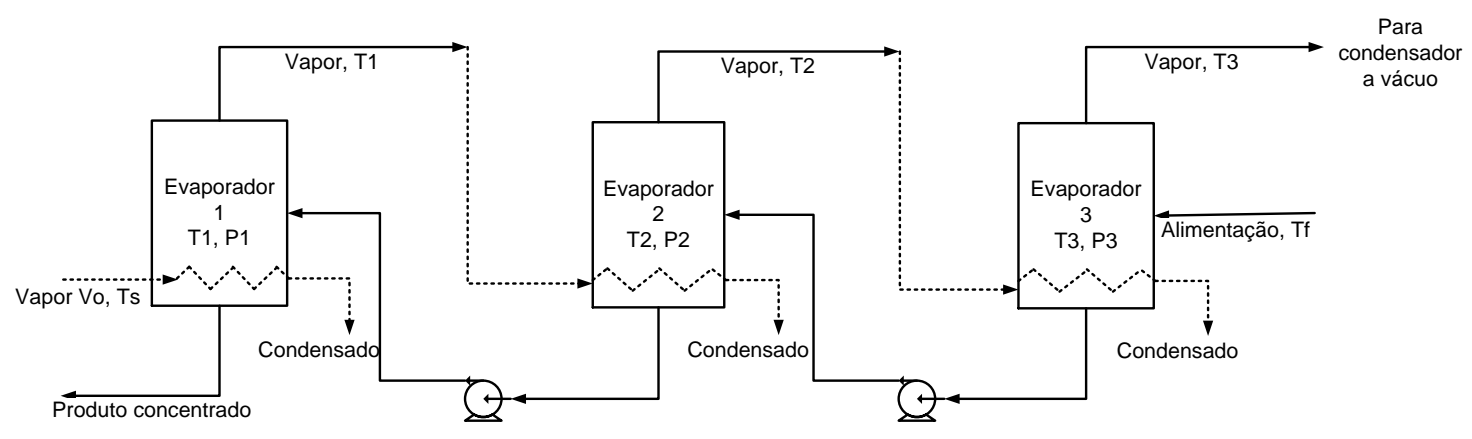

Figura 4 - Evaporador Múltiplo-efeito com alimentação contracorremte adaptado de Geankoplis, (2003)

Se a solução alimentada está a uma temperatura baixa ou a solução possui uma viscosidade elevada, é vantajoso trabalhar com uma alimentação em contracorrente com o vapor (Figura 4). A solução é alimentada no último e mais frio efeito e sai concentrada no primeiro efeito e com uma menor viscosidade 
devido à temperatura mais elevada, melhorando os coeficientes de troca térmica. Uma desvantagem desse sistema é que a solução deve ser bombeada entre os sucessivos estágios de evaporação, já que o fluxo segue do evaporador de menor para o de maior pressão.

Quando os produtos são cristais e a solução alimentada está saturada, é comum utilizar um sistema com alimentação paralela (Figura 5), onde a solução fresca é alimentada independentemente em cada efeito. Essa é a configuração estudada neste trabalho e será melhor detalhada na descrição do processo.

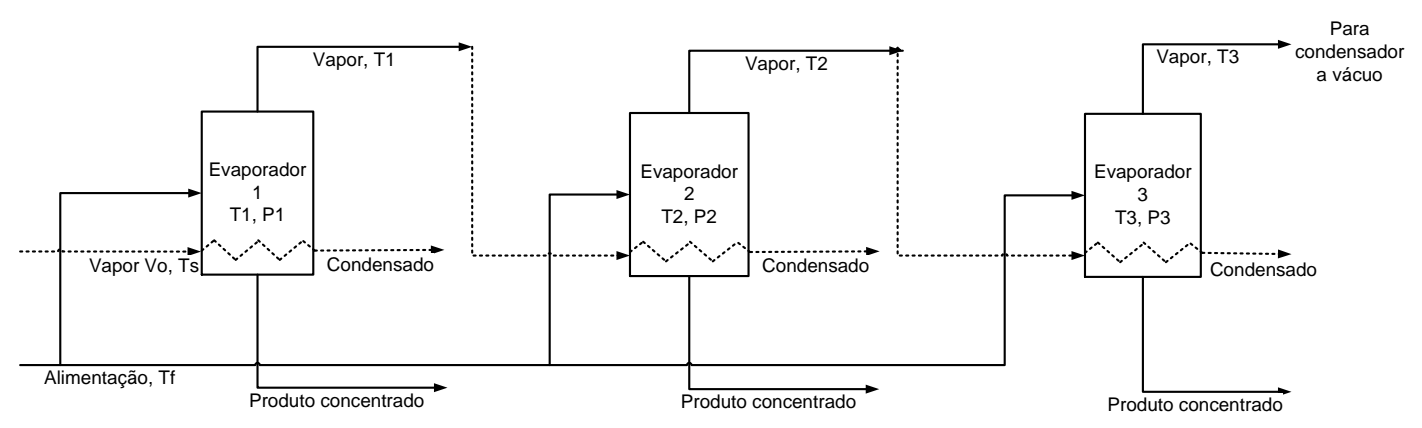

Figura 5 - Evaporador Múltiplo-efeito com alimentação paralela

\subsection{Modelos de evaporadores}

Os estudos de modelos de evaporadores tiveram início na década de 60, começando por modelos estacionários passando em seguida para modelos dinâmicos. Os modelos têm sido desenvolvidos para diversos objetivos, desde a avaliação de controladores clássicos do tipo PID via modelagem fenomenológica até a identificação de modelos via dados disponíveis de evaporadores em operação, bem como para a aplicação ou simplesmente a avaliação de controladores avançados.

Um modelo matemático estacionário para um evaporador simples efeito foi proposto por Andersen et al (1961) (apud Yadav e Jana, 2010) e simulado para estudo da performance de um controlador em malha fechada. Em 1965 Kropholler e Spikins desenvolveram um modelo empírico para um evaporador de simples-efeito a ser aplicado em um controlador do tipo PID, para mais 
tarde, em 1968, Andre e Ritter desenvolverem um modelo não-linear para um sistema de evaporação de duplo-efeito (apud Yadav e Jana, 2010).

O primeiro modelo dinâmico para um sistema múltiplo-efeito foi desenvolvido por Burdett e Holland (1971) para uma planta de 12 efeitos de dessalinização da água do mar e consistiu em balanços de massa e energia. $O$ objetivo de seu estudo era prever o comportamento da unidade frente a distúrbios.

A partir daí novos modelos dinâmicos foram desenvolvidos com o objetivo de estudar os efeitos de perturbações no processo e simular qual seria a melhor estratégia de controle. Nesse caminho, Runyon et al (1991) desenvolveram um modelo dinâmico não-linear para uma planta de produção de polpa de tomate concentrado por um sistema de evaporação por duplo-efeito com alimentação em série e contracorrente. Com o modelo desenvolvido foi possível estudar duas estratégias diferentes para o controle PID da produção, cujos objetivos descritos foram o de manter a concentração e viscosidade da polpa constantes, a temperatura abaixo de um limite para evitar a degradação do produto e minimizar o consumo energético, tendo como variáveis manipuladas a vazão de alimentação de polpa de tomate, o vácuo do último efeito e a vazão de vapor que alimenta o primeiro efeito. Nesse caso, ambas as estratégias responderam satisfatoriamente aos objetivos de controle, sem que uma se sobressaísse à outra.

A simulação permite que se avaliem diferentes estratégias de controle e diferentes controladores para um determinando processo, levando à escolha do melhor método de controle sem a necessidade de testes numa planta industrial. No caso de Runyon et al (1991), qualquer uma das estratégias escolhidas poderia ser empregada com o mesmo nível de satisfação, mas outro exemplo desenvolvido por Yadav e Jana (2010) mostra que a simulação permitiu avaliar que uma determinada estratégia de controle é superior a outra, sendo melhor indicada à aplicação industrial.

Yadav e Jana (2010) deram continuidade aos estudos de Runyon et al (1991), avaliando diferentes modelos de controladores do tipo PI, como o PI (Proportional and Integral) clássico para sistemas lineares, o NLPI (Nonlinear 
Proportional Integral) para modelos não-lineares e GSPI (Gain-scheduled Proportional Integral) para ganho variável, obtendo uma melhor performance para o controlador não linear NLPI.

A vantagem que o domínio do modelo dinâmico traz em estudar uma operação sem a necessidade de se fazer testes nas plantas, elevando os custos industriais, permitiram a Lee e Lee (1993) simularem dinamicamente um evaporador de simples efeito e observar a resposta para diferentes controladores, como Fuzzy e PID, determinando que o primeiro seja o melhor entre eles. Com o modelo em mãos também foi possível entender alguns fenômenos físicos que determinam alguns parâmetros de produção, como o fator de descontaminação.

A simulação computacional a partir de um modelo permite não somente determinar o melhor controlador para um sistema de evaporação múltiploefeito, mas também comparar entre diferentes modelos qual seria o melhor para aplicação em um mesmo controlador, como fizeram Kam e Tadé (2000). Os autores determinaram entre dois diferentes modelos qual se adaptaria melhor à estratégia de controle para um evaporador de cinco efeitos utilizado para a concentração de alumina. O primeiro modelo era não-linear de múltiplas entradas e múltiplas saídas MIMO (Multi-Input, Multi-Output) e o segundo composto por modelos de simples entradas e simples saídas SISO (SingleInput, Single-Output) usados para um controlador linear.

\subsection{O Controle preditivo}

O conceito básico do controle preditivo, ou MPC (do inglês Model Predictive Control), é usar um modelo dinâmico para prever o comportamento do sistema físico e otimizar a ação prevista do controlador, de modo a produzir a melhor ação a ser tomada pelo controlador no próximo instante de tempo. Os modelos matemáticos que representam um sistema físico são, portanto, de grande importância para todas as formas de MPC (Rawlings e Mayne, 2009). Uma vez que a ação do controlador ótimo depende do estado inicial do sistema dinâmico, um segundo conceito básico do MPC é o uso de dados medidos no passado para determinar o estado futuro mais provável do sistema. 
O MPC é uma forma de controle na qual a ação do controle é obtida resolvendo-se "online", a cada instante de tempo amostrado, um problema ótimo de horizonte finito no qual o estado inicial é o estado atual da planta, no momento da amostragem. A otimização fornece uma sequência finita de ações de controle, mas apenas a primeira ação dessa sequência é aplicada na planta, repetindo-se o mesmo procedimento a cada instante de amostragem. O MPC se diferencia dos controladores convencionais por determinar a ação do controlador em tempo real, procurando sempre o estado futuro ótimo, enquanto os controladores convencionais determinam a lei de controle antes da operação.

Os objetivos gerais de um controlador MPC foram sumarizados por Qin and Badgwell (2003) e estão descritos a seguir:

- Prevenir violações das restrições impostas para as variáveis de entrada e saída;

- Direcionar algumas variáveis de saída para os seus set-points ótimos, ou manter essas ou outras variáveis de saída em uma faixa ótima específica;

- Prevenir movimentos excessivos das variáveis de entrada;

- Controlar tantas variáveis de processo quanto possíveis quando um sensor ou um atuador não estiver disponível.

A ação do controlador MPC, como já dito, utiliza um modelo do processo para predizer o valor atual das variáveis de saída. A diferença entre o valor predito e o valor real da planta, denominado resíduo, serve como um sinal "feedback" para um bloco de predição (Figura 6). 


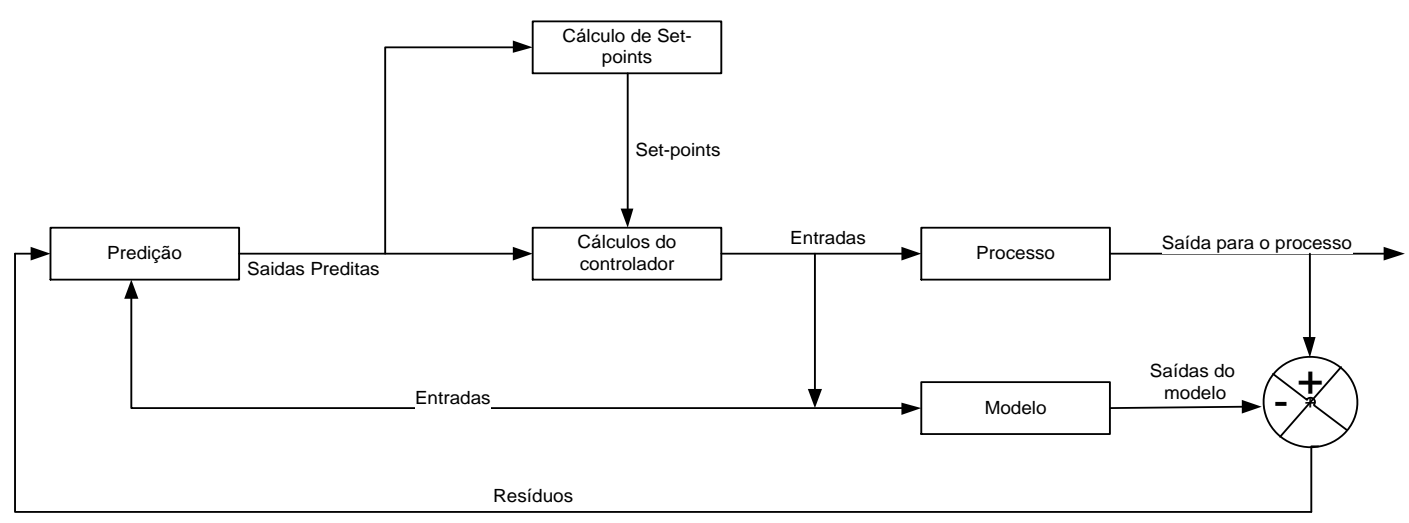

Figura 6 - Diagrama de blocos para o controle preditivo (Adaptado de Seborg et al, 2004)

Os novos set-points são determinados otimizando-se uma função econômica baseada num modelo linear do processo. Objetivos típicos na otimização incluem maximizar uma função lucro, minimizar uma função custo ou maximizar uma função que represente a taxa de produção (Wang, 2009). Uma vez definidos os valores econômicos dos "set-points", os mesmos são enviados ao seguinte problema de otimização que caracteriza o problema de controle:

$$
\begin{aligned}
& \left.\min _{\Delta u(k), \ldots, \Delta u(k+m+1)} V_{k}=\sum_{i=1}^{p}\left[\left(y(k+i \mid k)-y^{s p}\right)^{T} Q(k+i \mid k)-y^{s p}\right)\right]+ \\
& +\sum_{j=0}^{m-1} \Delta u(k+j \mid k)^{T} R \Delta u(k+j \mid k)
\end{aligned}
$$

Sujeito a

$$
\begin{aligned}
& -\Delta u^{\max } \leq \Delta u(k+j) \leq \Delta u^{\max } \\
& u^{\min } \leq u(k-1)+\sum_{j=0}^{i} \Delta u(k+j) \leq u^{\max } \\
& j=0,1,2, \ldots, m-1
\end{aligned}
$$

Onde

- $\quad y^{s p}$ é o valor de "set-point" das variáveis controladas. 
- ké o instante de tempo

- $\Delta u(k+j)=u(k+j)-u(k+j-1)$ é o incremento das entradas;

- $\quad p$ e $m$ são os horizontes de predição e controle;

- $Q$ e $R$ são respectivamente a matriz de pesos das variáveis controladas, a matriz de fatores de atenuação das variáveis manipuladas

Os valores ótimos dos "set-points" mudam frequentemente de acordo com as variações das condições do processo, especialmente quando há alterações nas inequações que representam alguma restrição devida a variações no processo, equipamentos e instrumentação, dados econômicos, preços e custos.

Os modelos dinâmicos utilizados para predição das variáveis de saída são em geral modelos lineares empíricos, obtidos através de dados gerados pela resposta da planta e identificados utilizando-se técnicas de identificação, ou são modelos obtidos pela representação física do processo estudado (Aguirre, 2007). Quando o modelo é não-linear, ou seja, não satisfaz o principio da superposição ${ }^{1}$, são feitas aproximações dos modelos não lineares por modelos lineares para aplicação do método MPC, geralmente observando o comportamento dos dados numa faixa relativamente estreita de operação, com possível perda de representatividade do processo. Por outro lado, existem processos cujos efeitos da não-linearidade são significativos e não devem ser ignorados, justificando o uso de métodos de predição baseados em modelos não lineares (NMPC - Nonlinear Model Predictive Control) (Kouvaritakis e Cannon, 2001).

O MPC foi primeiramente desenvolvido para unidades de produção de energia e refinarias de petróleo (Kouvaritakis e Cannon, 2001; Seborg et al., 2004; Pires, 2009), que na sua grande maioria podem ser bem representados por sistemas lineares. Isso fez com que o controle preditivo fosse inicialmente

\footnotetext{
${ }^{1}$ Uma equação satisfaz o princípio da superposição se dada uma função $f=g(x)$, para uma combinação linear $\times 3=a \times 1+b \times 2$, teremos que $g(x 3)=a g(x 1)+b g(x 2)$. Para a e b constantes (Aguirre, 2007).
} 
desenvolvido para otimizar sistemas representados por modelos explícitos lineares. O método de predição de respostas futuras mostrou-se promissor para outros sistemas, expandindo-se para setores produtivos tais como plantas químicas, indústria alimentícia, automotiva, aeroespacial, metalúrgica e papel e celulose, onde processos cuja não linearidade levou ao desenvolvimento de métodos de predição adequados (NMPC) (Henson, 1998).

\subsubsection{Programação quadrática}

A otimização de uma função custo como a apresentada pela Equação 6 não é trivial, sendo a resolução numérica a melhor opção para esse caso.

Para sistemas lineares o problema definido em 6 e 7 é um problema de programação quadrática, que consiste em um algoritmo que otimiza uma função quadrática, respeitando as restrições lineares que compõem o problema (Rawlings e Mayne, 2009). De forma geral, esse problema pode ser representado pela função objetivo definida em 8 sujeita a um conjunto de restrições definido em 9:

$V_{k, X}=X^{T} H X+2 f^{T} X+C$

$M X \leq \gamma$

Onde $X, H, f, C, M$ e g são matrizes e vetores de dimensões compatíveis sendo $\mathrm{X}$ o vetor de variáveis de decisão e $\mathrm{H}$ uma matriz simétrica positiva definida (Wang, 2009).

\subsubsection{Representação em espaço de estado}

Pode-se definir o estado de um sistema dinâmico como o menor conjunto de variáveis (variáveis de estado $x_{k}$ ) em $t=t_{0}$, influenciado pelas entradas futuras conhecidas $u_{k}+n$ que determinam o comportamento do sistema para $t \geq t_{0}$ (Ogata, 2003), ou seja, variáveis que representam direta ou indiretamente o estado atual da planta ou qualquer outro sistema físico que se deseja representar por um modelo dinâmico.

As saídas de um sistema são afetadas pelo seu estado, e de vez em quando, são afetadas diretamente pelas entradas (Bao-Cang, 2010). A saída desse 
sistema pode ser uma função do estado ou o próprio estado do processo. Já esse estado pode ser afetado pela variação das variáveis de entrada. Para enfatizar essa variação no estado, pode-se representar o modelo matemático de um sistema como uma função do estado e das variáveis de entrada $(\dot{x}=f(x, u, t), \dot{y}=g(x, u, t))$.

Os modelos do processo que compõem o controlador normalmente são representados na forma espaço de estado, conforme as equações a seguir:

$$
\begin{aligned}
& x_{k+1}=A x_{k}+B u_{k} \\
& y_{k}=C x_{k}+D u_{k}
\end{aligned}
$$

Onde:

- $u_{k}$ são as variáveis manipuladas,

- $x_{k}$ é o vetor variável de estado.

- $y_{k}$ é a saída controlada.

- A a matriz de estado

- B a matriz de entradas

- C a matriz de saída.

- D é a matriz que relaciona diretamente as variáveis de entrada com a saída, sendo essa matriz nula se considerado que a entrada no instante $k$ não afeta a saída no mesmo instante $k$ (Wang, 2009).

\subsubsection{Estimadores de estado}

É comum em um processo que nem todas as variáveis de estado sejam mensuráveis ou estejam disponíveis para medição e seus dados realimentados no controlador. Nesses casos é comum estimar as variáveis de estado $x_{k}$ a partir de variáveis mensuráveis do sistema. $O$ algoritmo utilizado para estimar variáveis de estado desconhecidas é referido como observador (Wang, 2009). 
O observador de estado utiliza as variáveis de saída da planta $y_{k}$ para estimar as variáveis de estado $\tilde{x}_{k}$, reconstruindo o vetor de estado da planta. Esse tipo de algoritmo costuma utilizar o mesmo modelo dinâmico matemático da planta, corrigido por um fator erro de estimação que compensa as incertezas das matrizes $A$ e $B$ da planta devido às não-linearidades, mudanças no processo devido a fadigas e falhas, dentre outros.

O erro de estimação é dado como a diferença entre o valor medido y e o valor estimado $C \tilde{x}_{k}$. Assim, da Equação 10 pode-se escrever para o estimador recursivo de estado:

$$
\tilde{x}_{k+1}=A \tilde{x}_{k}+B u_{k}+K_{o b}\left(y_{k}-C \tilde{x}_{k}\right)
$$

Onde $\tilde{x}_{k}$ é o vetor de estado estimado e $K_{o b}$ é a matriz de ganho do observador.

Entre os estimadores conhecidos, destaca-se o estimador recursivo ótimo conhecido como filtro de Kalman, que parte da proposição de minimizar a covariânça do erro da estimativa do estado para calcular a matriz de ganho do observador $K_{o b}$ (Aguirre, 2007).

$K_{o b}=A P C^{T}\left(V+C P C^{T}\right)^{-1}$

Sendo $P$ dado pela Equação 14 .

$$
P=A P A^{T}-A P C^{T}\left[V+C P C^{T}\right]^{-1} C P A^{T}+W
$$

Onde $W$ e $V$ são as matrizes de covariança das incertezas (ruídos) no estado e na saída respectivamente.

\subsubsection{Controle preditivo de horizonte infinito}

Em linhas gerais, o controle preditivo se baseia na otimização da trajetória futura, isto é, na minimização da distância entre a trajetória futura prevista da saída e o valor desejado (ou set-point), assumindo um horizonte de predição finito $p$. Essa minimização é feita em relação aos incrementos no sinal de controle $\Delta u$ para $k=0,1,2,3 . . \mathrm{m}-1$ que são capturados pelo vetor de controle 
$\Delta u$ enquanto o resto das ações para $k=m, m+1, m+2, \ldots, p$ assume-se que é zero. No entanto, Wang (2009) demonstrou que há casos em que $\Delta u$ só será zero para valores muito grandes de $p$, aumentando o número de variáveis computadas a cada iteração.

Assumindo-se que para valores cada vez maiores de $p$, a variável de controle $\Delta u$ vai se tornar mais próxima de zero, pode se inferir que para valores de $p$ tendendo ao infinito na variação das variáveis de entrada $\Delta u$ tenderá a zero, ou seja, o sistema será nominalmente estável.

A primeira sugestão de controle preditivo com horizonte infinito foi dada por Bitmead et. al (1990), que desenvolveu um método com a desvantagem de não incluir restrições, o que foi adicionado posteriormente no trabalho desenvolvido por Rawlings e Muske (1993), onde um problema de horizonte infinito foi resolvido mantendo-se um número finito de variáveis de decisão. Isso trouxe como vantagem um menor gasto computacional ao diminuir o sistema a um número menor de variáveis calculadas, além de levar o sistema a ser nominalmente estável enquanto for possível resolver o problema de otimização (Rodrigues e Odloak, 2003).

\subsubsection{Controle preditivo com controle por faixas}

Existem processos químicos em que não há a necessidade de se atingir valores exatos das variáveis controladas, podendo a planta atuar dentro de uma determinada faixa de operação sem que haja prejuízo às características do produto, à integridade do processo e limitações econômicas.

Podemos citar processos de refino de petróleo, os quais devem ser adaptáveis às diferentes características do petróleo proveniente de diferentes regiões do planeta. Essa adaptabilidade pode ser definida dentro de uma faixa de operação associada às características dos produtos desejados, critérios de segurança e fatores econômicos.

Essa ideia pode ser estendida a processos de cristalização, principalmente processos contínuos, onde é permissível operar dentro de uma faixa de temperatura, sem prejuízo à qualidade dos cristais, assim como à concentração 
de cristais, que deve situar-se entre um valor mínimo e um máximo para evitar problemas como incrustação.

Pensando nesses processos adaptáveis, González e Odloak (2009) apresentaram um controlador preditivo de controle por faixa, obtendo uma lei de controle que leva a planta a operar dentro da zona pré-definida, e não um set-point fixo, ao mesmo tempo em que o algoritmo procura dentro dessa faixa um ponto ótimo de operação, determinado por um critério econômico e operacional. A estratégia de controle utilizada pelos autores é resumida na Figura 7.

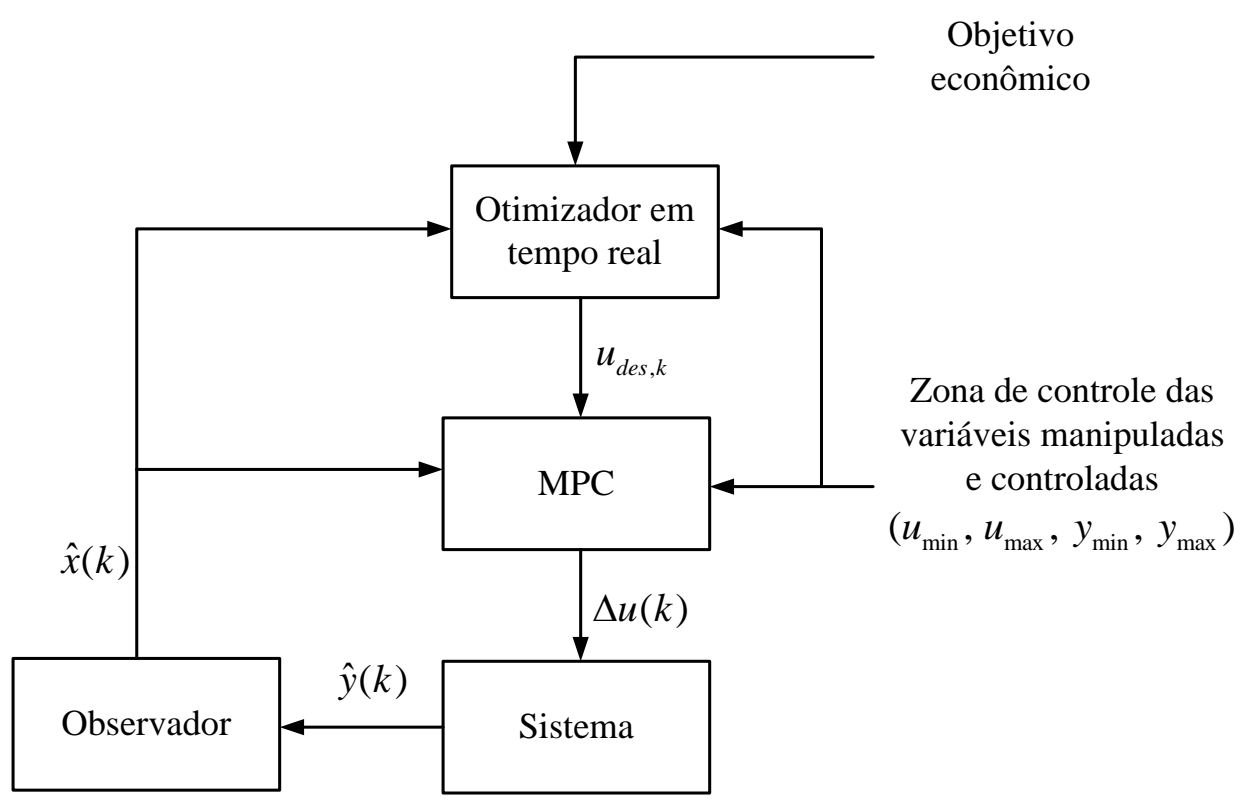

Figura 7 - Estrutura de controle (adaptado de González e Odloak (2009))

A estrutura descrita na Figura 7 propõe um otimizador operando em tempo real, baseado em modelo estacionário da planta, que calcula o valor ótimo da variável manipulada $u_{\text {des }}$ de acordo com os critérios econômicos préestabelecidos. Esse valor ótimo é enviado ao controlador como variável "alvo", ou seja, valor ótimo a ser atingindo pelo controlador preditivo, que o faz procurando um valor dentro da faixa de controle das variáveis controladas ( $y_{\min }$, $\left.y_{\max }\right)$. 
O valor incremental da variável manipulada $\Delta u_{k}$ é então enviado ao sistema real cujas saídas $\hat{y}$ são utilizadas pelo observador para correção do estado usado pelos modelos de predição tanto do controlador como do otimizador $\hat{x}$.

\subsection{Aplicação de controle preditivo}

Entre as diversas aplicações encontradas para o controle preditivo, podem-se destacar os estudos realizados para processos de cristalização e processos de evaporação.

\subsubsection{Cristalização}

Os processos de cristalização costumam utilizar modelos fenomenológicos obtidos de balanços de massa, energia e populacional para aplicação no controlador. Há uma grande diferença no tipo de controle aplicado para processos em batelada e processos contínuos, principalmente pela maior facilidade de se manipular as variáveis do primeiro caso para se atingir uma determinada distribuição de partículas.

O objetivo de controle para cristalizadores em batelada costuma variar dependendo da estratégia escolhida. Em sua revisão, Shi et al (2006) listaram alguns autores que definiram como objetivo de controle aproximar o máximo possível o tamanho médio dos cristais ao especificado sendo a curva de resfriamento a variável de decisão, manipulando a temperatura do equipamento. Seguindo esse mesmo objetivo, Shi et al (2006) escolheram como objetivo minimizar o terceiro momento dependente da nucleação, ou seja, minimizar a concentração de finos, tendo como variável controlada a temperatura do reator e monitorando a concentração de cristais. Esse controlador forneceu um perfil de temperatura que, comparado a um perfil linear pré-determinado, apresentou uma redução desejável na concentração de finos em $13,4 \%$.

Suárez et al (2009) compararam o controlador do tipo NMPC com um controlador clássico PI num processo semi-batelada de produção de açúcar. Para isso os autores modelaram o processo a partir do balanço populacional, massa e energia. Diferentes estratégias foram estudadas, tais como o controle 
da supersaturação e concentração de cristais, manipulando a temperatura do cristalizador. O controlador preditivo permitiu um consumo menor de energia, uma melhora no desempenho do crescimento dos cristais e uma maior produtividade, se comparado ao controlador clássico.

No mesmo trabalho antes citado, Shi et al (2006) estudaram um controlador preditivo para um processo de cristalização continua, cujo objetivo era estabilizar o processo em malha fechada normalmente instável em malha aberta. As variáveis de controle desse sistema eram a temperatura do cristalizador e a concentração de cristais, partindo da suposição que era possível medir os quatro momentos representantes do balanço de momento no equipamento. Os autores utilizaram o balanço de momento para o cálculo do tamanho médio das partículas, apresentando um desvio pouco significativo comparado ao modelo de balanço populacional. Trabalho semelhante para cristalizadores contínuos foi realizado por Liu et al (2008), cuja função objetivo, assim como Shi et al (2006), era minimizar uma função de Lyapunov para estabilidade.

Os exemplos descritos anteriormente têm em comum o uso de modelos físicos obtidos por balanços populacionais para aplicação do controlador. Porém, o uso de controle preditivo em processos de cristalização também pode ser aplicado com outras metodologias. Rohani et al., 1999b utilizaram modelos identificados por métodos lineares como o ARX e estruturas não lineares parametrizados por redes neurais para obter o modelo a ser aplicado no controlador.

\subsubsection{Evaporação}

Em processos evaporativos, são também utilizados modelos fenomenológicos para aplicação no controlador preditivo. Cadet et al (1999) desenvolveram um modelo a partir de balanços de massa e energia para uma planta de concentração de solução de sacarose. O processo era composto por um sistema de evaporação por cinco efeitos com alimentação em série e era aplicado industrialmente. O modelo validado com os dados da planta em operação foi aplicado no controlador preditivo não linear. Com o objetivo 
principal de minimizar o consumo energético mantendo as condições operacionais como temperaturas e concentração abaixo da saturação, os autores concluíram que o controlador proposto é melhor do que um controlador preditivo linear ou o controlador clássico, que, naquele momento, mantinha a planta em operação.

Outros autores utilizaram modelos identificados do processo para aplicação do MPC, como fizeram Atuonwu et al (2009) e Damour et al (2010). Nos dois trabalhos os autores utilizaram um modelo obtido por rede neural para aplicação no controlador avançado, dispensando a necessidade de criar um modelo físico e obtendo pequenas oscilações e rápida estabilização das variáveis se comparadas a um controlador PI clássico.

\subsection{Considerações}

A descrição de processos que aplicam o controlador preditivo com vantagem sobre controladores clássicos apresentados aqui contemplam processos de cristalização e processos evaporativos por múltiplo-efeito em casos isolados.

No caso dos processos que envolviam cristalização, os modelos propostos para esses controladores focavam no fenômeno acontecendo dentro de um único equipamento cristalizador, sem a influencia dos fenômenos externos que afetariam a operação, como aconteceria numa operação em que a energia necessária para a operação de um cristalizador dependesse da operação de outro cristalizador vizinho.

Do mesmo modo, os modelos propostos para sistemas de evaporação que dependem da energia fornecida por um evaporador vizinho têm seus modelos focados nos fenômenos de evaporação, muitas vezes aplicado a processos de concentração de soluções. Para um processo de cristalização por evaporação múltiplo-efeito, utilizado na produção de diversos produtos particulados, devese a analisar os dois fenômenos, levando-se em conta os efeitos que um cristalizador terá sobre o efeito vizinho.

Visando as possíveis aplicações industriais, nesse trabalho se propõe estudar um processo de cristalização por múltiplo-efeito, com foco no controle desse 
tipo processo. Como exemplo neste estudo será considerado um processo de produção de cloreto de sódio, historicamente feito em evaporadores de circulação forçada, operando em múltiplo-efeito (Badger, 1955).

O controlador estudado será um preditivo com horizonte infinito IHMPC por controle de faixas, devido à estabilidade intrínseca a esse controlador com a possibilidade de manter a planta operando dentro de restrições inerentes ao processo. O controlador avançado será comparado a um controlador clássico do tipo PID, para avaliar os ganhos que o controlador avançado pode trazer para esse tipo de processo.

Para simular o processo foi criado um modelo a partir de balanços de massa, energia e momento, considerando que o balanço de momento apresenta uma maior simplicidade de resolução se comparado ao balanço populacional e fornece as informações suficientes para os objetivos deste trabalho. 


\section{MÉTODOS}

\subsection{Descrição do processo}

O fluxograma do processo proposto para a produção de sal alimentício é apresentado na Figura 8. O sistema consiste de cinco cristalizadores trabalhando em múltiplo-efeito, comumente usado para a cristalização de cloreto de sódio. Cada efeito é composto por um cristalizador do tipo circulação forçada. Os cinco efeitos são numerados da esquerda para direita como CR01, CR-02, CR-03, CR-04 e CR-05. Cada cristalizador é alimentado paralelamente por uma solução saturada de salmoura através da perna de circulação (corrente $A_{c}$ ) e pela perna elutriadora (corrente $A_{p}$ ), sendo a vazão de alimentação na perna elutriadora fixa para que se mantenham as condições de elutriação. Cada cristalizador é dotado de um sistema de recirculação e aquecimento de suspensão nos condensadores TC-01, TC-02, TC-03 TC-04 e TC-05, que fará com que o solvente evapore quando este retornar ao cristalizador, promovendo a supersaturação na solução, acarretando na cristalização dos cristais de cloreto de sódio.

$O$ aquecimento da suspensão em circulação do primeiro efeito se dá pela alimentação de vapor vivo $\left(V_{0}\right)$ no condensador TC-01, enquanto os outros trocadores de calor são alimentados pelo vapor gerado $\left(V_{i}, i=1,2,3\right.$ e 4) em cada efeito anterior.

O vapor vegetal gerado no último efeito $\left(V_{5}\right)$ é enviado a uma unidade de vácuo composta por um ejetor que tem como finalidade promover a baixa pressão do ultimo efeito.

Os produtos saem em suspensão pela perna elutriadora de cada efeito, representados pelas correntes $P_{i}$ com i=1 a 5 na Figura 8 . 


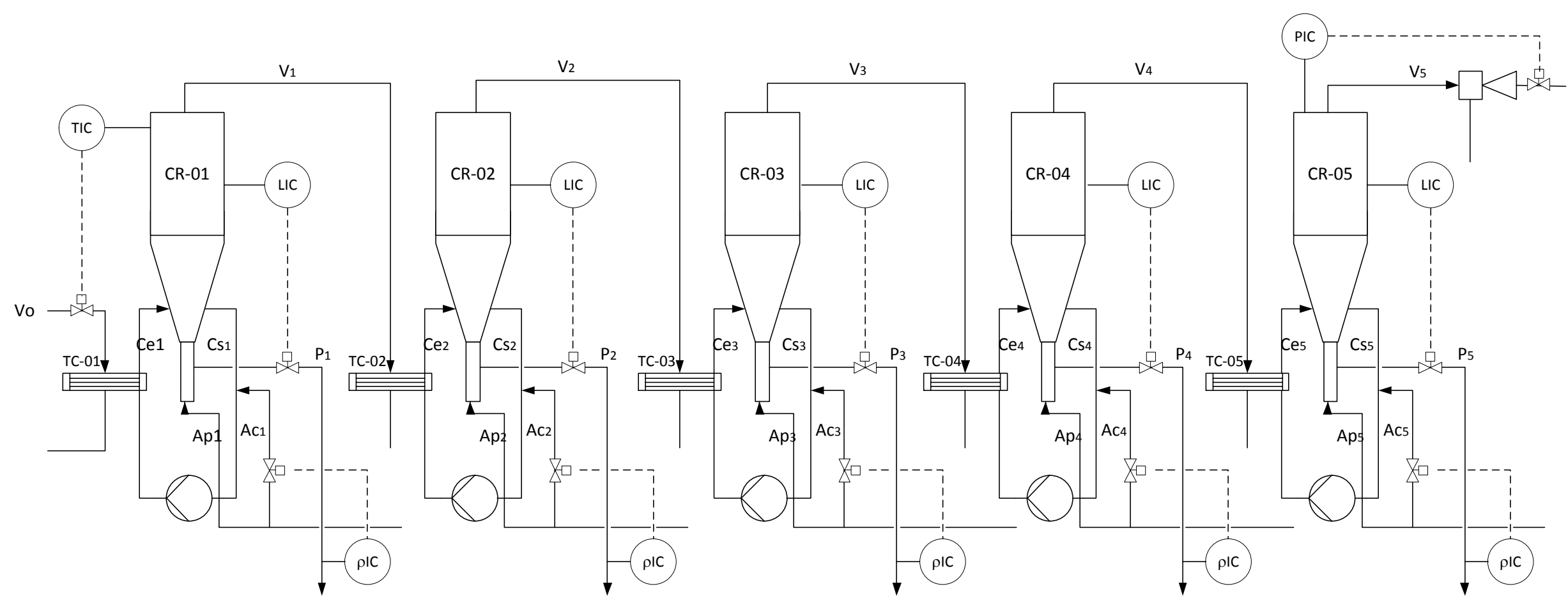

Figura 8 - Fluxograma Simplificado do Processo 


\subsection{Modelo proposto}

O modelo dinâmico do processo de cristalização evaporativa em 5 efeitos foi desenvolvido a partir dos balanços de massa, energia e balanços de momentos, derivados do balanço populacional para sistemas particulados (Randolph e Larson, 1988). Tomaram-se como base os trabalhos realizados por (Runyon et al., 1991; Lee e Lee, 1993; Miranda e Simpson, 2005), onde foram desenvolvidos modelos para sistemas de evaporação múltiplo-efeito e para sistemas de circulação forçada, respectivamente. Para o modelo de cristalização, foram consultados trabalhos realizados por (Shi et al., 2006; Lakatos et al., 2007) para cristalizadores contínuos MSMPR, que podem ser igualmente aplicados para cristalizadores de circulação forçada (Myerson, 2002). O modelo leva em conta as seguinte hipóteses:

- O volume de suspensão em cada efeito é controlado de forma que não se perceba variação interna do volume total.

- Não há perdas de energia para o meio externo

- A temperatura e a concentração de cristais são homogêneas em cada cristalizador

- O calor latente varia com a temperatura de cada cristalizador

- O coeficiente global de troca térmica é constante

- Não há agregação, quebra ou dissolução das partículas.

- A taxa de crescimento das partículas não varia com o tamanho dos cristais.

\subsubsection{Balanço de massa global}

Para realizar os balanços foi considerado como volume de controle o corpo do cristalizador, como representado pela Figura 9. 


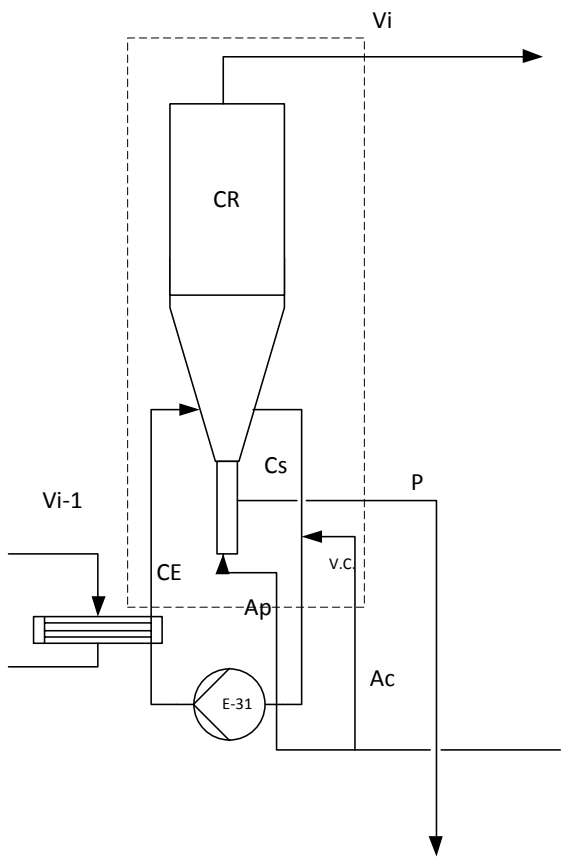

Figura 9 - Volume de controle para balanços

Pela lei da conservação de massa, tem-se que:

Acúmulo $=$ Entra - sai + gerado - consumido

Aplicando ao volume de controle da Figura 9, o balanço de massa total é dado por:

$\frac{d M_{i}}{d t}=A c_{i}+A p_{i}-P_{i}-V_{i}$

Onde

- $A c_{i}$ é a vazão mássica de alimentação na perna de elutriação;

- $A p_{i}$ a vazão mássica de alimentação na perna elutriadora;

- $\quad P_{l}$ é a vazão de produto em suspensão;

- $\quad V_{i}$ é a vazão de vapor;

- $M_{i}$ é a massa total de suspensão no evaporador $i$. 
Inicialmente, supôs-se que a variação do volume dentro do cristalizador é mínima, desprezando esse termo pode-se dizer que $\frac{d V t_{i}}{d t}=0$, sendo $V t_{i} \circ$ volume total dentro do cristalizador do efeito $i$, para $i=1,2, . ., 5$.

De acordo com a relação 5 , sabe-se que a densidade de uma suspensão é dependente da concentração de cristais, considerando que a densidade pode ser calculada pela relação $\rho_{i}=\frac{M_{i}}{V t_{i}}$, considerando que a variação de volume é nula pode-se escrever que:

$$
\frac{d V t_{i}}{d t}=\frac{d\left(M_{i} / \rho_{i}\right)}{d t}=\left(1 / \rho_{i}\right) \frac{d\left(M_{i}\right)}{d t}+M_{i} \frac{d\left(1 / \rho_{i}\right)}{d t}=0
$$

É possível notar que o inverso da variação de densidade do cristalizador será um valor muito pequeno e pode ser desprezado. Essa hipótese foi testada, mostrando que a variação da densidade pouco influenciou no balanço mássico global para o processo em questão, como se pode ver no exemplo apresentado no Anexo (Figura A. 1). Assim, pode-se dizer que a variação de massa dentro do cristalizador será nula, ou seja, $\frac{d M_{i}}{d t}=0$.

Finalmente, o balanço de massa global de cada efeito pode ser escrito como.

$$
P_{i}=A c_{i}+A p_{i}-V_{i}
$$

\subsubsection{Balanço de momentos e soluto}

Desprezando as taxas de agregação e quebra de partículas, o balanço de momento pode ser escrito, a partir do modelo desenvolvido pelas Equações $3 \mathrm{e}$ 4 como (Randolph e Larson, 1988):

$$
\frac{d m_{j, i}}{d t}+m_{j, i} \frac{d\left(\log V t_{i}\right)}{d t}+\sum_{k} \frac{\dot{V}_{k} m_{j, k, i}}{V t_{i}}=j G o\left(m_{j-1}+a m_{j}\right)+0^{j} B o
$$

Onde 
- $m_{j}$ representa o j-ésimo momento

- $V t_{i}$ o volume total de suspensão no cristalizador $i$, cuja variação é desprezada.

- $V_{k}$ é a vazão volumétrica total da corrente $k$

- Go a taxa de crescimento de cristais

- Bo a taxa de nucleação,

Sendo que a taxa de crescimento de cristais e a nucleação podem ser representados pelas Equações 18 e 19.

$G o=k_{g}\left(c-c_{s}\right)^{g}(1-a L)$

$B o=k_{b} G o^{b}$

Sendo a uma constante empírica que relaciona a dependência da taxa de crescimento com o tamanho $L$ de cristais que pode ser considerada nula desde que a taxa de crescimento é independente do tamanho dos cristais (Grootscholten, 1982). Os valores adotados podem ser vistos nos Anexos.

Este balanço foi desenvolvido até o terceiro momento, proporcional à fração de cristais em cada cristalizador.

Para o balanço de massa no soluto sendo cristalizado, pode-se escrever (Myerson, 2002):

$\varepsilon V t_{i} \frac{d\left(c_{i}\right)}{d t}=\sum \dot{V}_{e k} c_{e k}-\sum \dot{V}_{p} c_{i}-3 G o\left(\rho-c_{i}\right) k_{v} m_{2} V t_{i}$

Onde $c_{i}$ é a concentração de soluto no efeito $i, k_{v}$ o fator de volume do cristal e $\varepsilon$ é a fração de vazios e pode ser calculada por $\varepsilon=1-k_{v} m_{3}$.

\subsubsection{Balanço de energia}

Para realizar o balanço de energia desse processo, considerando o volume de controle apresentado na Figura 9, é necessário visualizar alguns pontos onde há alguma troca de energia, a começar pelo balanço de energia no lado vapor 
do condensador. Para o esse balanço considerou-se que a temperatura de referência é de $273 \mathrm{~K}$.

O condensador recebe vapor gerado de um efeito anterior. Considerando que o vapor está em equilíbrio com a solução, a temperatura e a pressão do vapor gerado em cada efeito podem ser relacionadas pela equação de Antoine.

$$
\log \mathrm{P}_{v i}=A_{p}-\frac{B_{p}}{T+C_{p}}
$$

Sendo que essa relação será diferente para uma salmoura saturada e água pura, as constantes para equação de Antoine podem ser vistas no anexo.

Essa diferença levará à formação de um vapor superaquecido em cada efeito (Nevers, 2002), ou seja, a temperatura do vapor ( $\left.T_{i}\right)$ formado será maior do que a temperatura do vapor saturado $\left(T_{s}\right)$ à pressão de operação de cada efeito. Essas informações são utilizadas para o balanço energético em volta do condensador.

A energia fornecida ao efeito $i$ pelo vapor gerado no efeito anterior, considerando o calor sensível da supersaturação pode ser dado por:

$$
Q_{i}=V_{i-1}\left[\lambda\left(T s_{i-1}\right)+H v\left(T_{i-1}\right)-H v\left(T s_{i-1}\right)\right]
$$

Onde

- $\lambda$ é a entalpia de vaporização a temperatura de saturação $T_{s}$ da água na pressão de operação do cristalizador;

- $H_{v}$ é a entalpia do vapor a temperatura de operação do cristalizador $T_{i-1} \mathrm{e}$ a temperatura de saturação $T_{s}$.

- $V_{i}$ é a vazão de vapor.

A equação geral de troca de energia no condensador é dada por: 
$Q_{i}=U_{i} A_{i} \Delta T_{l m}$

Considerando que a dinâmica de troca do condensador seja rápida o suficiente para ser desprezível (Lee e Lee, 1994) é possível prever a vazão de vapor do efeito anterior igualando as Equações 22 e 23.

$$
V_{i-1}=\frac{U_{i} A_{i} \Delta T_{l m}}{\left[\lambda\left(T s_{i-1}\right)+H v\left(T_{i-1}\right)-H v\left(T s_{i-1}\right)\right]}
$$

Sendo que

$$
\Delta T_{l m}=\frac{\left(T c_{E, i}-T_{i}\right)}{\ln \left(\frac{T_{i-1}-T c_{i}}{T_{i-1}-T_{i}}\right)}
$$

Onde $T C_{E i}$ é a temperatura da suspensão em recirculação após o condensador. Agora fazendo o balanço de energia para o lado da suspensão no condensador, é fácil notar que o calor trocado pode ser dado por:

$$
Q_{i}=C_{E, i} C p_{C_{E i}}\left(T c_{E, i}-T_{i}\right)
$$

Onde $C_{E i}$ é a vazão mássica de suspensão na saída do condensador ( que é também a entrada do cristalizador). Igualando as equações 23 e 26, é possível determinar a temperatura da suspensão na saída do condensador $T C_{E i}$.

$$
T c_{E, i}=T_{i-1}-\left(T_{i-1}-T_{i}\right) \exp \left(-\frac{U_{i} A_{i}}{C_{E i} C p_{C_{E}, i}}\right)
$$

O calor específico da suspensão é dado pela média ponderada dos calores específicos da salmoura e dos cristais.

$$
C p s=\sum_{l=1}^{\infty} x_{l} C p_{l}
$$


Com essas informações e considerando o volume de controle da Figura 9, é possível aplicar a lei de conservação de energia e obter o seguinte balanço.

$$
\begin{aligned}
& \frac{d\left(M_{i} C p_{i} T_{i}\right)}{d t}=A_{p_{i}} C p_{A p, i} T_{a p, i}+C_{E i} C p_{C_{E}, i} T_{C_{E}, i}-C_{S_{i}} C p_{i} T_{i}-P_{i} C p_{i} T_{i}+ \\
& +V_{i}\left[\lambda\left(T s_{i}\right)+H v\left(T_{i}\right)-H v\left(T s_{i}\right)\right]+V_{i} \frac{w_{i}}{1-w_{i}} \Delta H_{c r}
\end{aligned}
$$

Onde

- $C p_{i}$ é o calor específico da suspensão no estágio $i ;$

- $C p_{a p, i}$ é o calor específico da vazão de entrada pela perna elutriadora no estágio $i$

- $C_{s i}$ é a vazão mássica de suspensão que sai pela recirculação e $C_{E i}=A_{C i}+C_{S i}$

- $T_{a p, i}$ é a temperatura de alimentação na perna elutriadora;

- $T_{i}$ é a temperatura no estágio i;

- $w_{i}$ é a fração mássica de soluto na saturação

- $\lambda\left(T_{i}\right)$ é o calor latente de vaporização a temperatura $T_{i}$;

- $\Delta H_{c r}$ é a entalpia de cristalização.

\subsection{Identificação do sistema - Modelo auto-regressivo com entradas externas.}

$\mathrm{Na}$ literatura especializada em controladores preditivos, destacam-se aqueles cujos algoritmos foram desenvolvidos para realizar predições discretas no tempo, ou seja, para determinados instantes de tempo $k+n$. Wang (2008) cita que os algoritmos discretos no tempo foram os primeiros a serem desenvolvidos devido à sua grande relevância para aplicação industrial e uma maior facilidade para seu desenvolvimento. 
Este trabalho utiliza algoritmos discretos no tempo para aplicação do controlador preditivo, seguindo outros trabalhos desenvolvidos para este tipo de controlador (Rawlings et al, 1993; Gonzalez e Odloak, 2009; Rodrigues e Odloak, 2003). Por isso faz-se necessário que o modelo utilizado para predição do controlador também seja discreto no tempo.

O modelo dinâmico desenvolvido anteriormente é contínuo no tempo, sendo então necessário encontrar a partir desse modelo contínuo um modelo discreto que represente a dinâmica da planta de cristalização e possa ser utilizado pelo controlador preditivo. O modelo discreto é composto por diversos modelos do tipo SISO.

Para identificar os modelos discretos, partiu-se da simulação do modelo contínuo perturbando as variáveis de temperatura do primeiro e quinto efeito e as vazões de alimentação de salmoura dos cinco efeitos. As respostas da concentração de cristais nos cristalizadores às perturbações degrau foram coletados para identificação. Esse método é comumente utilizado em processos reais para identificar modelos discretos das plantas em operação.

A partir dos dados levantados com as perturbações, os modelos discretos foram identificados pelo método auto-regressivo com entradas externas (ARX do inglês autoregressive with exogenous inputs).

De acordo com Aguirre (2007) um modelo ARX pode ser obtido a partir do modelo geral de representação de tempo discreto:

$$
A(q) y(k)=\frac{B(q)}{F(q)} u(k)+\frac{C(q)}{D(q)} v(k)
$$

\section{Dado que}

- $\quad v(k)$ o ruído branco no instante $k$;

- $\quad y(k)$ a variável de saída no instante $k$;

- $u(k)$ a variável de entrada no instante $k$;

- $q^{-1}$ é o operador de atraso, de forma que $y(k) q^{-1}=y(k-1)$. 
Tomando-se $C(q)=D(q)=F(q)=1$, sendo $A(q)$ e $B(q)$ polinômios arbitrários, 0 modelo ARX será obtido pela seguinte representação.

$$
A(q) y(k)=B(q) u(k)+v(k)
$$

Os polinômios $A(q)$ e $B(q)$ são representados por:

$$
\begin{aligned}
& A(q)=1-a_{1} q^{-1}-\ldots-a_{n_{y}} q^{-n_{y}} \\
& B(q)=b_{1} q^{-1}+\ldots+b_{n_{u}} q^{-n_{u}}
\end{aligned}
$$

A análise da perturbação degrau aplicado ao modelo contínuo e os modelos discretos identificados podem ser vistos na próxima seção deste trabalho.

\subsection{Controlador Proporcional, Integral e Derivativo}

A estratégia de controle baseada em controladores PID foi realizada conforme sugerido por Myerson (2002) para esse tipo de processo, sendo que em todos os efeitos a concentração de cristais era controlada pela vazão de alimentação e as temperaturas do primeiro e do último efeito eram controladas pela temperatura do vapor vivo e pela pressão do quinto efeito, respectivamente.

A lei de controle foi implementada conforme a Equação 34 para o controle clássico.

$$
\mathrm{u}(t)=K_{p} e(t)+K_{i} \int_{0}^{t} e(\tau) d \tau+K_{d} \frac{d}{d t} e(t)
$$

Sendo $K_{p}, K_{i}$ e $K_{d}$ os ganhos proporcional, integral e derivativo e e $(\mathrm{t})$ o erro da variável controlada em relação ao set-point predefinido $e(t)=y_{s p}-y(t)$. 


\subsection{Controlador preditivo de horizonte infinito com controle por faixas}

Considerando um sistema multivariável com nu entradas e ny saídas e representando a função de transferência de Laplace que relaciona a entrada $u_{j}$ e a saída $y_{i}$ por

$$
\begin{aligned}
& G_{i, j}(s)=\frac{b_{i, j, 0}+b_{i, j, 1} s+\ldots+b_{i, j, n b} s^{n b}}{\left(1+a_{i, j, 1} s+a_{i, j, 2} s^{2}+\ldots+a_{i, j, n a} s^{n a}\right) s} \\
& \{n a, n b \in \mathbb{N} \mid n b<n a+1\}
\end{aligned}
$$

Sendo os polos do sistema distinguíveis, é possível escrever a resposta de um modelo a uma perturbação degrau como na Equação 36 (Rodrigues e Odloak, 2003):

$$
S(t)=d_{i, j}^{0}+\sum_{l=1}^{n a}\left[d_{i, j, l}^{d}\right] e^{r t_{a}}
$$

Onde $r_{1}$, para $l=1,2, \ldots$, na são os polos do sistema e os coeficientes $d^{0}, d_{i}^{d}, \ldots, d_{n a}{ }^{d}$ são obtidos pela expansão em frações parciais da resposta ao degrau da função transferência $G_{i, j}$ e $t_{a}$ representa o tempo amostral.

Assumindo que o sistema a ser controlado pode ser representado na forma de estado de espaço, um controlador do tipo MPC livre de offset pode ser representado na seguinte forma, conforme González e Odloak (2009):

$$
\begin{aligned}
& {\left[\begin{array}{c}
x^{x}(k+1) \\
x^{d}(k+1)
\end{array}\right]=\left[\begin{array}{cc}
I_{n y} & 0_{n y}, n d \\
0_{n d, n y} & F
\end{array}\right]\left[\begin{array}{c}
x^{x}(k) \\
x^{d}(k)
\end{array}\right]+\left[\begin{array}{c}
D^{0} \\
D^{d} F N
\end{array}\right] \Delta u(k)} \\
& y(k)=\left[\begin{array}{ll}
I_{n y} & \Psi
\end{array}\right]\left[\begin{array}{l}
x^{s} \\
x^{d}
\end{array}\right] .
\end{aligned}
$$

Sendo que 


$$
\begin{aligned}
& x^{s}=\left[\begin{array}{lll}
x_{1} & \cdots & x_{n y}
\end{array}\right]^{T}, x^{s} \in \mathbb{R}^{n y}, \\
& x^{d}=\left[\begin{array}{lll}
x_{n y+1} & \cdots & x_{n y+n d}
\end{array}\right]^{T}, x^{d} \in \mathbb{C}^{n d}, \\
& F=\operatorname{diag}\left(e^{r_{1,1,1} T} \ldots e^{r_{1,1, n a} T} \ldots e^{r_{l, n u, n a} T} \ldots e^{r_{n y, 1,1} T} \ldots e^{r_{n y, 1, n a} T} \ldots e^{r_{n y, n u, 1} T} \ldots e^{r_{n y, n u, n a} T}\right) \\
& F \in \mathbb{C}^{n d x n d}, \\
& \Delta u(k)=u(k)-u(k-1),
\end{aligned}
$$

$\Psi=\left[\begin{array}{ccc}\Phi & & 0_{1, \text { nuna }} \\ & \ddots & \\ 0_{1, \text { nuna }} & & \Phi\end{array}\right], \Psi \in \mathbb{R}^{\text {nyxnd }}$

$$
\Phi=\left[\begin{array}{lll}
1 & \cdots & 1
\end{array}\right], \Phi \in \mathbb{R}^{\text {nuna }}
$$

$D^{0}=\left(\begin{array}{ccc}d_{1,1}^{0} & \cdots & d_{1, n u}^{0} \\ \vdots & \ddots & \vdots \\ d_{n y, 1}^{0} & \cdots & d_{n y, n u}^{0}\end{array}\right), D^{0} \in \mathbb{R}^{n y x n u}$

$D^{d}=\operatorname{diag}\left(d_{1,1,1}^{d} \ldots d_{1,1, n a}^{d} \ldots d_{1, n u, 1}^{d} \ldots d_{n y, 1,1}^{d} \ldots d_{n y, 1, n a}^{d} \ldots d_{n y, n u, 1}^{d} \ldots d_{n y, n u, n a}^{d}\right)$

$$
D^{d} \in \mathbb{C}^{n d x n d}
$$




$$
N=\left[\begin{array}{c}
J_{1} \\
\vdots \\
J_{1}
\end{array}\right], N \in \mathbb{R}^{n d x n u}
$$

$$
J_{i}=\left[\begin{array}{cccc}
1 & 0 & \cdots & 0 \\
\vdots & \vdots & \ddots & \vdots \\
1 & 0 & \cdots & 0 \\
& & \ddots & \\
0 & 0 & \cdots & 1 \\
\vdots & \vdots & \ddots & \vdots \\
0 & 0 & \cdots & 1
\end{array}\right], J_{i} \in \mathbb{R}^{\text {nunaxnu }}
$$

A componente $x^{s}$ do vetor de estado corresponde aos polos integradores produzidos pela forma incremental do modelo, e $x^{d}$ corresponde aos polos estáveis do sistema.

\subsubsection{Função custo}

Como discutido anteriormente, o controlador do tipo MPC resolve a cada tempo amostral um problema de otimização para alcançar os set-points dependendo das condições de processo, conforme Equação 6.

Esse problema pode ser estendido para que se possa levar em consideração a otimização em tempo real (RTO) da planta através de um modelo estacionário, respeitando a operação dentro de uma faixa de controle pré-definida. Esse controlador estendido (Equação 49) foi proposto por Gonzalez e Odloak (2009) e foi adotado para o controle da planta de cristalização por múltiplo-efeito.

$$
\begin{aligned}
& V_{k, u}=\sum_{j=0}^{\infty}\left(y(k+j \mid k)-y_{s p, k}-\delta_{y, k}\right)^{T} Q_{y}\left(y(k+j \mid k)-y_{s p, k}-\delta_{y, k}\right)+ \\
& +\sum_{j=0}^{\infty}\left(u(k+j \mid k)-u_{d e s, k}-\delta_{u, k}\right)^{T} Q_{u}\left(u(k+j \mid k)-u_{d e s, k}-\delta_{u, k}\right)+ \\
& +\sum_{j=0}^{m-1} \Delta u(k+j \mid k)^{T} R \Delta u(k+j \mid k)+\delta_{y, k}^{T} S_{y} \delta_{y, k}+\delta_{u, k}^{T} S_{u} \delta_{u, k},
\end{aligned}
$$


A função custo estendida acima é utilizada para se obter o controlador, resolvendo-se o seguinte problema de otimização:

$\min _{\Delta u_{k}, y_{s p, k}, \delta_{y, k}, \delta_{u, k}} V_{k, u}$

Sujeito a

$$
\begin{aligned}
& -\Delta u_{\max } \leq \Delta u(k+j \mid k) \leq \Delta u_{\max } \\
& j=0,1, \ldots, m-1 \\
& \Delta u(k+j \mid k)=0: j \geq m \\
& u_{\min } \leq u(k-1)+\sum_{i=0}^{j} \Delta u(k+i \mid k) \leq u_{\max } \\
& j=0,1, \ldots, m-1 \\
& y_{\min } \leq y_{s p, k} \leq y_{\max }, \\
& x^{s}(k)+\tilde{D}^{0} \Delta u_{k}-y_{s p, k}-\delta_{y, k}=0 \\
& u(k-1)+\tilde{D}^{u} \Delta u_{k}-u_{d e s, k}-\delta_{u, k}=0
\end{aligned}
$$

Sendo que $Q_{u}$ e $Q_{y}$ representam os pesos adotados para as variáveis manipuladas e controladas $u$ e $y$ respectivamente. $S_{u}$ e $S_{y}$ são os pesos para as variáveis de folga $\delta_{u}$ e $\delta_{y}$. $u_{d e s}$ é o valor ótimo da variável manipulada calculado pela camada de otimização em tempo real (RTO) que fica acima da camada de controle preditivo na estrutura de controle da planta. $y_{s p, k}$ é o valor ótimo da variável controlada que também é uma variável de decisão do controlador.

Os mesmos autores desenvolveram a Equação 49, eliminando o problema da soma infinita e tornando possível a sua solução computacional, reapresentando-a na forma da Equação 52. 


$$
\begin{aligned}
& V_{k, u}=\sum_{j=0}^{m-1}\left\{\left(y(k+j \mid k)-y_{s p, k}-\delta_{y, k}\right)^{T} Q_{y}\left(y(k+j \mid k)-y_{s p, k}-\delta_{y, k}\right)+\right. \\
& \left.+\left(u(k+j \mid k)-u_{d e s, k}-\delta_{u, k}\right)^{T} Q_{u}\left(u(k+j \mid k)-u_{d e s, k}-\delta_{u, k}\right)\right\}+ \\
& +\sum_{j=0}^{m-1} \Delta u(k+j \mid k)^{T} R \Delta u(k+j \mid k)+\left(x^{d}(k+m \mid k)\right)^{T} \bar{Q}\left(x^{d}(k+m \mid k)\right)+ \\
& +\delta_{y, k}^{T} S_{y} \delta_{y, k}+\delta_{u, k}^{T} S_{u} \delta_{u, k},
\end{aligned}
$$

A matriz $\bar{Q}$ é obtida pela solução da equação de Lyapunov (Equação 53).

$$
\bar{Q}=\Psi^{T} Q_{y} \Psi+F^{T} \bar{Q} F
$$

\subsubsection{Representação na forma quadrática}

Como brevemente discutido anteriormente, pode-se reduzir o problema definido em 50 e 51 a um problema de programação quadrática. Dentro dessa perspectiva foi necessário adaptar o problema para que tenha a forma da Equação 8.

Para isso, a função custo representada pela Equação 52 foi dividida em quatro termos seguindo a mesma metodologia utilizada por Santoro (2011) em sua dissertação, que desenvolveu um controlador preditivo para sistemas integradores com tempo morto.

$$
\begin{aligned}
& V_{k, u}=\underbrace{\sum_{j=0}^{m-1}\left\{\left(y(k+j \mid k)-y_{s p, k}-\delta_{y, k}\right)^{T} Q_{y}\left(y(k+j \mid k)-y_{s p, k}-\delta_{y, k}\right)\right.}_{1^{\circ} \text { termo }}+ \\
& +\underbrace{\left.\left(u(k+j \mid k)-u_{d e s, k}-\delta_{u, k}\right)^{T} Q_{u}\left(u(k+j \mid k)-u_{d e s, k}-\delta_{u, k}\right)\right\}}_{2^{\circ} \text { termo }}+ \\
& +\underbrace{\sum_{j=0}^{m-1} \Delta u(k+j \mid k)^{T} R \Delta u(k+j \mid k)}_{3^{\circ} \text { termo }}+\underbrace{\left(x^{d}(k+m \mid k)\right)^{T} \bar{Q}\left(x^{d}(k+m \mid k)\right)}_{4^{\circ} \text { termo }}+ \\
& +\delta_{y, k}^{T} S_{y} \delta_{y, k}+\delta_{u, k}^{T} S_{u} \delta_{u, k},
\end{aligned}
$$

\subsubsection{Primeiro termo}

Considera-se o primeiro termo da função objetivo. 
$\sum_{j=0}^{m-1}\left\{\left(y(k+j \mid k)-y_{s p, k}-\delta_{y, k}\right)^{T} Q_{y}\left(y(k+j \mid k)-y_{s p, k}-\delta_{y, k}\right)\right.$

Para desenvolver o primeiro termo da Equação 52, primeiramente considerouse o modelo em espaço de estados para reescrever a variável de saída $y(k+j \mid k)$ conforme se vê a seguir:

$y(k+j \mid k)=C A x(k+j-1)+C B \Delta u(k+j-1)$

Sendo que $A, B$ e $C$ são matrizes do modelo em variáveis de estado definido na Equação 10.

Considerando que o primeiro termo da Equação 52 é definido para os instantes $k+j$, sendo $j=0,1,2, \ldots, m-1$, pode-se expandir a variável de saída para os instante de tempo.

$$
\begin{aligned}
& y(k)=C x(k) \\
& y(k+1)=C A x(k)+C B \Delta u(k) \\
& \begin{aligned}
y(k+2 \mid k)=C A x(k+1 \mid k)+C B \Delta u(k+1 \mid k) \\
=C A^{2} x(k)+C A B \Delta u(k \mid k)+C B \Delta u(k+1 \mid k) \\
y(k+3 \mid k)=C A^{3} x(k)+C A^{2} B \Delta u(k \mid k)+C A B \Delta u(k+1 \mid k)+C B \Delta u(k+2 \mid k) \\
y(k+m-1)=C A^{m-1} x(k)+C A^{m-2} B \Delta u(k \mid k)+\ldots+C A B \Delta u(k+m-2)+ \\
+C B \Delta u(k+m-1)
\end{aligned}
\end{aligned}
$$

Rearranjando na forma matricial, o vetor de saídas preditas pode ser escrito como 


$$
\underbrace{\left[\begin{array}{c}
y(k \mid k) \\
y(k+1 \mid k) \\
y(k+2 \mid k) \\
\vdots \\
y(k+m-1 \mid k)
\end{array}\right]}_{\bar{y}}=\underbrace{\left[\begin{array}{c}
C \\
C A \\
C A^{2} \\
\vdots \\
C A^{m-1}
\end{array}\right]}_{\bar{A}} x(k)+\underbrace{\left[\begin{array}{ccccc}
0 & 0 & \cdots & 0 & 0 \\
C B & 0 & \cdots & 0 & 0 \\
C A B & C B & \ddots & 0 & 0 \\
\vdots & \vdots & \cdots & \cdots & \vdots \\
C A^{m-2} B & C A^{m-3} B & \cdots & C A B & C B
\end{array}\right]}_{\bar{B}} \underbrace{\left[\begin{array}{c}
\Delta u(k \mid k) \\
\Delta u(k+1 \mid k) \\
\Delta u(k+2 \mid k) \\
\vdots \\
\Delta u(k+m-1 \mid k)
\end{array}\right]}_{\Delta u_{k}}
$$

Ou representando por uma forma simplificada;

$\bar{y}=\bar{A} x(k)+\bar{B} \Delta u_{k}$

Onde as matrizes $\bar{A}, \bar{B}$ e $\bar{y}$ são respectivamente

$$
\bar{A}=\left[\begin{array}{c}
C \\
C A \\
C A^{2} \\
\vdots \\
C A^{m-1}
\end{array}\right]
$$

$\bar{B}=\left[\begin{array}{ccccc}0 & 0 & \cdots & 0 & 0 \\ C B & 0 & \cdots & 0 & 0 \\ C A B & C B & \ddots & 0 & 0 \\ \vdots & \vdots & \cdots & \cdots & \vdots \\ C A^{m-2} B & C A^{m-3} B & \cdots & C A B & C B\end{array}\right]$

$\bar{y}=[y(k \mid k) ; y(k+1 \mid k) ; y(k+2 \mid k) ; \ldots ; y(k+m-1 \mid k)]$

Considerando que as variáveis de folga e o $y_{s p}$ são os mesmos para $j=0,1,2$, ..., $m$-1, pode-se reescrever o primeiro termo como 
$\left(\bar{y}(k \mid k)-\bar{I}_{n y} y_{s p, k}-\bar{I}_{n y} \delta_{y, k}\right)^{T} \bar{Q}_{y}\left(\bar{y}(k \mid k)-\bar{I}_{n y} y_{s p, k}-\bar{I}_{n y} \delta_{y, k}\right)$

Para $\bar{I}_{n y}=\left[\begin{array}{lll}I_{n y} I_{n y} & \cdots & I_{n y}\end{array}\right]^{T}$, sendo que $I_{n y}$ é uma matriz identidade de dimensões ny.

Substituindo $\bar{y}$ da Equação 57 na Equação 58 finalmente chega-se a:

$$
\left(\bar{A} x(k)+\bar{B} \Delta u_{k}-\bar{I}_{n y} y_{s p, k}-\bar{I}_{n y} \delta_{y, k}\right)^{T} \bar{Q}_{y}\left(\bar{A} x(k)+\bar{B} \Delta u_{k}-\bar{I}_{n y} y_{s p, k}-\bar{I}_{n y} \delta_{y, k}\right)
$$

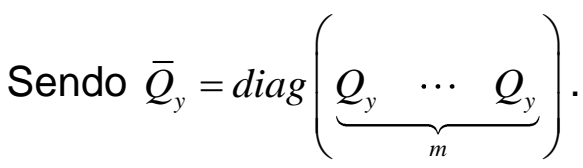

\subsubsection{Segundo termo}

Considera-se o segundo termo da função objetivo.

$$
\sum_{j=0}^{m-1}\left(u(k+j \mid k)-u_{d e s, k}-\delta_{u, k}\right)^{T} Q_{u}\left(u(k+j \mid k)-u_{d e s, k}-\delta_{u, k}\right)
$$

Por definição, sabe-se que a variação nas entradas é dada por $\Delta u(k+j \mid k)=u(k+j \mid k)-u(k+j-1 \mid k)$, rearranjando essa equação de modo a isolar a entrada $u$ no instante $k+j$, tem-se:

$u(k+j \mid k)=\Delta u(k+j \mid k)+u(k+j-1)$

Da mesma forma como no primeiro termo, o segundo termo é definido para os instantes $k+j$, sendo $j=0,1,2, \ldots, m-1$. Assim, pode-se expandir a variável de entrada $u$ para os instantes de tempo.

$$
\begin{aligned}
& u(k)=\Delta u(k)+u(k-1) \\
& u(k+1)=\Delta u(k+1)+\Delta u(k)+u(k-1) \\
& u(k+m-1)=\Delta u(k+m-1)+\Delta u(k+m-2)+\ldots+\Delta u(k)+u(k-1)
\end{aligned}
$$

Como feito para as saídas preditas (Equação 56), o vetor de entradas pode ser definido como: 


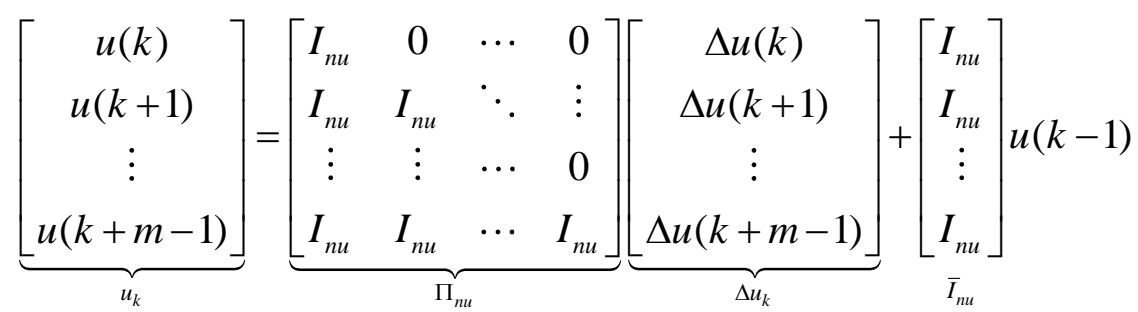

Escrevendo a Equação 61 na forma simplificada tem-se que:

$u_{k}=\Pi_{n u} \Delta u_{k}+\bar{I}_{n u} u(k-1)$

Daí, substituindo a Equação 62 no segundo termo da Equação 52, pode-se reescrever o segundo termo na seguinte forma:

$$
\left(\Pi_{n u} \Delta u_{k}+\bar{I}_{n u} u(k-1)-\bar{I}_{n u} u_{d e s, k}-\bar{I}_{n u} \delta_{u, k}\right)^{T} \bar{Q}_{u}\left(\Pi_{n u} \Delta u_{k}+\bar{I}_{n u} u(k-1)-\bar{I}_{n u} u_{d e s, k}-\bar{I}_{n u} \delta_{u, k}\right)
$$

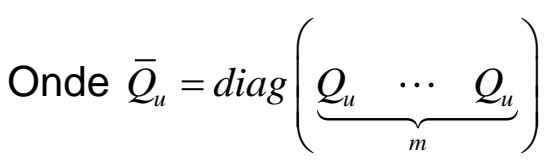

$\Pi_{n u}=\left[\begin{array}{cccc}I_{n u} & 0 & \cdots & 0 \\ I_{n u} & I_{n u} & \ddots & \vdots \\ \vdots & \vdots & \cdots & 0 \\ I_{n u} & I_{n u} & \cdots & I_{n u}\end{array}\right] \quad$ e $\quad \bar{I}_{n u}=\left[\begin{array}{c}I_{n u} \\ I_{n u} \\ \vdots \\ I_{n u}\end{array}\right]$ sendo $I_{n u}$ matrizes identidades de

dimensões $n u$.

\subsubsection{Terceiro termo}

Considera-se o terceiro termo da função objetivo.

$\sum_{j=0}^{m-1} \Delta u(k+j \mid k)^{T} R \Delta u(k+j \mid k)$

O tratamento para o terceiro termo é o mesmo utilizado para os termos anteriores. Definindo $\Delta u$ para os instantes $\mathrm{j}=0,1,2, \ldots, 3$, o terceiro termo é expandido para os instantes de tempo atual $k$ até $k+m-1$ : 
$\Delta u(k+1 \mid k)^{T} R \Delta u(k+1 \mid k)$

$\Delta u(k+m-1 \mid k)^{T} R \Delta u(k+m-1 \mid k)$

Observa-se que, como na Equação 56 e 61, é possível escrever a variável $\Delta u$ na forma vetorial.

$$
\underbrace{\left[\begin{array}{c}
\Delta u(k) \\
\Delta u(k+1) \\
\vdots \\
\Delta u(k+m-1)
\end{array}\right]}_{\Delta u_{k}} \underbrace{\left[\begin{array}{cccc}
R & 0 & \cdots & 0 \\
0 & R & \ddots & \vdots \\
\vdots & \vdots & \cdots & 0 \\
0 & 0 & \cdots & R
\end{array}\right]}_{\bar{R}} \underbrace{\left[\begin{array}{c}
\Delta u(k) \\
\Delta u(k+1) \\
\vdots \\
\Delta u(k+m-1)
\end{array}\right]}_{\Delta u_{k}}
$$

Que pode ser escrito na seguinte forma simplificada

$$
\Delta u_{k}^{T} \bar{R} \Delta u_{k}
$$

Onde $\bar{R}=\operatorname{diag}(\underbrace{R \quad \cdots \quad}_{m})$

\subsubsection{Quarto termo}

Considera-se o quarto termo da função objetivo.

$\left(x^{d}(k+m \mid k)\right)^{T} \bar{Q}\left(x^{d}(k+m \mid k)\right)$

Para um controlador preditivo de horizonte infinito, para 0 termo $x^{d}$ que representa os modos do sistema, pode-se escrever a seguinte relação (Gonzalez e Odloak, 2009):

$x^{d}(k+m \mid k)=F_{x} x^{d}(k)+F_{u} \Delta u_{k}$

Sendo que

$$
F_{x}=\left[\begin{array}{lll}
0_{n d x n y} & F^{m} & 0_{n d x n y}
\end{array}\right] \text { e } F_{u}=\left[\begin{array}{llll}
D^{d} F^{m} N & D^{d} F^{m-1} N & \cdots & D^{d} F N
\end{array}\right]
$$


Substituindo a relação apresentada em (66) no quarto termo da função custo, esse poderá ser reescrito conforme (67).

$\left(F_{x} x^{d}(k)+F_{u} \Delta u_{k}\right)^{T} \bar{Q}_{b}\left(F_{x} x^{d}(k)+F_{u} \Delta u_{k}\right)^{T}$

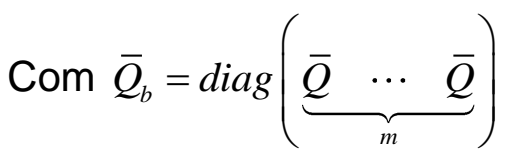

e $\bar{Q}$ pode ser obtido pela função de Lyapunov 53.

Definidos os quatro termos, podemos substituí-los na Equação 52 obtendo a seguinte relação:

$$
\begin{aligned}
& V_{k, u}=\left(\bar{A} x(k)+\bar{B} \Delta u_{k}-\bar{I}_{n y} y_{s p, k}-\bar{I}_{n y} \delta_{y, k}\right)^{T} \bar{Q}_{y}\left(\bar{A} x(k)+\bar{B} \Delta u_{k}-\bar{I}_{n y} y_{s p, k}-\bar{I}_{n y} \delta_{y, k}\right)+ \\
& +\left(\Pi_{n u} \Delta u_{k}+\bar{I}_{n u} u(k-1)-\bar{I}_{n u} u_{d e s, k}-\bar{I}_{n u} \delta_{u, k}\right)^{T} \bar{Q}_{u}\left(\Pi_{n u} \Delta u_{k}+\bar{I}_{n u} u(k-1)-\bar{I}_{n u} u_{d e s, k}-\bar{I}_{n u} \delta_{u, k}\right)+ \\
& +\Delta u_{k}^{T} \bar{R} \Delta u_{k}^{T}+\left(F_{x} x^{d}(k)+F_{u} \Delta u_{k}\right)^{T} \bar{Q}_{b}\left(F_{x} x^{d}(k)+F_{u} \Delta u_{k}\right)^{T}+\delta_{y, k}^{T} S_{y} \delta_{y, k}+\delta_{u, k}^{T} S_{u} \delta_{u, k}
\end{aligned}
$$

Que é substituída no problema de otimização definido em 50 sujeito às restrições apresentadas em 51.

Assim pode-se reorganizar a função 68 de modo que se assemelhe à forma quadrática apresentada em 8.

$$
V_{k, X}=X^{T} H X+2 f^{T} X+C
$$

Sendo que para o problema específico de controle por faixa, as variáveis calculadas são definidas abaixo:

$$
X=\left[\begin{array}{c}
\Delta u_{k} \\
y_{s p, k} \\
\delta_{y, k} \\
\delta_{u, k}
\end{array}\right]
$$


Fazendo para $H=\left[\begin{array}{cccc}a_{H} & b_{H} & c_{H} & d_{H} \\ e_{H} & f_{H} & g_{H} & h_{H} \\ i_{H} & j_{H} & l_{H} & k_{H} \\ m_{H} & n_{H} & o_{H} & p_{H}\end{array}\right]$ e $f=\left[\begin{array}{llll}q_{f} & r_{f} & s_{f} & t_{f}\end{array}\right]$, desenvolvendo

a Equação 68 e rearranjando todas as variáveis para que se assemelham a Equação 8, tem-se que os termos de $H$ são definidos pelo seguinte conjunto de equações.

$$
\begin{aligned}
& a_{H}=\bar{B}^{T} \overline{Q_{y}} \bar{B}+\Pi_{n u}^{T} \bar{Q}_{u} \Pi_{n u}+F_{u}^{T} \bar{Q}_{b} F_{u} \\
& b_{H}=-\bar{B}^{T} \bar{Q}_{y} \bar{I}_{n y} \\
& b_{H}=c_{H} \\
& d_{H}=-\Pi_{n u}^{T} \bar{Q}_{u} \bar{I}_{n u} \\
& e_{H}=i_{H}=b_{H}^{T} \\
& f_{H}=g_{H}=j_{H}=\bar{I}_{n y}^{T} \bar{Q}_{y} \bar{I}_{n y}
\end{aligned}
$$

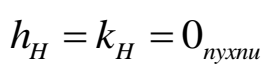

$$
\begin{aligned}
& l_{H}=\bar{I}_{n y}^{T} \bar{Q}_{y} \bar{I}_{\tilde{n} y}+S_{y} \\
& m_{H}=-\bar{I}_{n u}^{T} \bar{Q}_{u} \Pi_{n u} \\
& n_{H}=o_{H}=0_{\text {nuxny }} \\
& p_{H}=-\bar{I}_{n u}^{T} \bar{Q}_{u} \bar{I}_{n u}+S_{u} \\
& q_{f}=-x_{k}^{T} \bar{A}^{T} \bar{Q}_{y} \bar{B}-\left[\Pi_{n u}^{T} \bar{Q}_{u} \bar{I}_{n u}\left(u(k-1)-u_{d e s, k}\right)\right]^{T}+\left(u(k-1)-u_{d e s, k}\right)^{T} \bar{I}_{n u}^{T} \bar{Q}_{u} \Pi_{n u}+ \\
& +x^{d T} F_{x}^{T} \bar{Q}_{b} F_{u}+\left(F_{u}^{T} \bar{Q}_{b} F_{x} x^{d}\right)^{T} \\
& r_{f}=s_{f}=-x_{k}^{T} \bar{A}^{T} \bar{Q}_{y} \bar{I}_{n y}-\left(\bar{I}_{n y}^{T} \bar{Q}_{y} \bar{A} x_{k}\right)^{T} \\
& t_{f}=-\left(u(k-1)-u_{d e s, k}\right)^{T} \bar{I}_{n u}^{T} \bar{Q}_{u} \bar{I}_{n u} S_{u}-\left(\bar{I}_{n u}^{T} \bar{Q}_{u} \bar{I}_{n u}\left(u(k-1)-u_{d e s, k}\right)\right)^{T}
\end{aligned}
$$

O termo $C$ da Equação 8 pode ser escrito como: 
$C=x_{k}^{T} \bar{A}^{T} \bar{Q}_{y} \bar{A} x_{k}+x^{d T} F_{x}^{T} \bar{Q}_{b} F_{x} x^{d}$

A programação desse algoritmo foi realizada dentro da estrutura do controle preditivo apresentado na Figura 7.

\section{6 otimizador}

Um dos parâmetros utilizados pelo controlador para determinar o ponto de operação da planta é o valor ótimo das variáveis manipuladas $u_{d e s}$, esses valores ótimos podem ser calculados por um problema de otimização onde a função objetivo atende a critérios econômicos. Para este trabalho definiu-se como objetivo de otimização a minimização do consumo energético da planta, que será calculado a cada tempo amostral fornecendo dados para 0 controlador IHMPC, conforme esquema da Figura 7.

\subsubsection{Desenvolvimento do problema de otimização - mínimo consumo de energia}

O consumo energético para essa planta pode ser definido como a energia gasta para produzir $1 \mathrm{~kg}$ de cristal. Desprezando os gastos energéticos de equipamentos periféricos, cujo consumo é pouco significativo comparado ao consumo de vapor vivo, o consumo energético é determinado pelo calor latente fornecido pelo vapor vivo $V_{o}$ dividido pela massa total de cristais produzido no intervalo de tempo determinado:

$$
\text { Con }=\frac{V_{0}\left[\lambda\left(T s_{0}\right)+H v\left(T_{0}\right)-H v\left(T s_{0}\right)\right]}{\sum_{i=1}^{5} P_{i} x_{i}}
$$

Sendo que o termo $\sum_{i=1}^{5} P_{i} x_{i}$ é a produção total da planta dentro daquele intervalo de tempo e o termo do numerador é a energia consumida pelo sistema.

Pelo balanço de massa geral, a Equação 16 relaciona a produção $P$ com as vazões de entrada Aci e Api e a água evaporada Vi.

Fazendo 
$A_{T, i}=A_{c, i}+A_{p, i}$

Desconsiderando efeitos de supersaturação, pode-se notar que um simples balanço de massa de cristais pode ser escrito como:

$\frac{d\left(M_{i} x_{i}\right)}{d t}=A_{p_{i}} x_{a p, i}+C_{E i} x_{C e, i}-C_{S i} x_{i}-P_{i} x_{i}+V_{i} \frac{w_{i}}{1-w_{i}}$

para

$C_{E i}=A_{C i}+C_{S i}$

e

$C_{E i} x_{C e, i}=A_{C i,} x_{A_{c}, i}+C_{S i} x_{i}$

E considerando as Equações 73 e 74 e substituindo $V_{i}$ da Equação 72 pode-se escrever para o estado estacionário que.

$0=A_{T, i} x_{a p, i}-P_{i} x_{i}+\left(A_{T, i}-P_{i}\right) \frac{w_{i}}{1-w_{i}}$

Isolando $P_{i}$.

$P_{i}=\frac{A_{T, i}\left(x_{a p, i}+\frac{w_{i}}{1-w_{i}}\right)}{\left(x_{i}+\frac{w_{i}}{1-w_{i}}\right)}$

As alimentações $A_{t, i}$ estão entre as variáveis manipuladas calculadas, que na sua forma adimensional são os valores de $u$ (Equação 52).

Assim sendo, pode-se escrever 
$A_{T, i}=u_{i} A_{a d m, i}+A_{a d m, i}$

Da mesma forma

$x_{i}=y_{i}(k) x_{a d m, i}+x_{a d m, i}$

O termo xi (fração mássica de cristais no efeito i) pode ser calculado pelo modelo de espaço de estados $y(k)$ da Equação 10, tal que

$y_{i}(k)=I_{i}(C A x(k)+C B u(k))$

Onde o termo $l_{i}$ é um vetor linha que isola a variável $x_{i}$ desejada (relativo ao efeito) tal que

$\left[\begin{array}{l}I_{1} \\ I_{2} \\ I_{3} \\ I_{4} \\ I_{5}\end{array}\right]=\left[\begin{array}{lllll}1 & 0 & 0 & 0 & 0 \\ 0 & 1 & 0 & 0 & 0 \\ 0 & 0 & 1 & 0 & 0 \\ 0 & 0 & 0 & 1 & 0 \\ 0 & 0 & 0 & 0 & 1\end{array}\right]$

Pode-se reescrever utilizando as Equações de 76 a 79 o denominador da Equação 70 como:

$\sum_{i=1}^{5} P_{i} x_{i}=\sum_{i=1}^{5}\left\{\frac{\left(u_{i}(k) A_{a d m, i}+A_{a d m, i i}\right)\left(x_{a p, i}+\frac{w_{i}}{1-w_{i}}\right)\left[I_{i}(C A x(k)+C B u(k)) x_{a d m, i}+x_{a d m, i}\right]}{\left(I_{i}(C A x(k)+C B u(k)) x_{a d m, i}+x_{a d m, i}+\frac{w_{i}}{1-w_{i}}\right)}\right\}$

Portanto, a função objetivo será 


$$
\text { Con }=\frac{V_{0}\left[\lambda\left(T s_{0}\right)+H v\left(T_{0}\right)-H v\left(T s_{0}\right)\right]}{\sum_{i=1}^{5}\left\{\frac{\left(u_{i} A_{a d m, i}+A_{a d m, i i}\right)\left(x_{a p, i}+\frac{w_{i}}{1-w_{i}}\right)\left[I_{i}(C A x(k)+C B u(k)) x_{a d m, i}+x_{a d m, i}\right]}{\left(I_{i}(C A x(k)+C B u(k)) x_{a d m, i}+x_{a d m, i}+\frac{w_{i}}{1-w_{i}}\right)}\right\}}
$$

A cada tempo amostral será resolvido o problema de otimização, como demonstrado na Figura 7 procurando pelo valor das variáveis de entrada ótimas $u_{\text {des }}$ que minimizem o consumo de energia conforme definido abaixo.

$\min _{u}$ Con

Sujeito a

$$
\begin{aligned}
& u_{\text {min }} \leq u \leq u_{\max } \\
& y_{\text {min }} \leq y_{s p, k} \leq y_{\text {max }},
\end{aligned}
$$

\subsection{Estratégia de simulação}

Para avaliar os dois controladores propostos para a unidade de cristalização múltiplo-efeito, estruturou-se o modelo em duas seções. A primeira seção corresponde à planta, onde a partir do modelo físico proposto é simulado o processo, nessa etapa a simulação representa a operação real da planta. A segunda seção corresponde à simulação do controlador, nesta última foram programados os controladores do tipo PID e o IHMPC, utilizados conforme as avaliações propostas. A Figura 10 representa de forma simplificada e genérica a lógica utilizada para a simulação, dividindo em duas seções dependentemente interligadas: $O$ processo, simulação que representa a operação real da planta, e o controlador. Toda a simulação foi realizada em software Matlab®. 


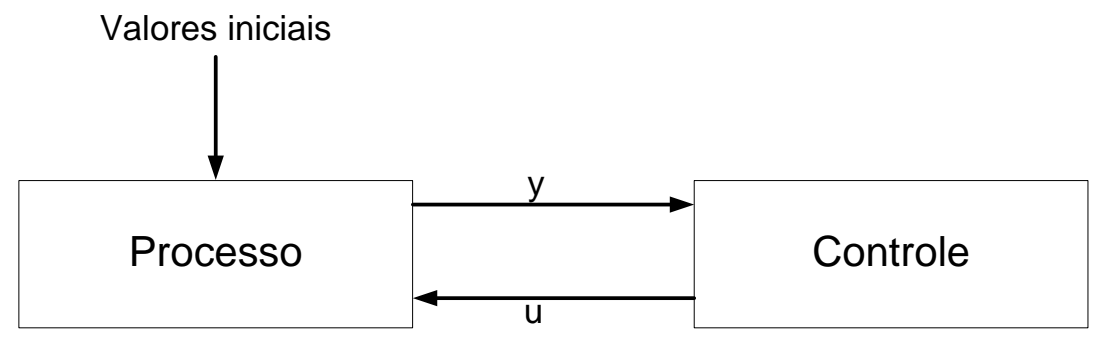

Figura 10 - Esquema simplificado de simulação do processo.

$\mathrm{Na}$ seção onde é simulado o processo são fornecidas as condições iniciais como vazões de alimentação de salmoura $A$, temperaturas e pressões das correntes e dos cristalizadores. Essas condições servem como entrada para 0 modelo físico que gera um conjunto de dados de saída, como por exemplo a concentração de cristais em cada efeito. Esses dados gerados pelo processo são então alimentados à seção onde é simulado o controlador. A partir das informações fornecidas pelo processo o controlador calculará novas variáveis de entrada para manter a operação dentro dos patamares desejados.

As informações geradas pelo controlador são então realimentadas à seção da esquerda da Figura 9 para simulação do processo, esse realizará uma nova simulação dinâmica utilizando os novos parâmetros determinados pelo controlador. A resposta gerada pela simulação da planta será então novamente enviada para o controlador onde esses dados serão utilizados para que 0 controlador novamente determine as novas condições de operação se essas ainda estiverem diferentes das condições pré-estabelecidas para a operação.

A atuação do controlador ocorre a cada período amostral $t_{a}$, que para esse processo foi determinado em 10 minutos considerando a dinâmica do processo.

Os cálculos dos controladores foram realizados de acordo com o tipo testado: 0 controlador PID e o controlador IHMPC. 


\subsubsection{Simulação da planta}

A estratégia de simulação da planta de cristalização por evaporação múltiploefeito foi determinada considerando a influência que cada efeito tem sobre o efeito posterior ou anterior.

Para cada efeito, foram utilizadas as Equações de 16 a 29 apresentadas anteriormente. Cada cristalizador é descrito por sete equações diferenciais que representam os balanços de massa, energia, soluto e momentos (Equações 17, 20 e 29 sendo que a primeira é desenvolvida para os momentos $0,1,2$ e 3). As propriedades físicas estão no anexo deste trabalho.

Observando a Figura 8 percebe-se que os cinco cristalizadores estão interligados entre si devido ao uso do vapor gerado por um efeito para fornecimento de energia no efeito seguinte. Isso faz com que as equações diferenciais que representam as dinâmicas de cada efeito dependam de informações geradas pela resolução das equações dos cristalizadores vizinhos. Essa integração de dados é realizada pelo balanço de energia em torno dos condensadores (Equação 23 a 27) utilizando para os cálculos a temperatura e vazão do vapor do efeito a montante do condensador e a temperatura e vazão de suspensão da linha de circulação a jusante do condensador.

Assim as 35 equações de balanços dinâmicos que modelam todos os cristalizadores formam um sistema de equações diferenciais ordinárias (EDOs) a serem resolvidas simultaneamente por método numérico.

O software Matlab® apresenta sete métodos para a resolução de sistemas de EDOs. Não foram observadas diferenças nas respostas geradas por cada um deles, sendo então adotado o método de Gear (ode15s) como padrão, simplesmente por apresentar um menor tempo de resolução do modelo fenomenológico. 


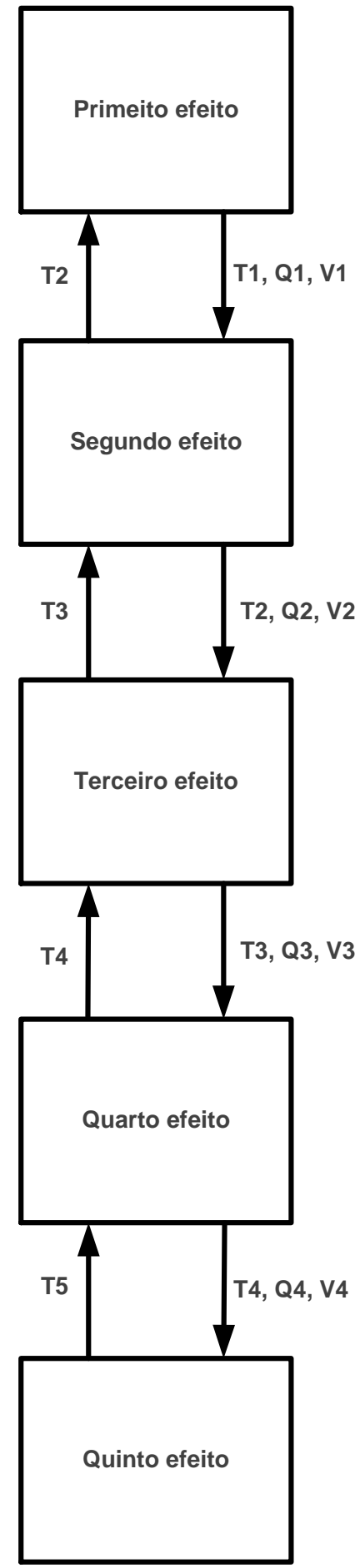

Figura 11 - Dependência de variáveis entre os efeitos.

A Figura 11 representa simplificadamente a solução do modelo de simulação da unidade de cristalização por múltiplo-efeito descrita anteriormente. Cada bloco da figura é composto pelo conjunto de equações que representam os fenômenos físicos de cada efeito. Cada efeito recebe e fornece informações 
para o efeito vizinho para resolução simultânea de todos os blocos. A solução de todos os blocos é realizada a cada instante da integração numérica.

A integração é realizada até que se atinja o tempo $t$ pré-determinado, esse tempo pode ser de 30 horas se simulado um sistema aberto ou de 10 minutos para cada atuação do controlador.

\subsubsection{Controle PID}

A estrutura utilizada para a simulação do controlador do tipo PID está representada na figura 7 e se baseia nas sugestões presentes no trabalho de Myerson (2002) para esse tipo de processo.

Para cada efeito existe uma válvula na alimentação de salmoura Ac que controla a concentração de cristais dentro do cristalizador a partir de uma leitura de densidade da suspensão na saída de produto $P$.

Apenas as temperaturas do primeiro e do quinto efeitos são controladas, sendo que o controle de temperatura do primeiro efeito é realizado por manipulação do vapor vivo alimentado no condensador enquanto a temperatura do quinto efeito é controlada manipulando-se a vazão do ejetor, aqui representada pela respectiva pressão nesse equipamento, responsável pelo ajuste de pressão do quinto efeito. A vazão do vapor vivo está ligada diretamente a sua temperatura e inversamente à temperatura do primeiro cristalizador, tendo em vista que ela depende da troca térmica no primeiro condensador (Equação 24), sendo assim considera-se que é manipulada a fonte do vapor vivo de forma a determinar sua temperatura $e$ consequentemente sua vazão.

Em todos os efeitos há um controle de nível atuando na vazão de saída de produto $\mathrm{P}$, porém esse controlador não faz parte da estrutura PID estudada. Considera-se que a dinâmica dessa variável é rápida suficiente tal que seu efeito na estrutura de controle é desprezível, conforme hipótese assumida no desenvolvimento do modelo fenomenológico. 
O Controlador PID foi aplicado para o controle das variáveis temperatura do efeito 1 e 5 e concentração de cristais em cada um dos cinco efeitos, o esquema utilizado para cada uma dessas variáveis pode ser visto na Figura 12.

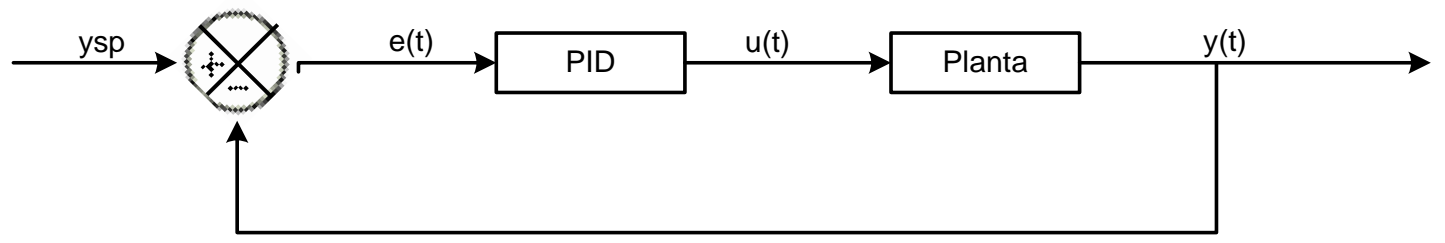

Figura 12 - Esquema de aplicação do controlador PID

Para esse controlador, foi definido um "set-point" para cada variável, cujo erro $e(t)$ é calculado pela diferença entre o "set-point" e do valor da variável controlada resultante do processo $y_{s p}-y(t)$. O erro calculado é então usado pelo controlador PID, através da Equação 33, para definir a ação $u(t)$ a ser aplicada na planta para correção dos erros.

Os "set-points" foram definidos como o ponto ótimo de operação para condições de projeto em estado estacionário.

Para ajustar o controlador PID utilizou-se o método de otimização que apresenta como resposta os parâmetros do controlador, procurando o ajuste que forneça o menor valor de ITAE ("integral of the time-weighted absolute error"), conforme Equação 83.

ITAE $=\int_{0}^{\infty} t|e(t)| d t$

Após o primeiro ajuste do controlador pelo método de otimização, os parâmetros foram ressintonizados por tentativa e erro até que foi encontrado o melhor ajuste da planta como um todo.

As variáveis manipuladas $u$ e variáveis controladas $y$ são as representações adimensionais, na forma: 


$$
\begin{aligned}
& u=\frac{\text { VarManip }- \text { VarManip }_{\text {ref }}}{\text { VarManip }_{r e f}} \\
& y=\frac{x-x_{\text {ref }}}{x_{\text {ref }}}
\end{aligned}
$$

\subsubsection{Controlador preditivo}

Para simulação do controlador preditivo, seguiu-se a estrutura apresentada na Figura 6 e discutida na seção 3.6. As variáveis manipuladas e controladas são as mesmas utilizadas pelo controlador PID.

Nessa estrutura o otimizador resolve o problema de RTO definido em 83 cujo objetivo é calcular os valores ótimos para as variáveis de entrada $u_{d e s}$ que ditem o mínimo custo energético de acordo com a função estática 82 , respeitando as restrições apresentadas em 84.

Para resolução desse problema o otimizador em estado estacionário é alimentado com informações do último estado conhecido da planta $\hat{x}(k)$ e os limites operacionais pré-estabelecidos.

O controlador MPC é então alimentado com a variável "alvo" $u_{\text {des }}$ e com as informações do último estado conhecido da planta $\hat{x}(k)$. Com esses dados o controlador resolve o problema determinado em (50) predizendo o estado futuro da planta, determinando o incremento $\Delta u_{k}$ a ser aplicado nas variáveis manipuladas da unidade de cristalização por múltiplo-efeito.

As informações geradas pela planta $y_{k}$ a partir das mudanças determinada pelo controlador são lidas por um observador que estima o estado $\hat{x}(k)$. $\mathrm{O}$ estimador de estado utilizado é o Filtro de Kalman (Equação 13).

Assim, o novo estado é utilizado novamente pelo RTO e pelo controlador para que um novo procedimento de cálculo seja realizado. $O$ otimizador e 0 controlador operam a cada tempo amostral $t_{a}$ determinado. 


\section{RESULTADOS E DISCUSSÃO}

\subsection{Malha aberta}

A partir dos balanços de massa e energia, e através do algoritmo desenvolvido foi possível simular o sistema de evaporação por múltiplo-efeito em malha aberta por tempo suficiente para que se atingisse o estado estacionário. Para a essa simulação foram considerados os dados iniciais de processo da Tabela 1.

Tabela 1 - Condições iniciais de processo para operação

\begin{tabular}{l|ccccc} 
& \multicolumn{5}{c}{ Efeito } \\
\hline $\mathrm{Ap}[\mathrm{kg} / \mathrm{h}]$ & 29000 & 26000 & 24000 & 25000 & 26000 \\
$\mathrm{Ac}[\mathrm{kg} / \mathrm{h}]$ & 14000 & 13000 & 12000 & 13000 & 13000 \\
$\mathrm{Cs}[\mathrm{kg} / \mathrm{h}]$ & 3000000 & 2800000 & 2600000 & 2500000 & 2700000 \\
$\mathrm{TO}\left[{ }^{\circ} \mathrm{C}\right]$ & 115 & 101 & 80 & 67,08 & 50,6 \\
$\mathrm{Te}\left[{ }^{\circ} \mathrm{C}\right]$ & 73 & 65 & 56 & 47 & 37 \\
Pressão $[\mathrm{bar}]$ & 1,25 & 0,78 & 0,35 & 0,208 & 0,095 \\
$\mathrm{C}\left[\mathrm{kg} / \mathrm{m}^{3}\right]$ & 370 & 370 & 370 & 360 & 360 \\
$\mathrm{x}$ & 0,204 & 0,204 & 0,204 & 0,204 & 0,204
\end{tabular}

Sendo $A p$ a vazão de alimentação na perna elutriadora, $A c$ a vazão de alimentação de salmoura na circulação, Cs a vazão de suspensão na linha de circulação forçada, TO é a temperatura inicial de simulação dos cristalizadores à pressão indicada, $T e$ a temperatura de entrada da salmoura saturada, $c$ a concentração inicial de soluto e $x$ a fração mássica de cristais. A temperatura e vazão de vapor vivo é respectivamente $127^{\circ} \mathrm{C}$ e $18000 \mathrm{~kg} / \mathrm{h}$. E a pressão do ejetor de 0,072 bar.

Inicialmente esses dados foram utilizados para simulação da unidade sem controlador, com o intuito de conhecer o comportamento dinâmico apresentado a seguir. 


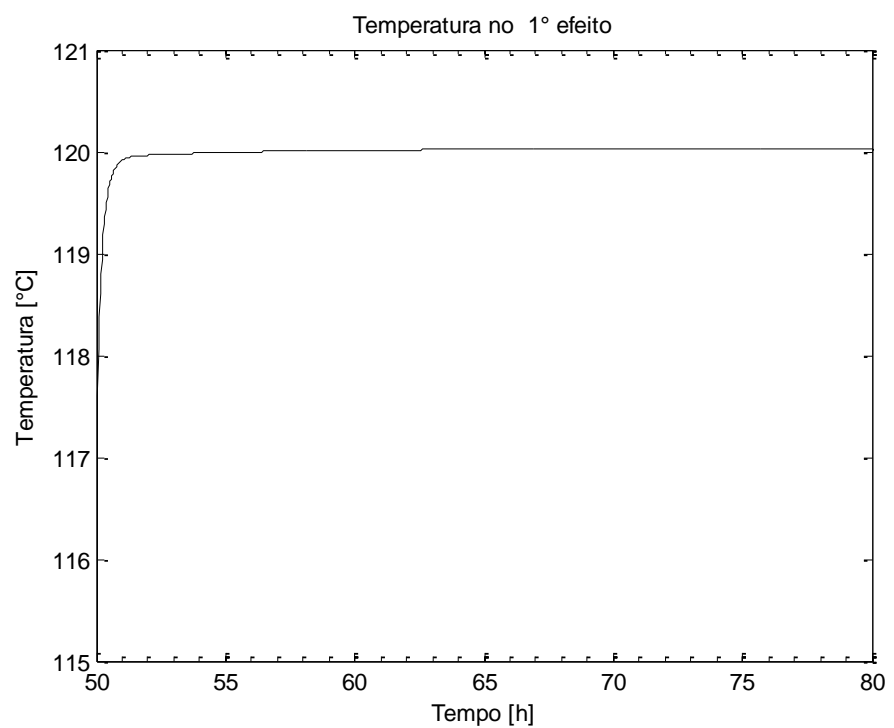

Figura 13 - Temperatura do primeiro efeito ao longo do tempo.

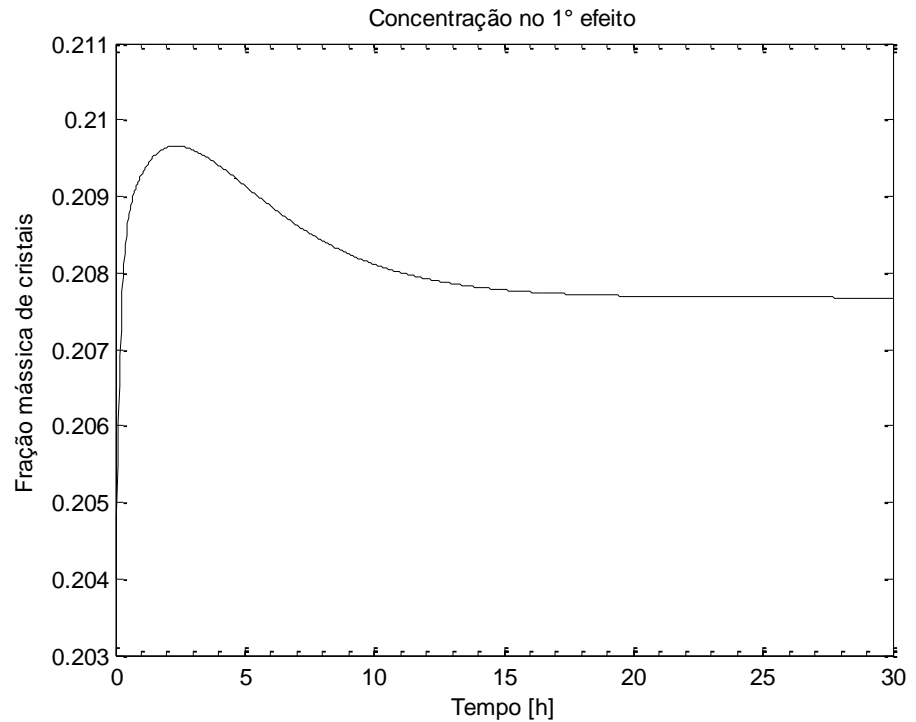

Figura 14 - Fração de sólidos do primeiro efeito ao longo do tempo 


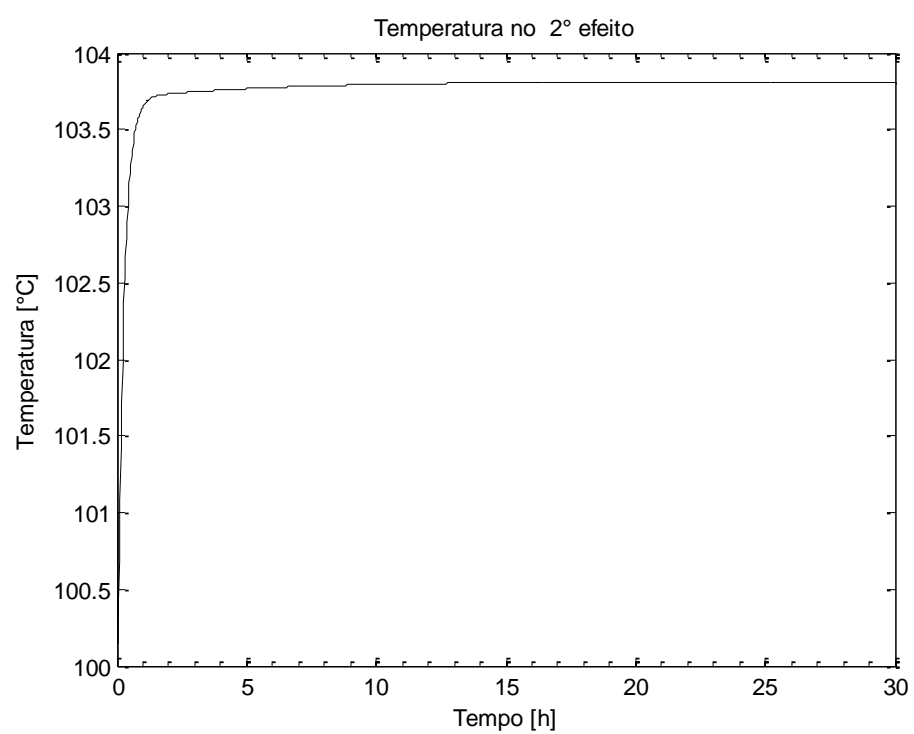

Figura 15 - Temperatura do segundo efeito ao longo do tempo

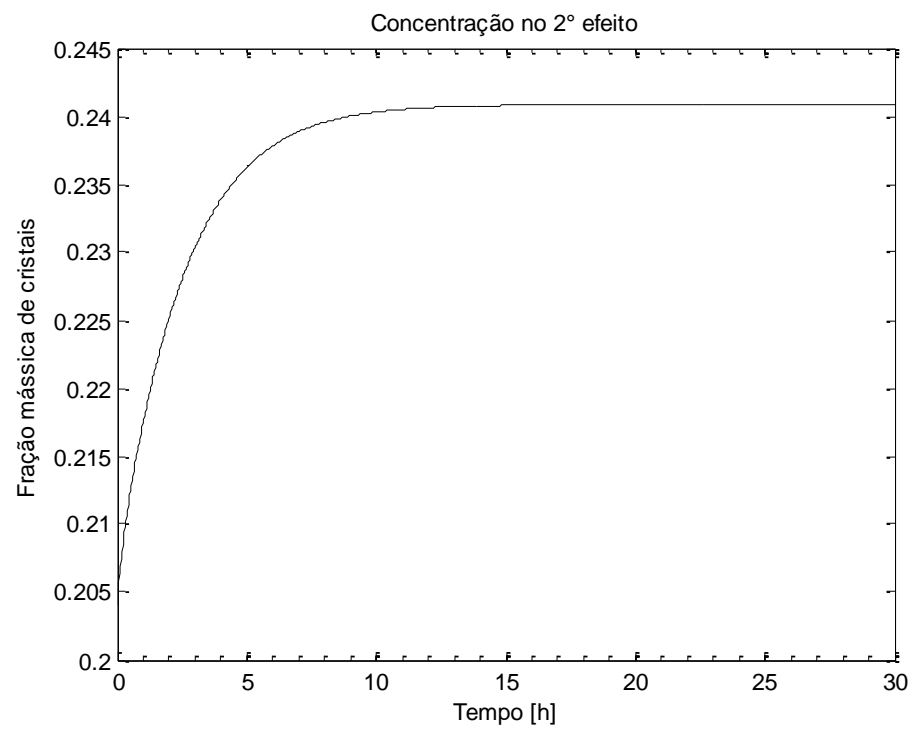

Figura 16 - Fração de sólidos do segundo efeito ao longo do tempo 


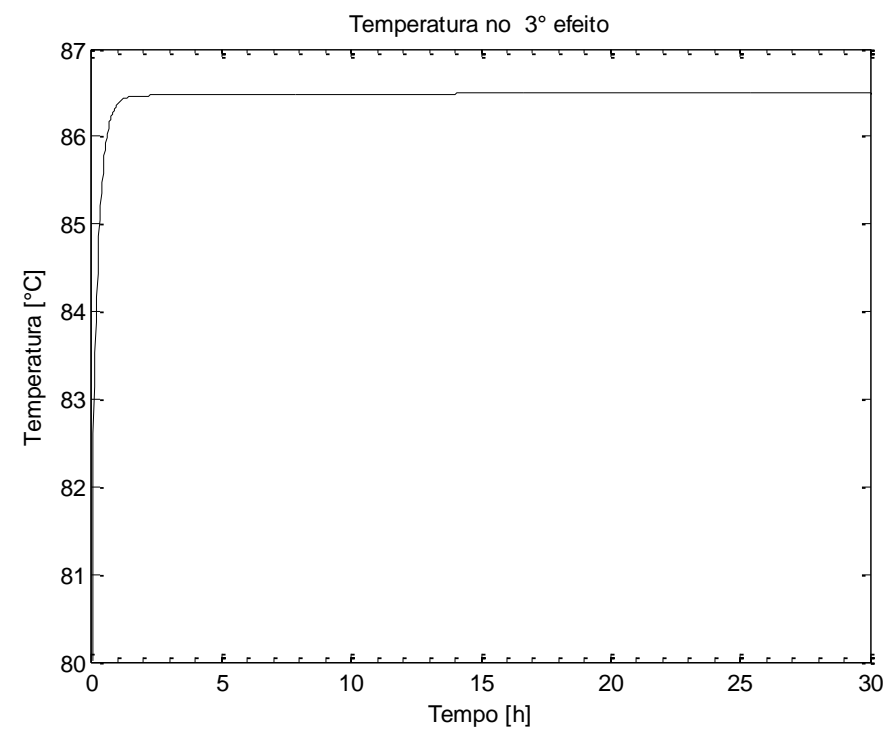

Figura 17 - Temperatura do terceiro efeito ao longo do tempo

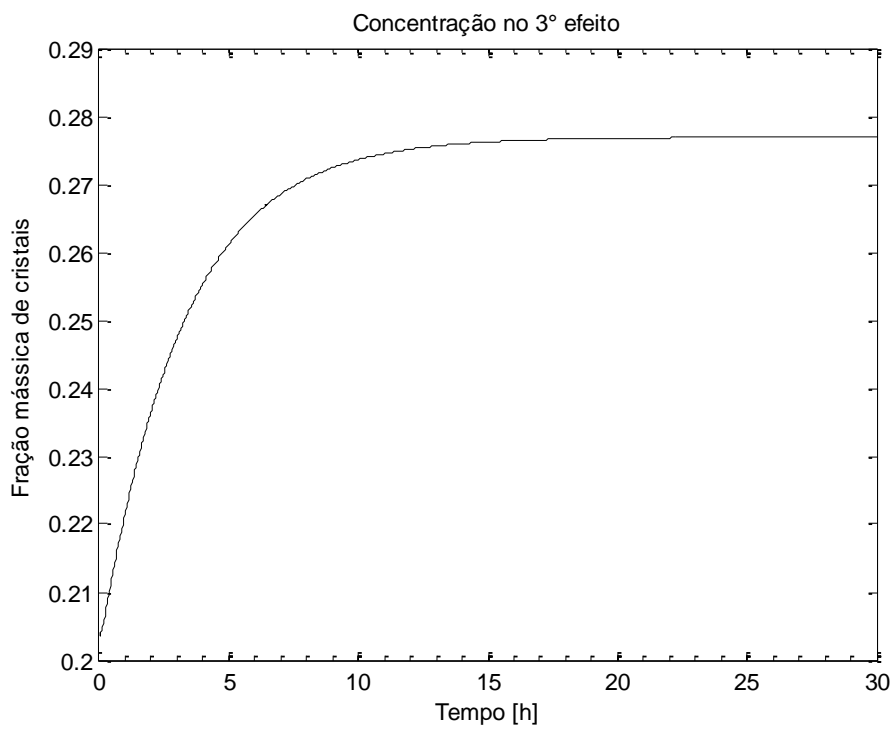

Figura 18 - Fração de sólidos do terceiro efeito ao longo do tempo 


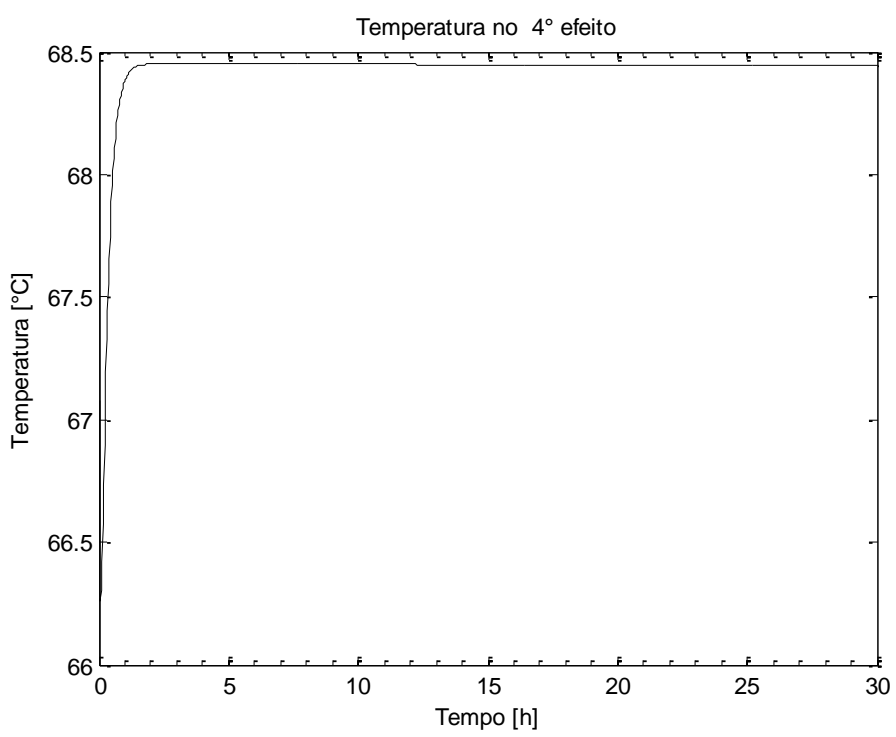

Figura 19 - Temperatura do quarto efeito ao longo do tempo

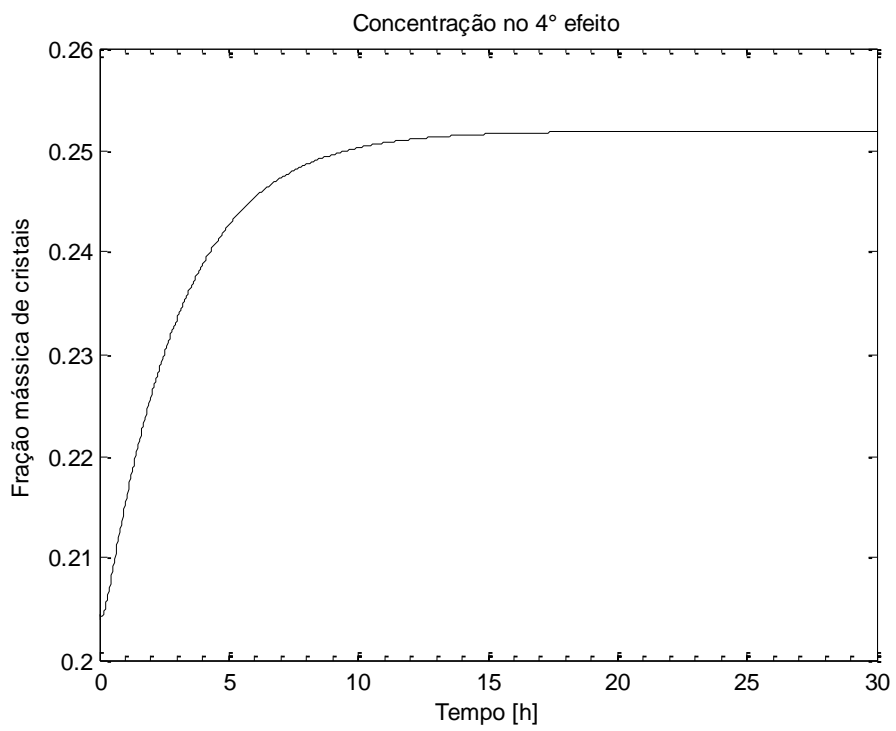

Figura 20 - Fração de sólidos do quarto efeito ao longo do tempo 


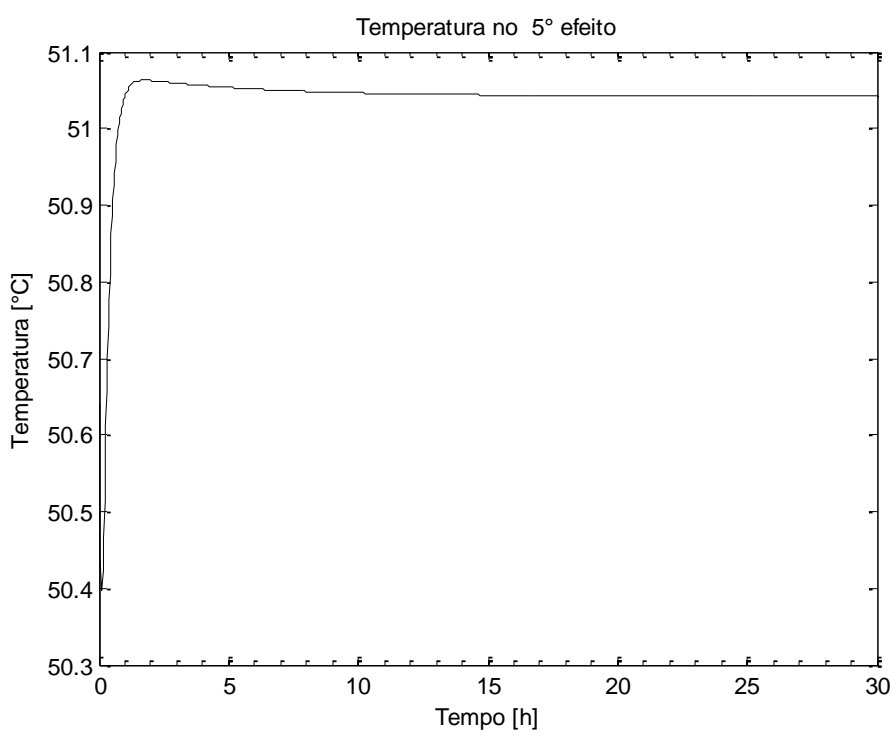

Figura 21 - Temperatura do quinto efeito ao longo do tempo

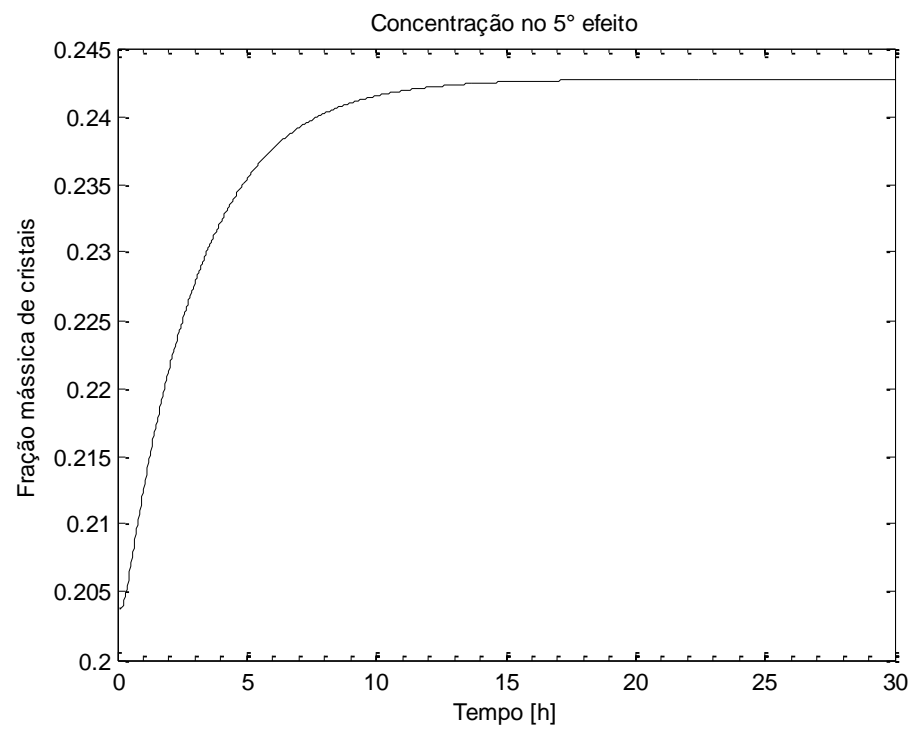

Figura 22 - Fração de sólidos do quinto efeito ao longo do tempo

A Figura 13 até a Figura 22 mostram o resultado da simulação considerando uma mesma fração mássica inicial de produto de 0,204 para todos os efeitos.

Observa-se que a dinâmica da temperatura dos sistemas (se considerarmos cada efeito como um sistema diferente) é bem diferente da dinâmica da fração mássica de cristais. O tempo necessário para a temperatura de cada efeito atingir o estado estacionário é de aproximadamente 2 horas enquanto que 0 
tempo para a fração de cristais atingir o estado estacionário é superior a 20 horas. Essa diferença pode ser explicada pelo fato de a variação de concentração de cristais ser dependente da cristalização do soluto causada pela supersaturação da solução, e depende do tempo de residência de cada cristalizador, que no caso, é grande por se tratar de volumes na faixa de 80 a $100 \mathrm{~m}^{3}$ (para esse caso, o tempo de residência é superior a $2 \mathrm{~h}$ ). Diferente de variações em processos cuja composição está diretamente relacionada com a temperatura do sistema por relações de equilíbrio termodinâmico, como acontece nos pratos de uma coluna de destilação, onde a dinâmica da temperatura é a mesma da concentração dos componentes, a concentração de sólidos vai depender da taxa de formação e crescimento de cristais.

O sistema em múltiplo-efeito tem a característica de a dinâmica de cada efeito ser dependente das variações que ocorrem nos diferentes efeitos. A Figura 23 a Figura 27 mostram para uma perturbação em um único efeito as consequências nos demais efeitos. Neste caso, visando um melhor entendimento da dinâmica da planta, simulou-se uma duplicação da vazão de alimentação no terceiro, num determinando instante em que o sistema se encontrava no estado estacionário.
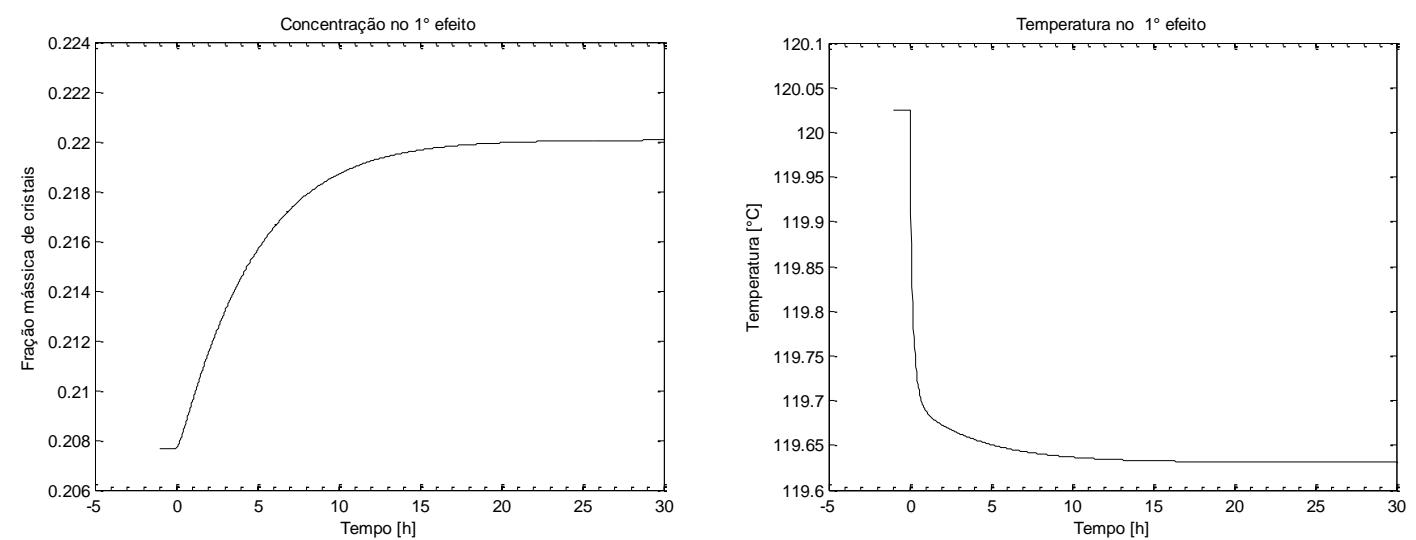

Figura 23 - Fração de sólidos e temperatura no primeiro efeito após perturbação na vazão de alimentação do terceiro efeito 

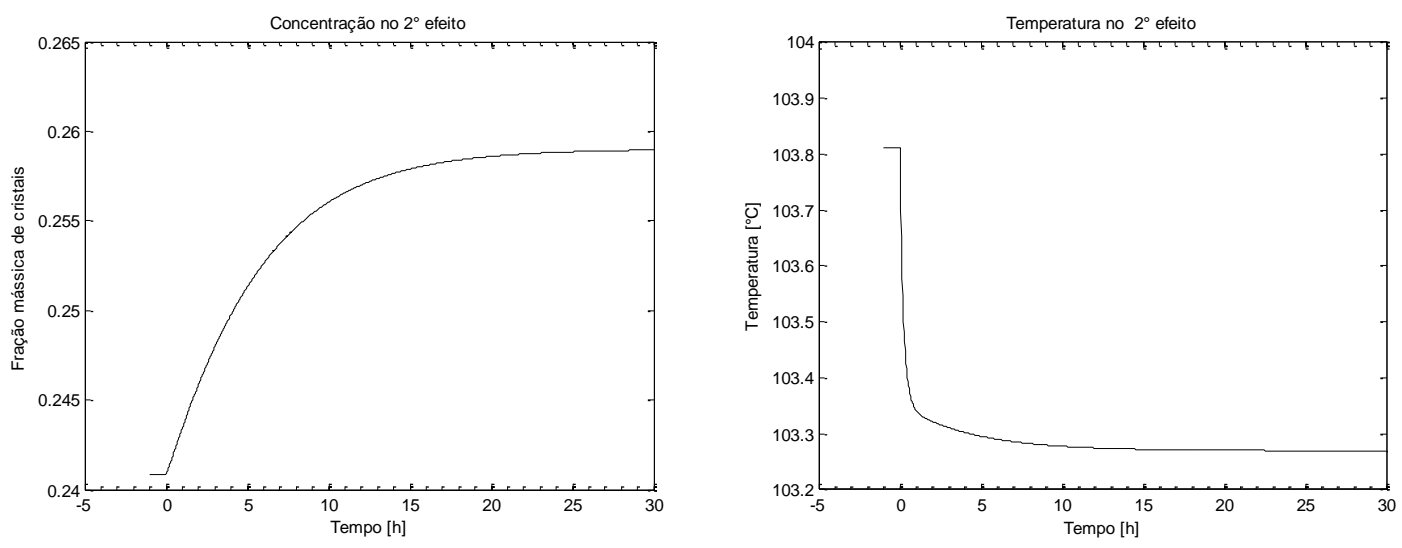

Figura 24 - Fração de sólidos e temperatura no segundo efeito após perturbação na vazão de alimentação do terceiro efeito
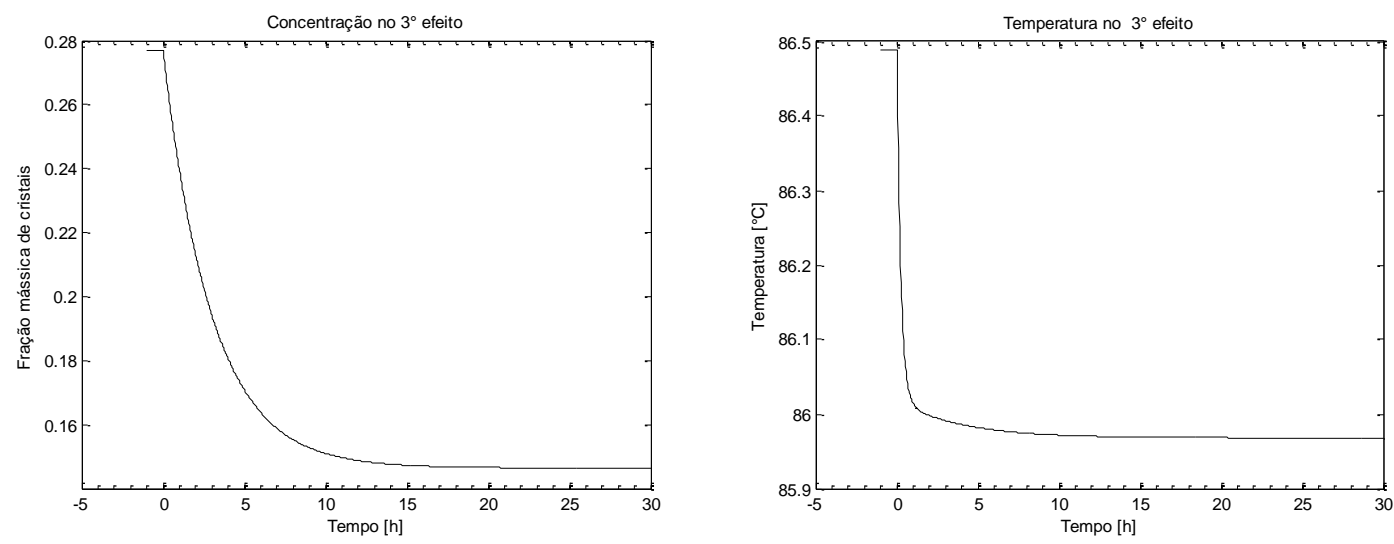

Figura 25 - Fração de sólidos e temperatura no terceiro efeito após perturbação na vazão de alimentação do terceiro efeito
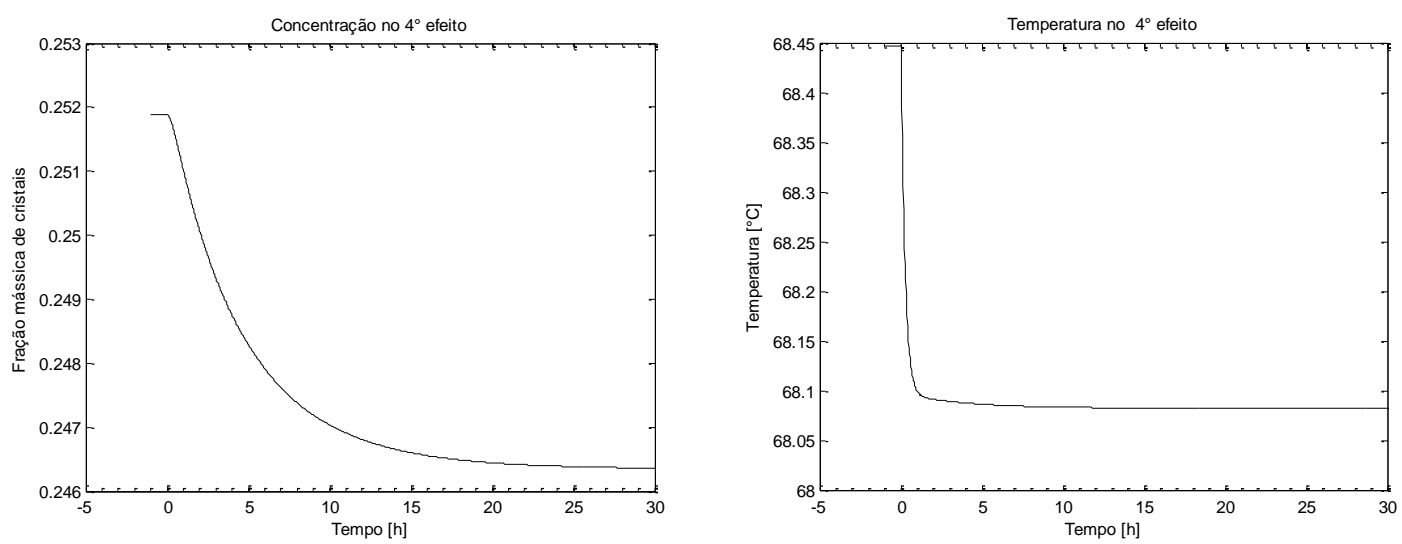
Figura 26 - Fração de sólidos e temperatura no quarto efeito após perturbação na vazão de alimentação do terceiro efeito
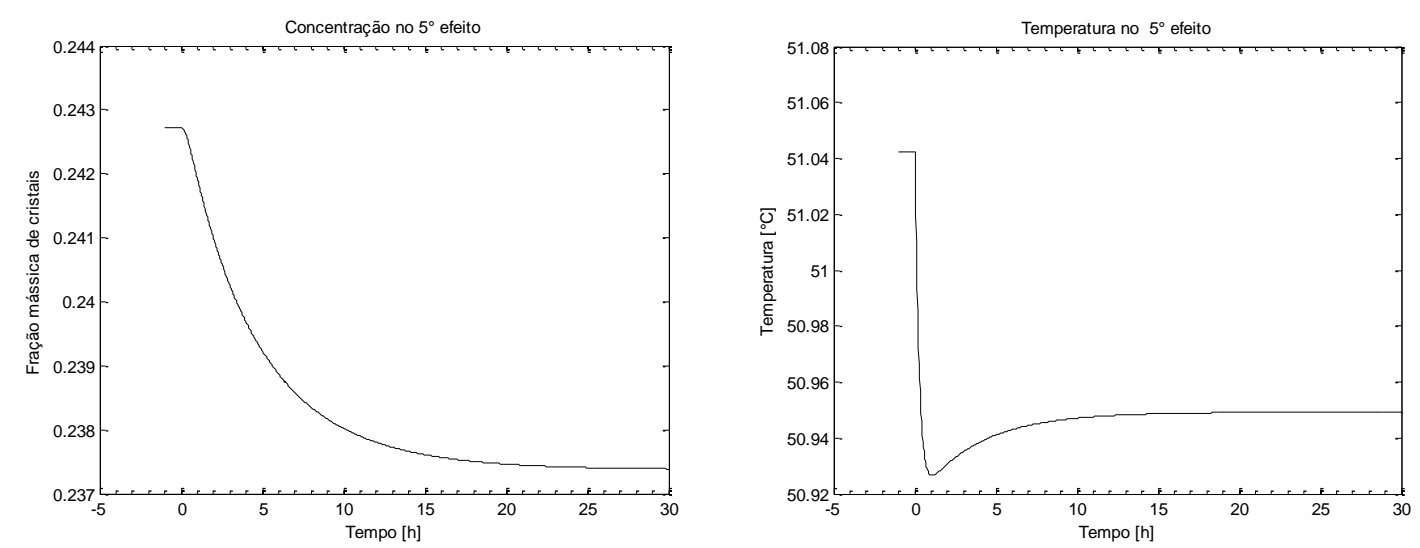

Figura 27 - Fração de sólidos e temperatura no quinto efeito após perturbação na vazão de alimentação do terceiro efeito

É possível notar que com o aumento da vazão, há uma queda de concentração de cristais e de temperatura no terceiro efeito. Nesse momento, diminui a energia por unidade de matéria introduzida no evaporador, levando a uma queda de temperatura e diminuição da taxa de evaporação, alterando a taxa de cristalização, fazendo com que a concentração de cristais caia no terceiro efeito.

Sendo assim, a diferença de temperatura entre o terceiro e o segundo efeito irá aumentar, aumentando o calor trocado no terceiro condensador (TC-03). Consequentemente a taxa de condensação no trocador é elevada causando uma queda de pressão no lado do vapor, levando também a uma queda de pressão no segundo efeito e elevando a taxa de evaporação $V_{2}$, de acordo com a Equação 14. Isso proporcionará um aumento da supersaturação e da taxa de cristalização, elevando o perfil de concentração do segundo efeito e a queda de temperatura (Figura 24). A queda de temperatura do segundo efeito fará com que ocorra o aumento da concentração e a queda de temperatura do primeiro efeito pelos mesmos motivos apresentados (Figura 23).

Em contrapartida, a queda de vazão de vapor no condensador do quarto efeito (TC-04) levará a uma menor troca térmica e a queda de temperatura do quarto 
efeito, diminuindo a temperatura e a taxa de evaporação $V_{4}$. Em consequência da queda da taxa de evaporação, a concentração de cristais também irá cair pela queda da formação de cristais (Figura 26). O último efeito irá sofrer as mesmas consequências pela baixa na vazão de vapor no condensador TC-05 (Figura 27).

Os resultados mostram a forte dependência que todos os efeitos têm em relação aos outros, porém a intensidade é relativamente menor das alterações nos efeitos vizinhos se comparado ao efeito perturbado. Isso pode ser visto quando se perturba alguma variável do primeiro efeito e não há alterações perceptíveis no último estágio (não mostrado)

A Figura 28 mostra a variação da fração de sólidos frente a um aumento de $100 \%$ da vazão de entrada $A c$ igual em todos os efeitos.

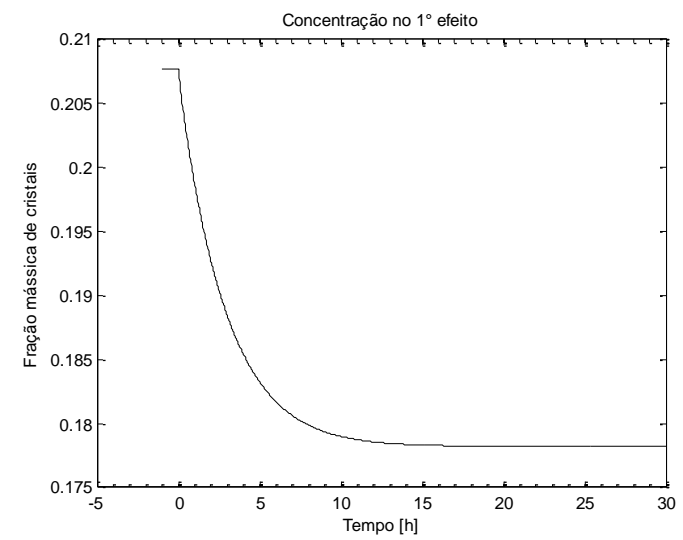

(a)

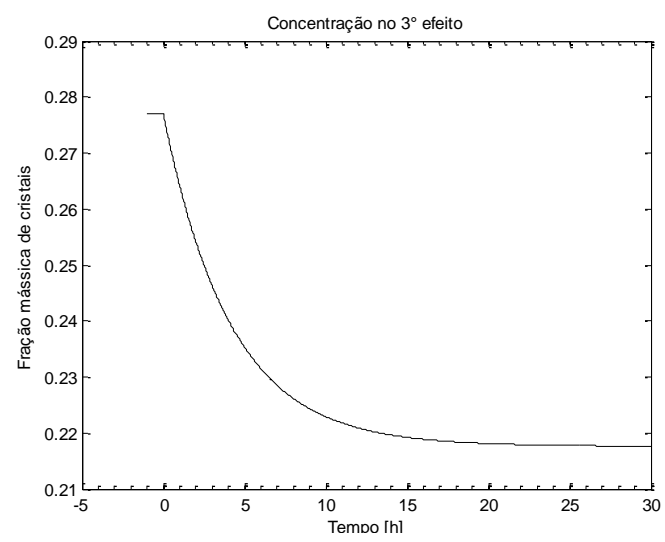

(c)

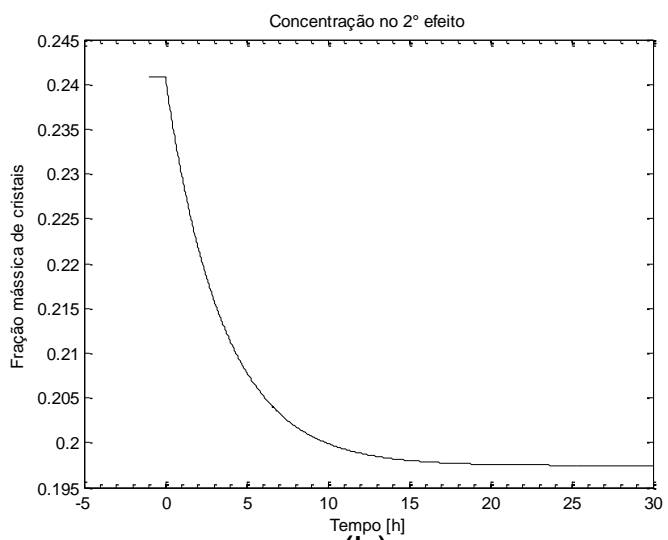

(b)

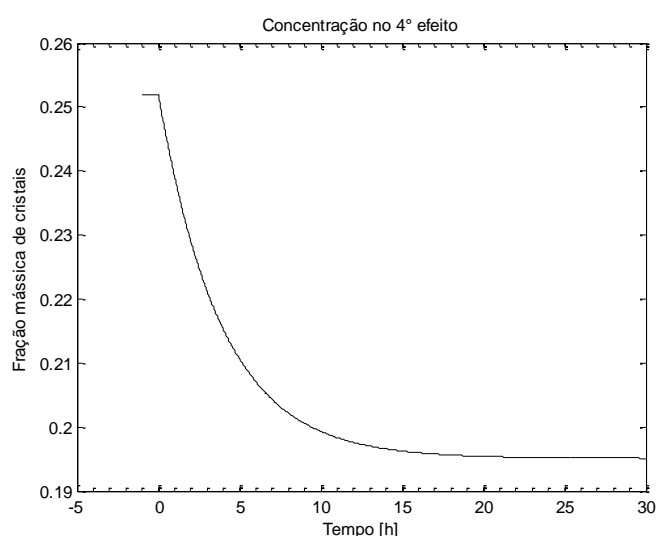

(d) 


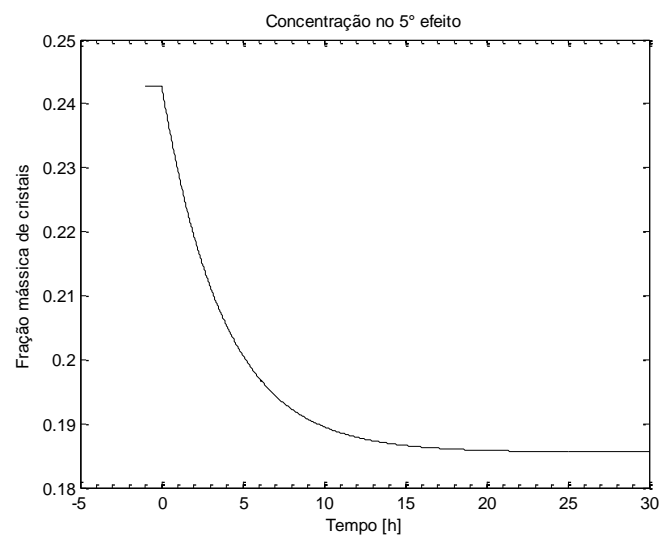

(e)

Figura 28 - Concentração de sólidos nos efeitos (a) 1, (b) 2, (c) 3, (d) 4, (e) 5 frente a uma duplicação na vazão de alimentação $A c$ de todos os efeitos

Nesse caso a variação de cada efeito é propagada para o efeito anterior, podendo ocasionar uma maior alteração das condições de operação ou até uma atenuação dos efeitos de perturbação de cada efeito. Na Figura $28 \mathrm{c}$ podese ver que a queda de concentração é menor se comparada a simulação anterior, pode-se dizer que isso acontece pelos fato da perturbação dos efeitos vizinhos estarem se propagando para o terceiro efeito, atenuando sua própria dinâmica pelas alterações ocorridas nesse efeito. O contrário também pode ser verdade, as alterações dos efeitos vizinhos somado às perturbações desse efeito podem ocasionar um desvio de maiores proporções nas condições operacionais. 


\subsection{Identificação do sistema}

A partir das respostas dinâmicas frente à perturbação de cada efeito foi possível identificar modelos lineares discretos que representam o sistema de cristalização em quíntuplo-efeito. A identificação foi feita utilizando-se a rotina identificação ARX do Matlab $\AA$, variando as variáveis manipuladas de acordo com o perfil representado na Figura 29. As variáveis $u$ e teta são as variáveis de entrada e tempo na forma adimensional.

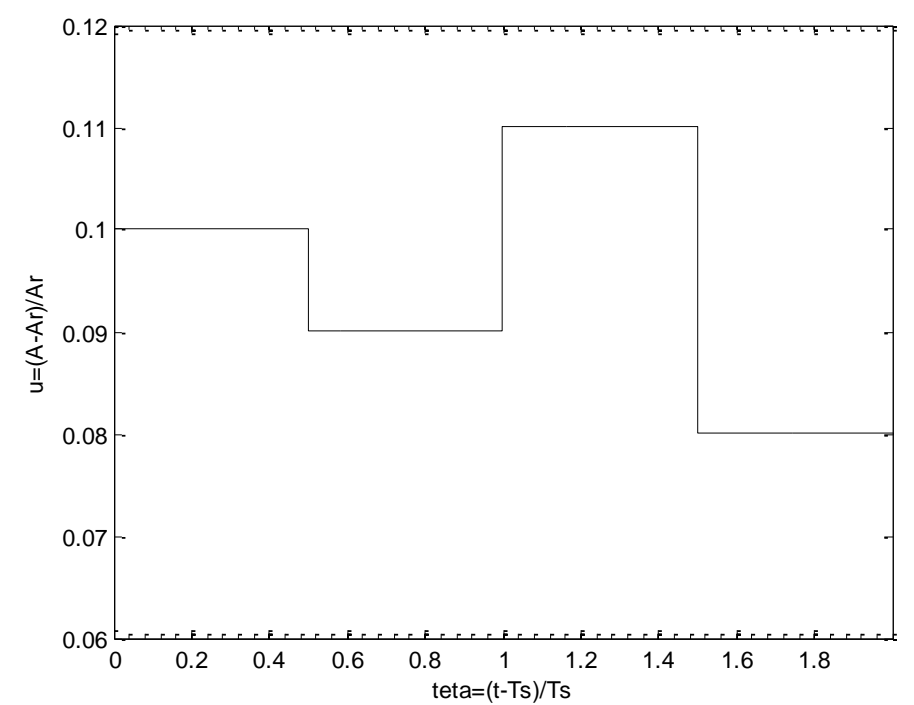

Figura 29 - Mudanças na variável manipulada para identificação do sistema

As figuras abaixo mostram as respostas de concentração de sólidos do modelo rigoroso e do modelo identificado 


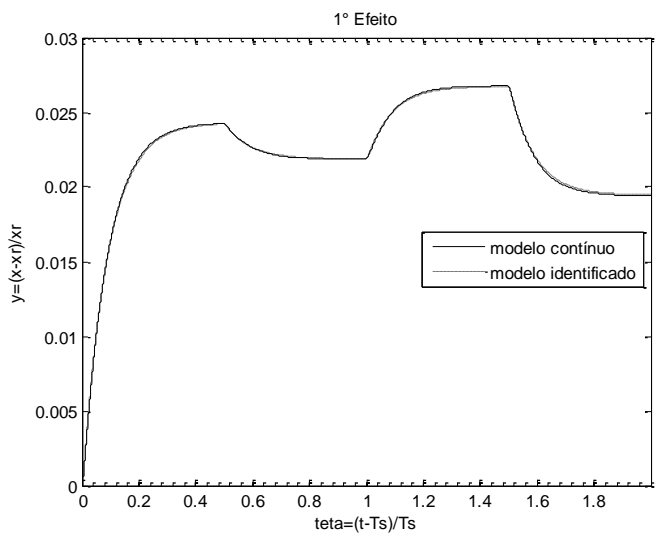

(a)

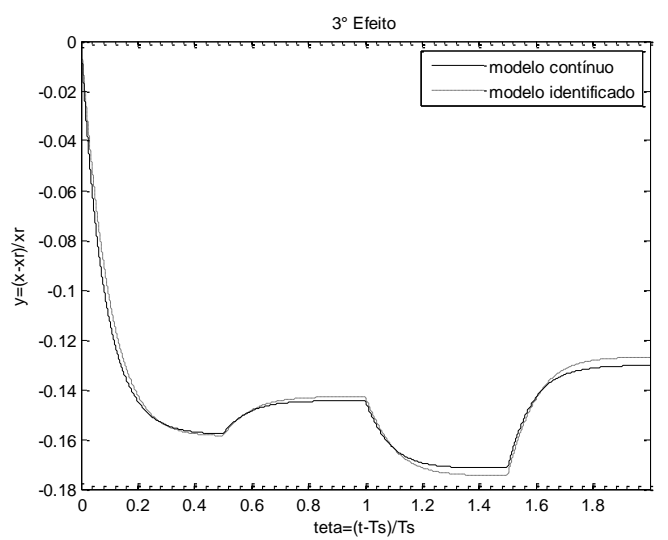

(c)

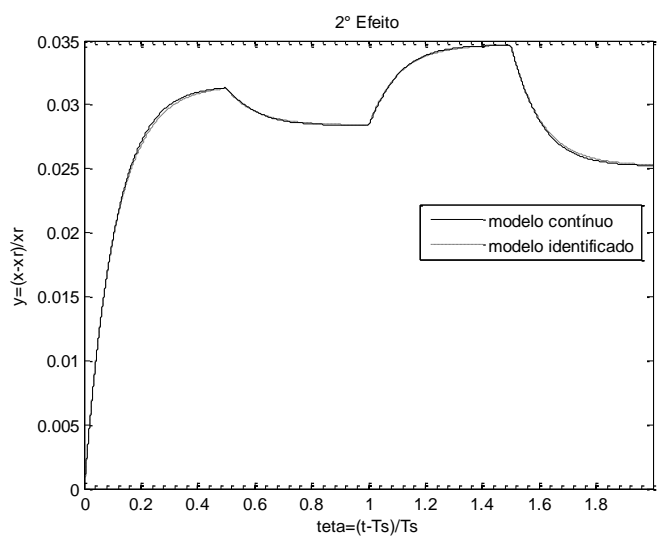

(b)

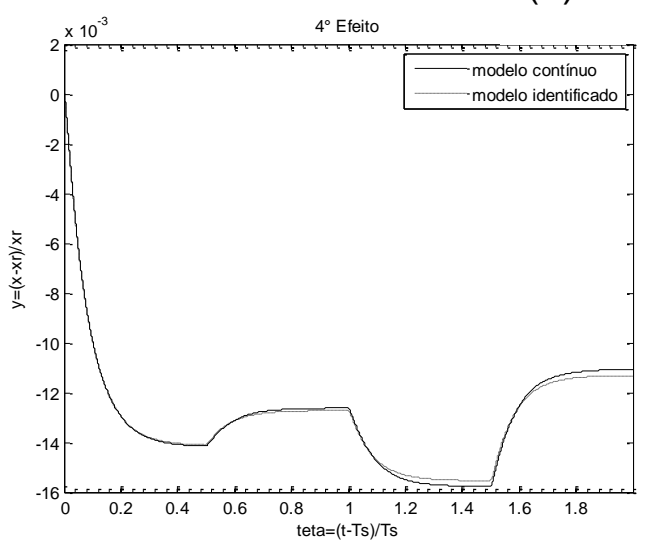

(d)

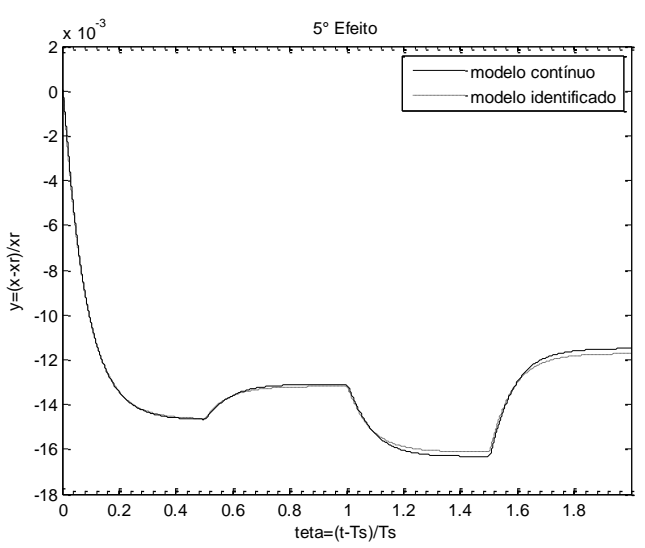

(e)

Figura 30 - Modelos lineares identificados a partir da resposta ao degrau na corrente de alimentação do terceiro estágio

A Figura 30 representa a identificação do modelo discreto para a resposta dinâmica do modelo contínuo, para uma perturbação na vazão de alimentação do terceiro efeito (Figura 23 a Figura 27). 
Nota-se que o modelo linear discreto se ajustou adequadamente para a resposta dinâmica do sistema de cristalização por evaporação múltiplo-efeito, que, por ser um modelo não linear, poderia trazer erros consideráveis ao ser aproximado por um modelo linear. Em todos os modelos identificados, a variança do ruído $v(k)$ obtida foi na rodem de $10^{-10}$ e este termo foi desprezado do modelo obtido.

A consideração de que o modelo pode ser adequadamente aproximado por um modelo linear leva a crer que a implementação de um controlador PID clássico, ou um controlador preditivo linear seja possível, dispensando o uso de métodos não lineares como o NMPC ou um controlador PID adaptativo projetado para sistemas não lineares.

Considerando que as aproximações lineares são suficientemente precisas, identificou-se 0 conjunto de modelos apresentados na Tabela 2 que representam a dinâmica do controlador frente a perturbações nas vazões de entrada Ac.

Esses modelos discretos foram aplicados no desenvolvimento do controlador preditivo. 
Tabela 2 - Modelos discretos identificados a partir da resposta da fração mássica ao degrau nas vazões de alimentação

\begin{tabular}{|c|c|c|c|c|c|}
\hline & $x_{1}$ & $x_{2}$ & $x_{3}$ & $X_{4}$ & $X_{5}$ \\
\hline$A c_{1}$ & $\frac{-4,958 \times 10^{-3} z+4,908 \times 10^{-3}}{z^{2}-1,988 z+0,9879}$ & $\frac{3,517 \times 10^{-5} z-1,314 \times 10^{-4}}{z^{2}-1,682 z+0,6837}$ & $\frac{4,625 \times 10^{-6} z-1,48 \times 10^{-5}}{z^{2}-1,958 z+0,9577}$ & $\frac{1,726 \times 10^{-6} z-1,327 \times 10^{-5}}{z^{2}-1,958 z+0,9584}$ & $\frac{1,61 \times 10^{-6} z-1,805 \times 10^{-5}}{z^{2}-1,94 z+0,9401}$ \\
\hline $\mathrm{Ac}_{2}$ & $\frac{3,14 \times 10^{-4} z-9,793 \times 10^{-5}}{z^{2}-1,859 z+0,8598}$ & $\frac{-4,469 \times 10^{-3} z+4,421 \times 10^{-3}}{z^{2}-1,988 z+0,9884}$ & $\frac{1,708 \times 10^{-5} z-4,079 \times 10^{-5}}{z^{2}-1,934 z+0,9342}$ & $\frac{3,212 \times 10^{-6} z-2,227 \times 10^{-5}}{z^{2}-1,951 z+0,9511}$ & $\frac{3,212 \times 10^{-6} z-2,654 \times 10^{-5}}{z^{2}-1,939 z+0,9396}$ \\
\hline $\mathrm{Ac}_{3}$ & $\frac{2,382 \times 10^{-5} z+3,593 \times 10^{-5}}{z^{2}-1,92 z+0,9198}$ & $\frac{1,729 \times 10^{-4} z-7,958 \times 10^{-5}}{z^{2}-1,886 z+0,8859}$ & $\frac{-4,125 \times 10^{-3} z+4,101 \times 10^{-3}}{z^{2}-1,993 z+0,9925}$ & $\frac{8,328 \times 10^{-6} z-3,913 \times 10^{-5}}{z^{2}-1,934 z+0,9345}$ & $\frac{1,336 \times 10^{-6} z-3,70 \times 10^{-5}}{z^{2}-1,927 z+0,9269}$ \\
\hline $\mathrm{Ac}_{4}$ & $\frac{1,322 \times 10^{-6} z+1,516 \times 10^{-5}}{z^{2}-1,954 z+0,9539}$ & $\frac{1,286 \times 10^{-5} z+1,256 \times 10^{-5}}{z^{2}-1,935 z+0,935}$ & $\frac{1,158 \times 10^{-4} z-1,094 \times 10^{-5}}{z^{2}-1,773 z+0,7737}$ & $\frac{-4,408 \times 10^{-3} z+4,382 \times 10^{-3}}{z^{2}-1,992 z+0,9924}$ & $\frac{-8,247 \times 10^{-6} z-6,396 \times 10^{-5}}{z^{2}-1,882 z+0,8829}$ \\
\hline $\mathrm{Ac}_{5}$ & $\frac{-2,984 \times 10^{-7} z+2,142 \times 10^{-6}}{z^{2}-1,981 z+0,9807}$ & $\frac{6,912 \times 10^{-7} z+1,69 \times 10^{-5}}{z^{2}-1,844 z+0,844}$ & $\frac{6,715 \times 10^{-6} z+5,046 \times 10^{-6}}{z^{2}-1,927 z+0,9272}$ & $\frac{7,588 \times 10^{-5} z-7,015 \times 10^{-5}}{z^{2}-1,966+0,9665}$ & $\frac{-4,627 \times 10^{-3} z+4,597 \times 10^{-3}}{z^{2}-1,992 z+0,9917}$ \\
\hline $\mathrm{Tv}$ & $\frac{2,357 \times 10^{-3} z-2,357 \times 10^{-3}}{z^{2}-1,72 z+0,7215}$ & $\frac{7,791 \times 10^{-4} z+7,791 \times 10^{-4}}{z^{2}-1,878 z+0,8788}$ & $\frac{3,005 \times 10^{-4} z+3,005 \times 10^{-4}}{z^{2}-1,948 z+0,9477}$ & $\frac{1,971 \times 10^{-4} z+1,971 \times 10^{-4}}{z^{2}-1,967+0,967}$ & $\frac{1,857 \times 10^{-4} z-1,857 \times 10^{-4}}{z^{2}-1,97++0,9701}$ \\
\hline $\mathrm{T}_{5}$ & $\frac{-3,834 \times 10^{-6} z-6,852 \times 10^{-5}}{z^{2}-1,947 z+0,9476}$ & $\frac{-1,564 \times 10^{-5} z-1,383 \times 10^{-4}}{z^{2}-1,894 z+0,8947}$ & $\frac{-1,233 \times 10^{-4} z-1,617 \times 10^{-4}}{z^{2}-1,813 z+0,814}$ & $\frac{-1,297 \times 10^{-3} z-1,163 \times 10^{-3}}{z^{2}-1,931 z+0,9303}$ & $\frac{-1,174 \times 10^{-2} z+1,13 \times 10^{-2}}{z^{2}-1,786+0,7868}$ \\
\hline
\end{tabular}




\subsection{Controle PID}

Para definir os parâmetros do controlador PID, utilizou-se do critério de ajuste o erro na variável controlada procurando-se o ajuste que forneça o menor valor de ITAE ('integral of the time-weighted absolute error"). $O$ ajuste final foi realizado por tentativa e erro.

Tabela 3 - Ajustes do controlador PID, para controle das concentrações $x_{1}, x_{2}$, $\mathrm{x}_{3}, \mathrm{x}_{4}$ e $\mathrm{x}_{5}$ para as temperaturas do primeiro e quinto efeito.

\begin{tabular}{|l|l|l|l|l|l|l|l|}
\hline & $\mathrm{x} 1$ & $\mathrm{x} 2$ & $\mathrm{x} 3$ & $\mathrm{x} 4$ & $\mathrm{x} 5$ & $\mathrm{~T} 1$ & $\mathrm{~T}$ \\
\hline $\mathrm{Kp}$ & 0,5 & 0,45 & 0,45 & 0,4 & 0,4 & 0,5 & 0,5 \\
\hline $\mathrm{Ti}(\mathrm{s})$ & 500 & 500 & 50 & 500 & 500 & 200 & 500 \\
\hline Td (s) & 0,01 & $1 \mathrm{e}-4$ & $1 \mathrm{e}-4$ & $1 \mathrm{e}-4$ & $1 \mathrm{e}-4$ & 0,01 & 0,01 \\
\hline ITAE & 387,4951 & 513,1415 & 653,7799 & 581,9063 & 563,0300 & 16,4982 & 48,2254 \\
\hline
\end{tabular}

Esse ajuste final corresponde ao melhor ajuste encontrado via tentativa e erro considerando o processo operando como um todo. Isso foi feito após um primeiro ajuste via um problema de otimização que minimizou o valor de ITAE para cada malha de controle individualmente. Para o teste definiu-se o "setpoint" como os valores ótimos de operação, mostrados na tabela a seguir:

Tabela 4 - Valores de "set-points" para controlador PID

\begin{tabular}{|c|c|c|c|c|c|c|c|}
\hline & $\mathrm{x} 1$ & $\mathrm{x} 2$ & $\mathrm{x} 3$ & $\mathrm{x} 4$ & $\mathrm{x} 5$ & $\mathrm{~T} 1^{\circ} \mathrm{C}$ & $\mathrm{T} 5^{\circ} \mathrm{C}$ \\
\hline ysp & 0,208 & 0,248 & 0,294 & 0,273 & 0,269 & 119,5 & 51,5 \\
\hline
\end{tabular}

Os resultados da análise, partindo de um ponto inicial diferente do set-point (Tabela 5) podem ser vistos nas Figura 31 a Figura 37. 
Tabela 5 - Valores iniciais para simulação do controlador

\begin{tabular}{|c|c|c|c|c|c|c|c|}
\hline & $\mathrm{x} 1$ & $\mathrm{x} 2$ & $\mathrm{x} 3$ & $\mathrm{x} 4$ & $\mathrm{x} 5$ & $\mathrm{~T} 1{ }^{\circ} \mathrm{C}$ & $\mathrm{T} 5^{\circ} \mathrm{C}$ \\
\hline $\mathrm{y}_{0}$ & 0,202 & 0,238 & 0,278 & 0,258 & 0,252 & 120,5 & 51 \\
\hline
\end{tabular}

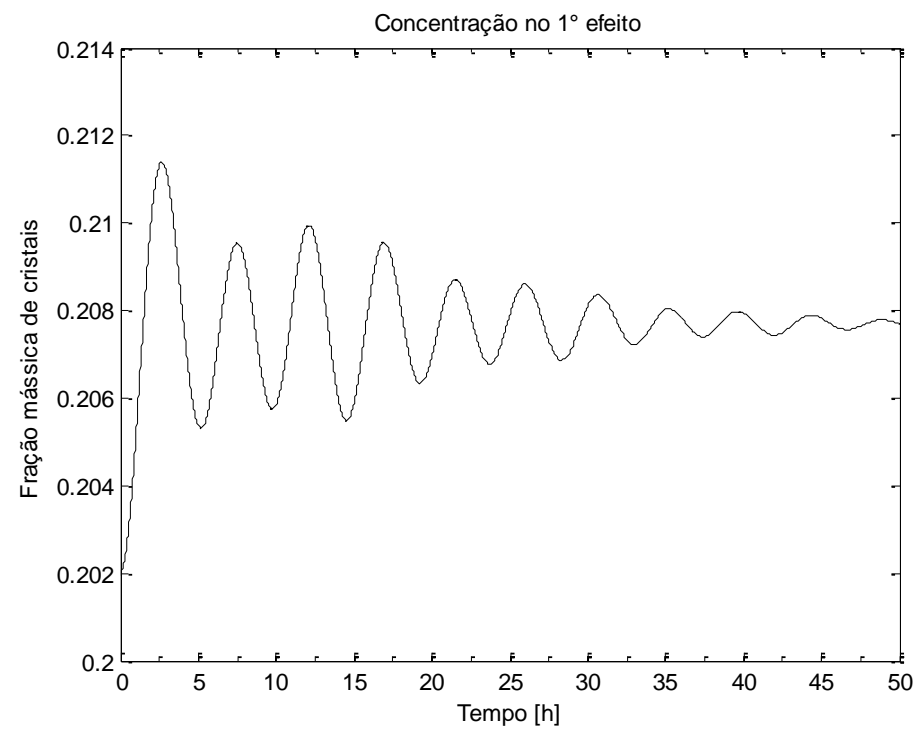

Figura 31 - Fração mássica de cristais no primeiro efeito para controle PID 


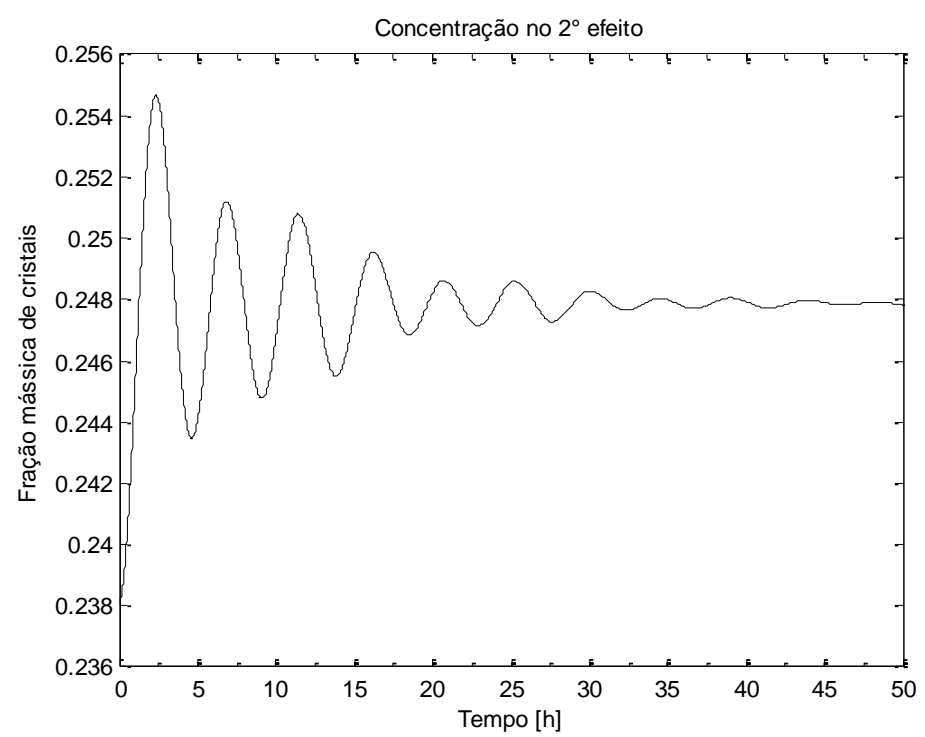

Figura 32 - Fração mássica de cristais no segundo efeito para controle PID

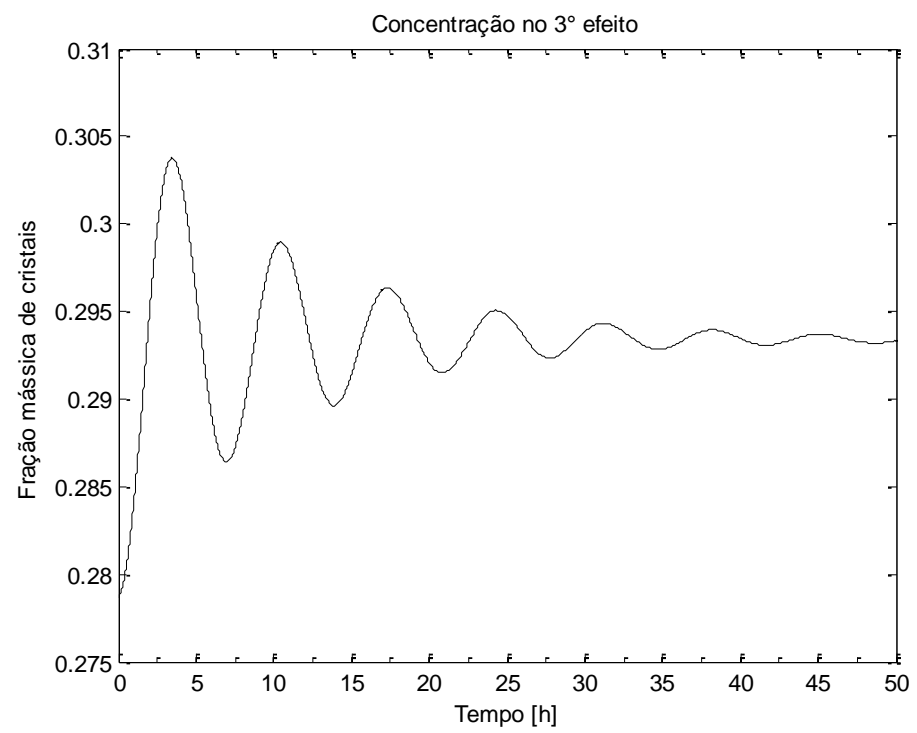

Figura 33 - Fração mássica de cristais no terceiro efeito para controle PID 


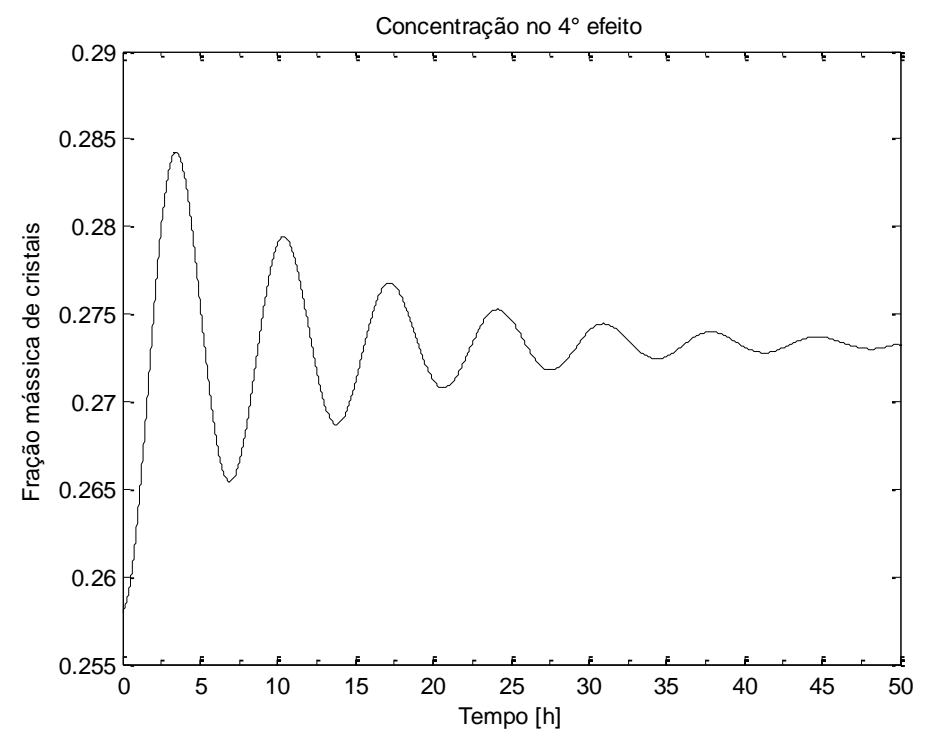

Figura 34 - Fração mássica de cristais no quarto efeito para controle PID

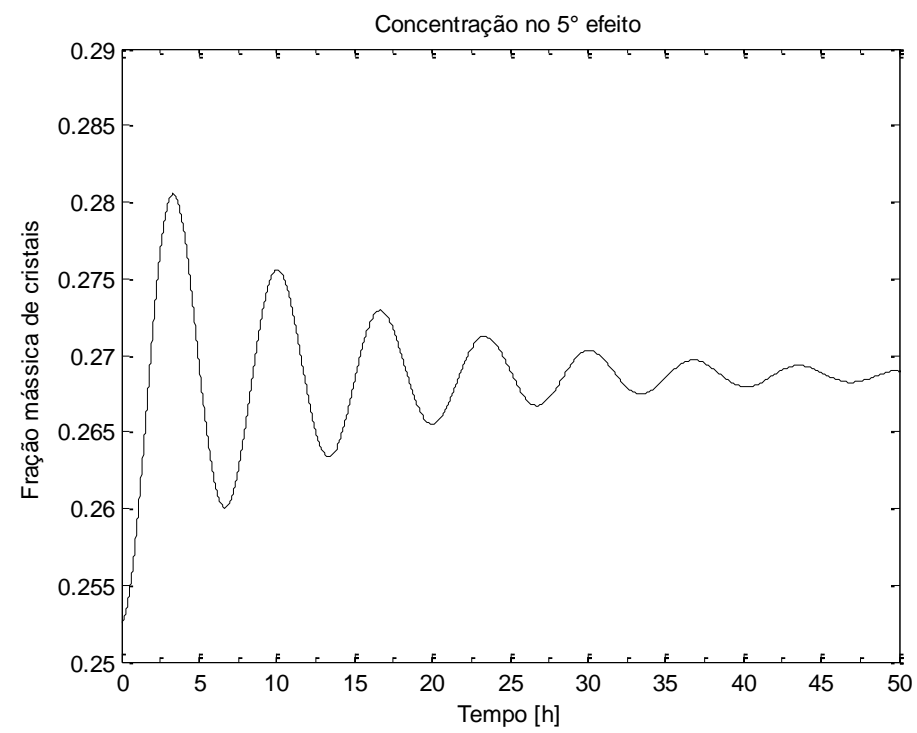

Figura 35 - Fração mássica de cristais no quinto efeito para controle PID 


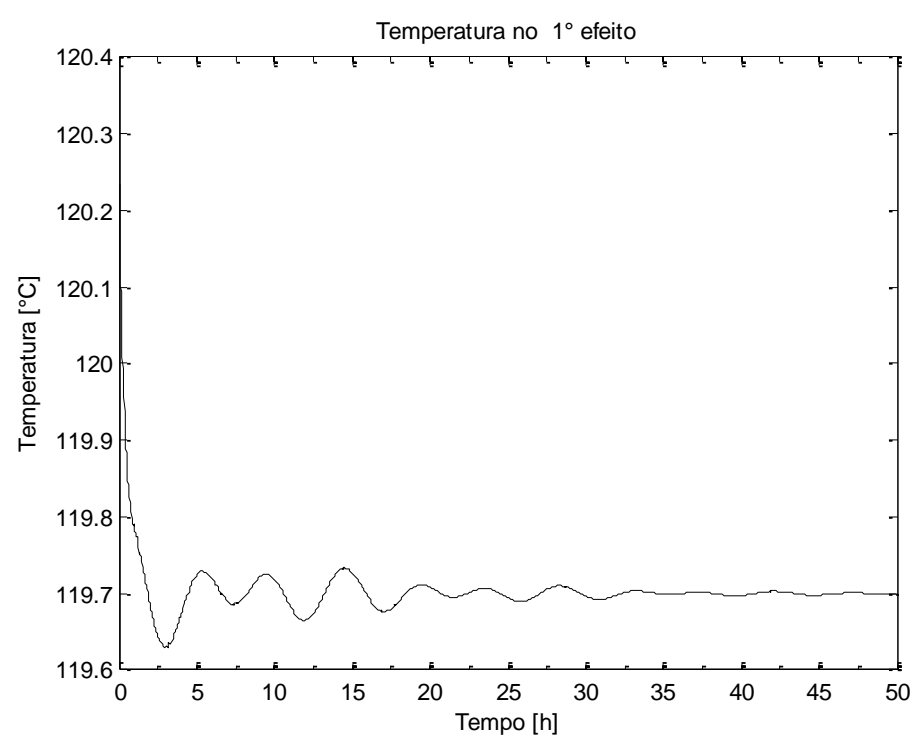

Figura 36 - Variação de temperatura no primeiro efeito para controle PID

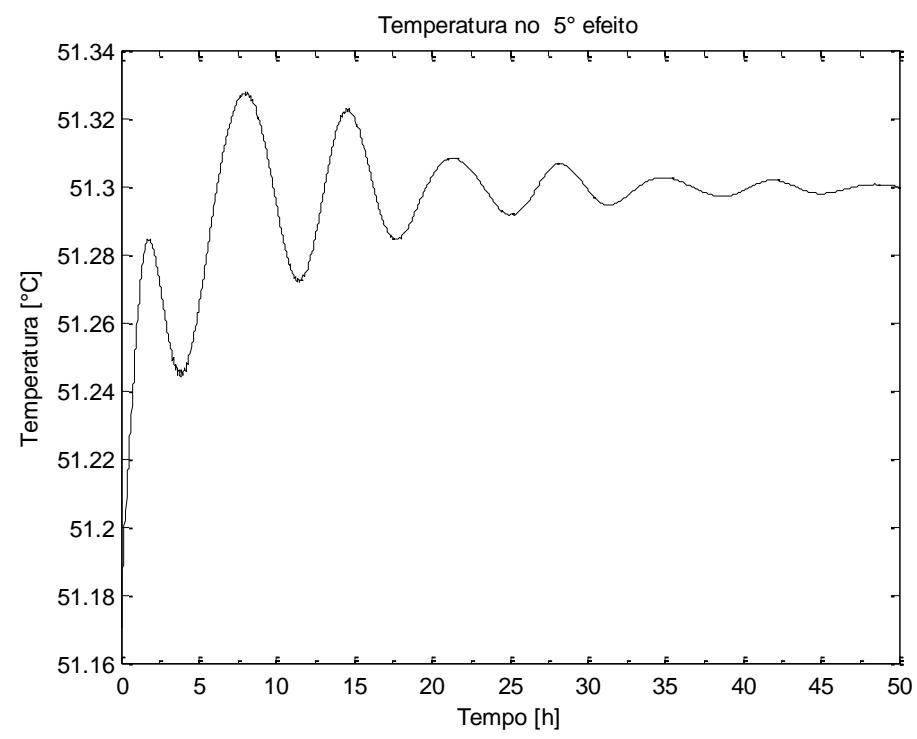

Figura 37 - Fração mássica de cristais no quinto efeito para controle PID

Os resultados para o controle do sistema de cristalização com a estrutura baseada em controladores PID mostram que o sistema tem um comportamento instável e oscila por um longo período de tempo para todos os efeitos. Para o primeiro estágio, o tempo levado para que se atenue a oscilação da fração mássica de soluto é maior do que 40 horas. O segundo efeito tende a ficar 
menos oscilatório e durante um tempo menor quando comparado ao primeiro efeito. Esse tempo é de aproximadamente 30 horas (Figura 32), porém ainda se pode considerar esse um tempo relativamente longo para estabilização, sendo de aproximadamente 25 tempos de residência. O terceiro, quarto e quinto efeitos (Figura 33, 34 e 35) se mostram com a mesma tendência que 0 primeiro efeito com relação ao tempo de estabilização.

A temperatura do primeiro estágio teve um tempo de estabilização relativamente mais curto comparado às frações mássicas, mas ainda consideravelmente longo comparado ao tempo de estabilização para o sistema aberto, como na Figura 13. Para o quinto efeito, cuja temperatura também é controlada, o tempo de estabilização foi maior do que para o primeiro efeito. Isso trouxe consequências na instabilidade das temperaturas ao longo dos efeitos intermediários, consequência da forte dependência já discutida entre os efeitos devido à interação energética.

A variação de temperatura não trará consequências na qualidade do produto considerando a formação de cristais de cloreto de sódio, mas afeta diretamente as condições operacionais prejudicando outros fatores como taxa de evaporação e consequentemente afetando a produção de cristais.

A contínua variação das condições de processo podem trazer outras consequências operacionais da planta de cristalização em múltiplo-efeito, na Figura 38 é possível ver a variação da supersaturação da salmoura ao longo do tempo. 


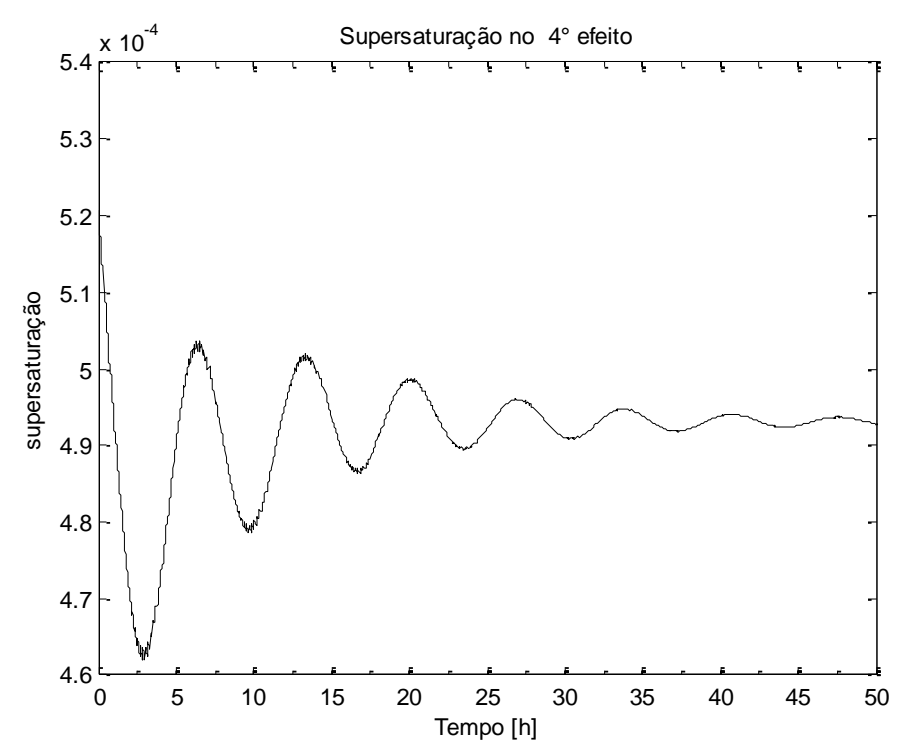

Figura 38 - supersaturação no quarto efeito para controle PID

A variação da supersaturação pode levar a consequências diretas na nucleação do cloreto de sódio, considerando essa a força motriz para a cristalização, impactando no número de cristais dentro do cristalizador, o que consequentemente levará a variação do tamanho médio dos cristais conforme mostra a Equação do balanço de momento (17).

Um dos fatores importantes para o consumidor final é a granulometria dos cristais de cloreto de sódio, que devem ser pequenos para propiciar uma sensação de toque agradável a quem o utiliza para fins culinários. Caso sejam muito grandes, podem trazer problemas ao aumentar as possibilidades de incrustação. Para uma alta formação de núcleos, a tendência é que os cristais não cresçam muito, já que a massa de cloreto de sódio ao se cristalizar se dividirá igualmente para uma população maior. $O$ contrário também será verdade, ou seja, uma pequena taxa de formação de núcleos fará com que a massa de cloreto de sódio ao se cristalizar se divida numa população pequena, levando à formação de cristais maiores.

O consumo energético também sofrerá consequências na variação contínua da planta (Figura 39). 


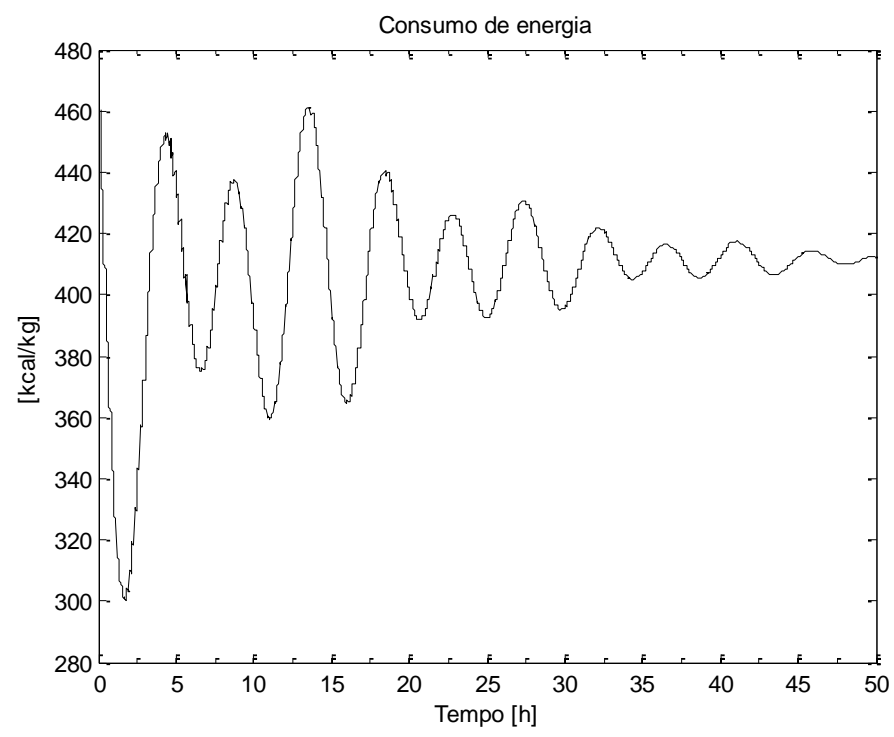

Figura 39 - Consumo energético da unidade para controle PID

\subsection{Controle IHMPC}

Os parâmetros do controlador preditivo Qy, Qu, R, Sy e Su foram determinados por tentativa e erro, sendo que os valores foram ajustados conforme se segue:

$$
Q_{y}=\left[\begin{array}{ccccc}
1 & 0 & 0 & 0 & 0 \\
0 & 1 & 0 & 0 & 0 \\
0 & 0 & 1 & 0 & 0 \\
0 & 0 & 0 & 1 & 0 \\
0 & 0 & 0 & 0 & 1
\end{array}\right], \quad Q_{u}=\left[\begin{array}{ccccccc}
0,1 & 0 & 0 & 0 & 0 & 0 & 0 \\
0 & 0,1 & 0 & 0 & 0 & 0 & 0 \\
0 & 0 & 0,1 & 0 & 0 & 0 & 0 \\
0 & 0 & 0 & 0,1 & 0 & 0 & 0 \\
0 & 0 & 0 & 0 & 0,1 & 0 & 0 \\
0 & 0 & 0 & 0 & 0 & 0,1 & 0 \\
0 & 0 & 0 & 0 & 0 & 0 & 0,1
\end{array}\right]
$$




$$
\begin{aligned}
R & =\left[\begin{array}{ccccccc}
0,1 & 0 & 0 & 0 & 0 & 0 & 0 \\
0 & 0,1 & 0 & 0 & 0 & 0 & 0 \\
0 & 0 & 0,1 & 0 & 0 & 0 & 0 \\
0 & 0 & 0 & 0,1 & 0 & 0 & 0 \\
0 & 0 & 0 & 0 & 0,1 & 0 & 0 \\
0 & 0 & 0 & 0 & 0 & 0,1 & 0 \\
0 & 0 & 0 & 0 & 0 & 0 & 0,1
\end{array}\right] \quad S_{y}=\left[\begin{array}{ccccc}
10^{2} & 0 & 0 & 0 & 0 \\
0 & 10^{2} & 0 & 0 & 0 \\
0 & 0 & 10^{2} & 0 & 0 \\
0 & 0 & 0 & 10^{2} & 0 \\
0 & 0 & 0 & 0 & 10^{2}
\end{array}\right] \\
S_{u} & =\left[\begin{array}{lllllll}
1 & 0 & 0 & 0 & 0 & 0 & 0 \\
0 & 1 & 0 & 0 & 0 & 0 & 0 \\
0 & 0 & 1 & 0 & 0 & 0 & 0 \\
0 & 0 & 0 & 1 & 0 & 0 & 0 \\
0 & 0 & 0 & 0 & 1 & 0 & 0 \\
0 & 0 & 0 & 0 & 0 & 1 & 0 \\
0 & 0 & 0 & 0 & 0 & 0 & 1
\end{array}\right] \quad m=2
\end{aligned}
$$

O controlador foi definido para operar dentro da faixa de 0,2 a 0,3 em fração mássica de sólidos em cada estágio. Partindo do mesmo ponto inicial da simulação realizada para o controlador PID (Tabela 5), obtiveram-se os seguintes resultados para o controlador preditivo, considerando os valores alvos $u_{\text {des }}$ calculados pelo otimizador.

Tabela 6 - Ponto ótimo calculado pelo RTO

\begin{tabular}{|c|c|c|c|c|c|c|}
\hline Ac1 & Ac2 & Ac3 & Ac4 & Ac5 & Tvivo & $\begin{array}{c}\text { Pressão } \\
\text { ejetor }\end{array}$ \\
\hline 12196,9 & 10985,8 & 10150,79 & 10713,83 & 10965,25 & 126,2 & 0,0732 \\
\hline
\end{tabular}


Os ruídos randômicos do modelo e da medida foram desprezados considerando que o erro do modelo é mínimo (seção 4.2) e considerando que não há erro na medida das variáveis, isso foi reproduzido nas matrizes de covariância da equação para o filtro de Kalman 14 para $W$ e $V$.

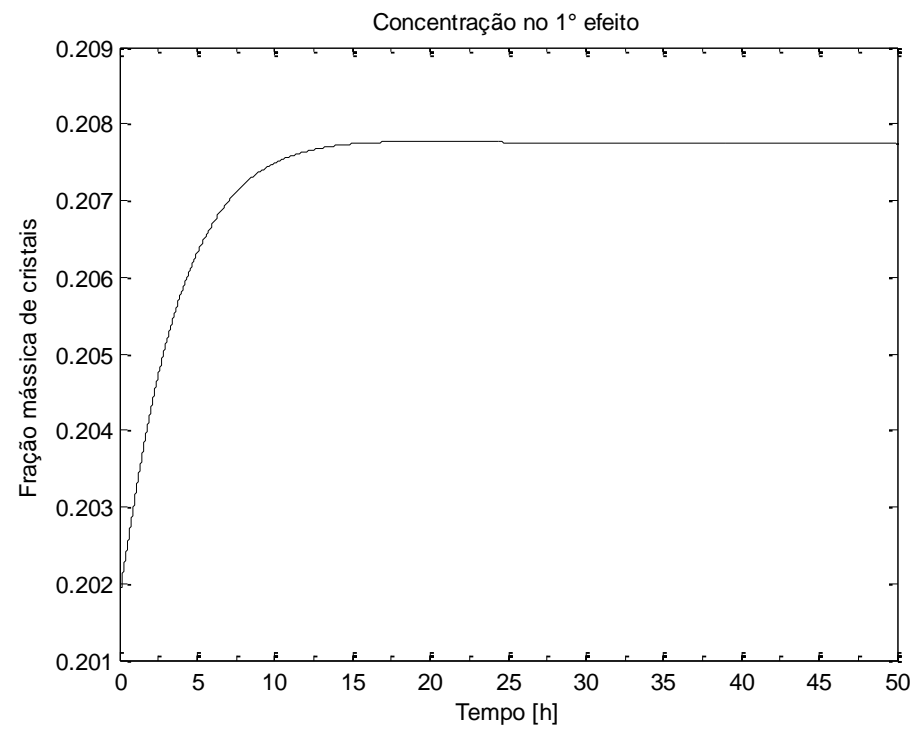

Figura 40 - Fração mássica de cristais no primeiro efeito para controle IHMPC

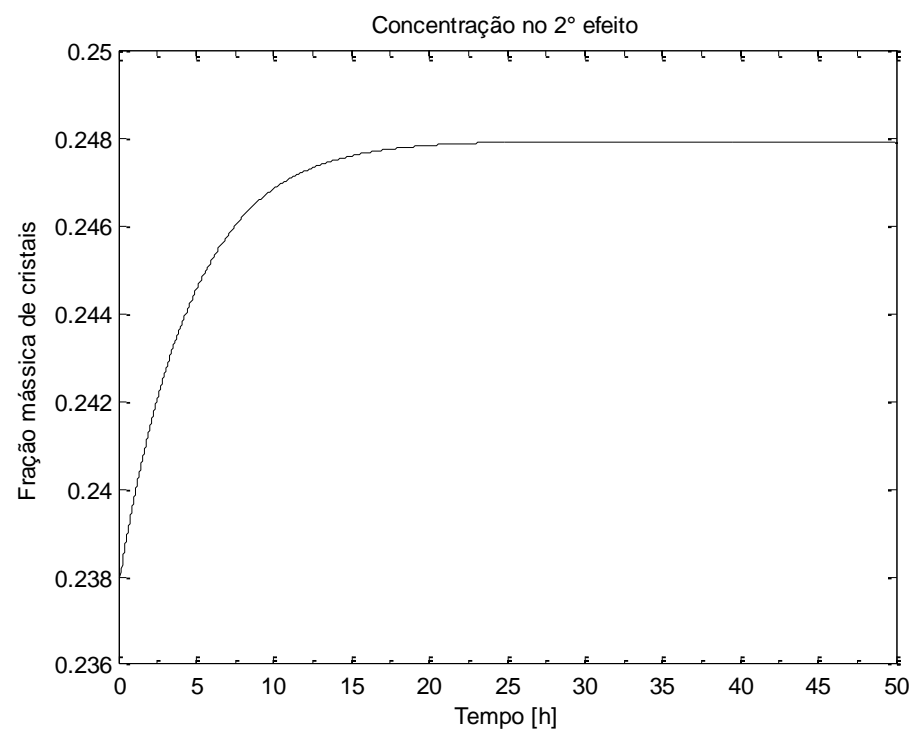

Figura 41 - Fração mássica de cristais no segundo efeito para controle IHMPC 


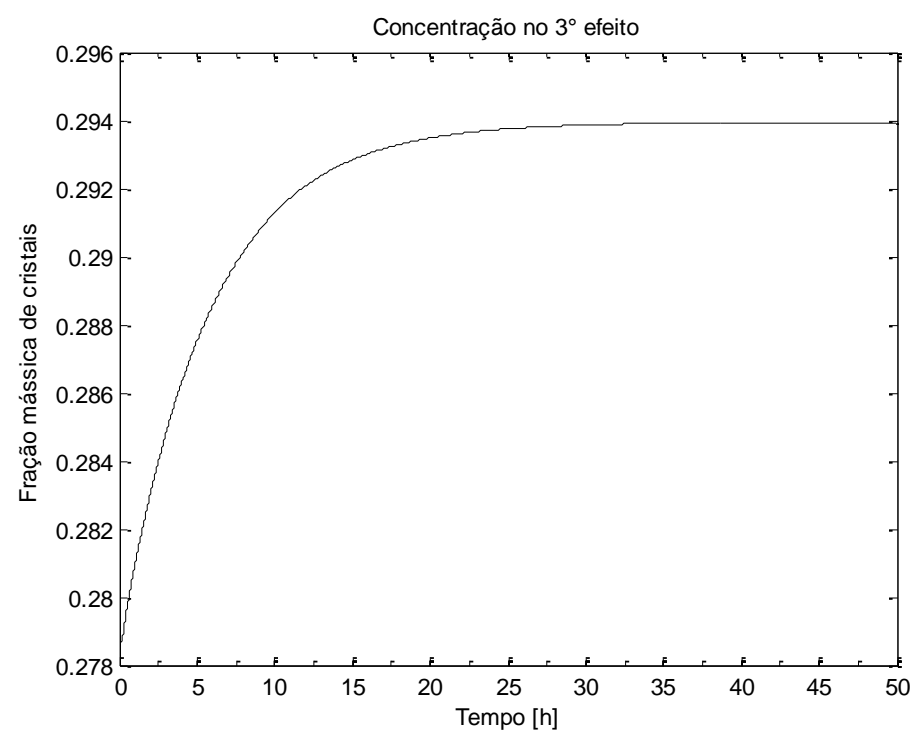

Figura 42 - Fração mássica de cristais no terceiro efeito para controle IHMPC

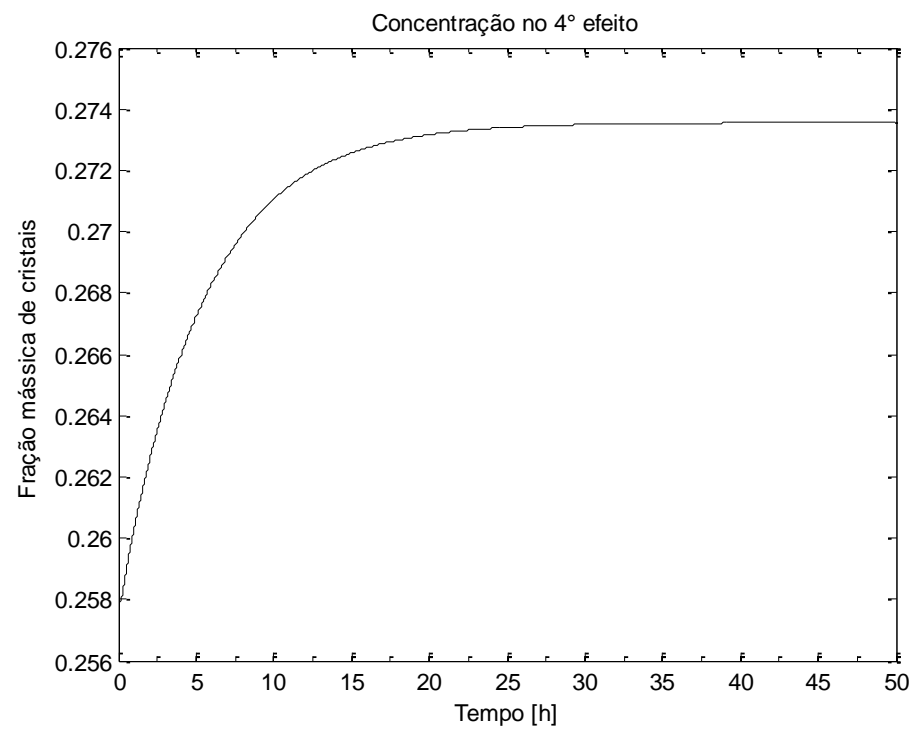

Figura 43 - Fração mássica de cristais no quarto efeito para controle IHMPC 


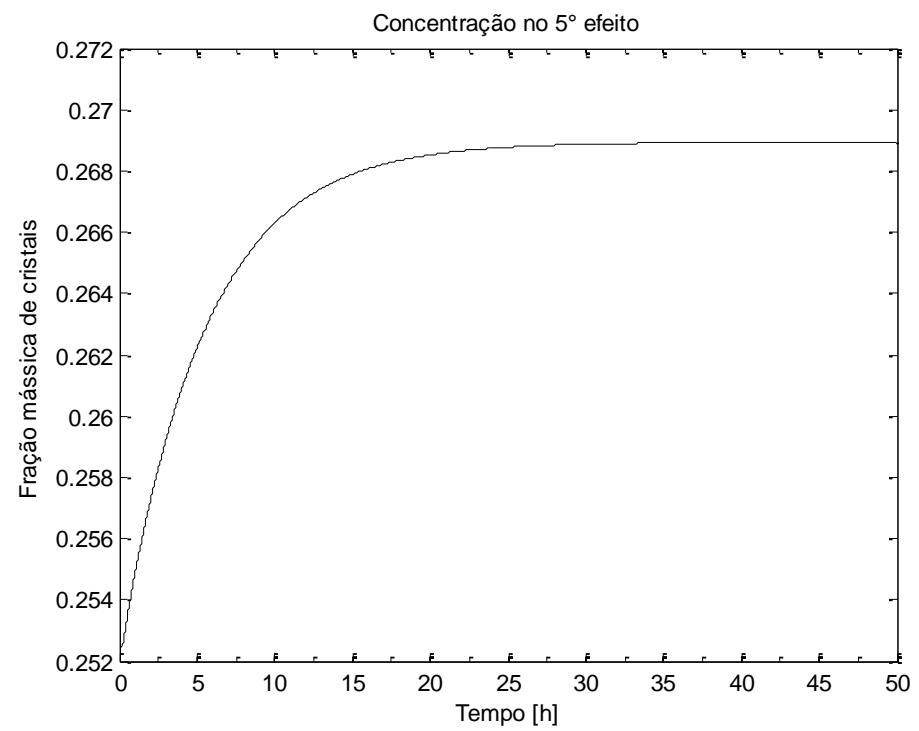

Figura 44 - Fração mássica de cristais no quinto efeito para controle IHMPC

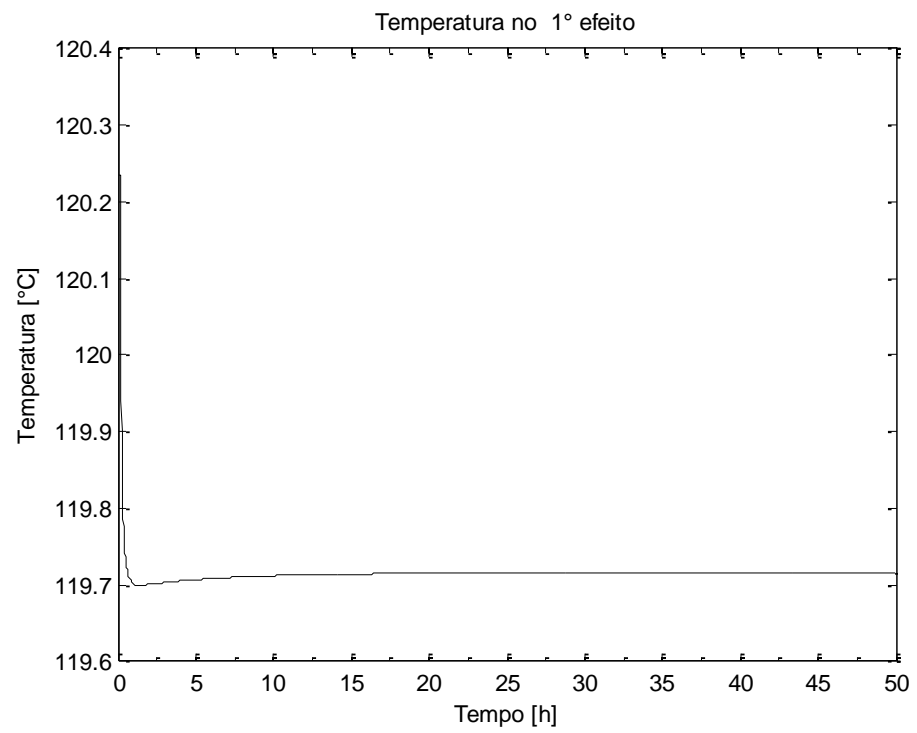

Figura 45 - Temperatura no primeiro efeito para controle IHMPC 


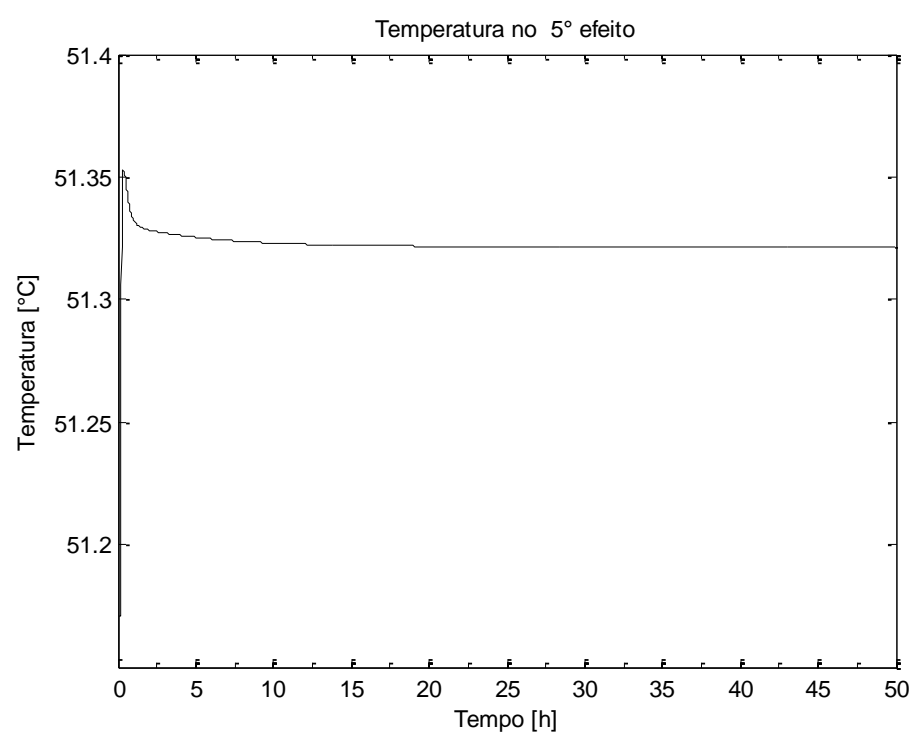

Figura 46 - Temperatura no quinto efeito para controle IHMPC

As Figuras 40 a 46 mostram a dinâmica da planta sob o controle do controlador avançado IHMPC. É evidente a maior estabilidade da planta quando usado o controle preditivo, na Figura 40 é possível ver que em 15 horas a planta, já estabilizada, atingiu seu ponto ótimo de operação, calculado pelo otimizador atuando em tempo real.

Do segundo ao quinto efeito o tempo de resposta foi um pouco mais longo, como se vê nas Figura 41 a Figura 44, sendo esse tempo de aproximadamente 20 horas, ainda assim, muito inferior ao tempo de resposta obtido pela atuação do controlador PID.

Credita-se a diferença de tempo entre o primeiro e os demais efeitos ao tempo de estabilização da temperatura. Comparando as Figura 45 e Figura 46 nota-se que a temperatura do primeiro efeito se estabiliza em pouco mais de uma hora, enquanto que a temperatura do quinto efeito se estabiliza em aproximadamente cinco horas, afetando a dinâmica do efeito durante esse intervalo de tempo e atrasando a resposta do sistema neste espaço de tempo. A avaliação da dinâmica de temperatura se estende para o segundo, terceiro e quarto efeito (não mostrado). 


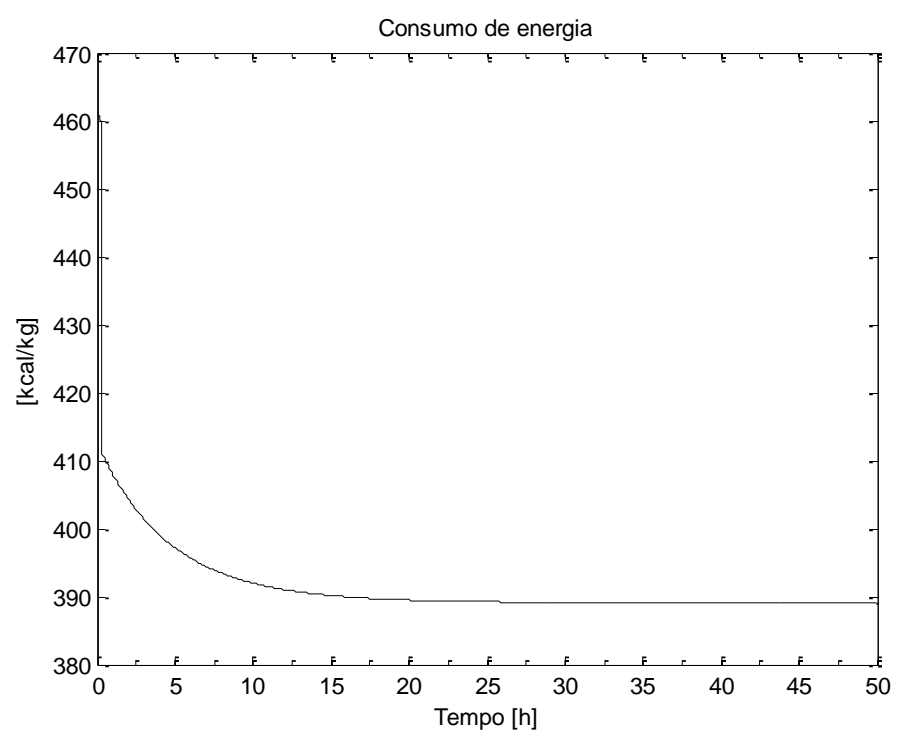

Figura 47 - Consumo energético da unidade para controle IHMPC

Nota-se a mesma estabilidade encontrada para outras variáveis. Comparando o consumo energético (Figura 47) com o do controlador PID (Figura 39), observa-se além da maior estabilidade um consumo menor de energia por massa de cristal produzido. O controlador preditivo permitiu que a planta chegasse a um estado ótimo, manipulando as variáveis de entrada para que se atingisse um melhor consumo energético, de acordo com o otimizador (Equação 82) atuando junto ao controlador. $\mathrm{O}$ controlador preditivo levou $\mathrm{O}$ consumo energético a uma queda de $5 \%$ quando comparado ao consumo da planta controlada por um controlador clássico do tipo PID.

Uma maior estabilidade da planta será vantajosa quanto ao tamanho médio dos cristais formados, considerando que a supersaturação não variou consideravelmente (Figura 48), ao contrário do controlador PID (Figura 38). 


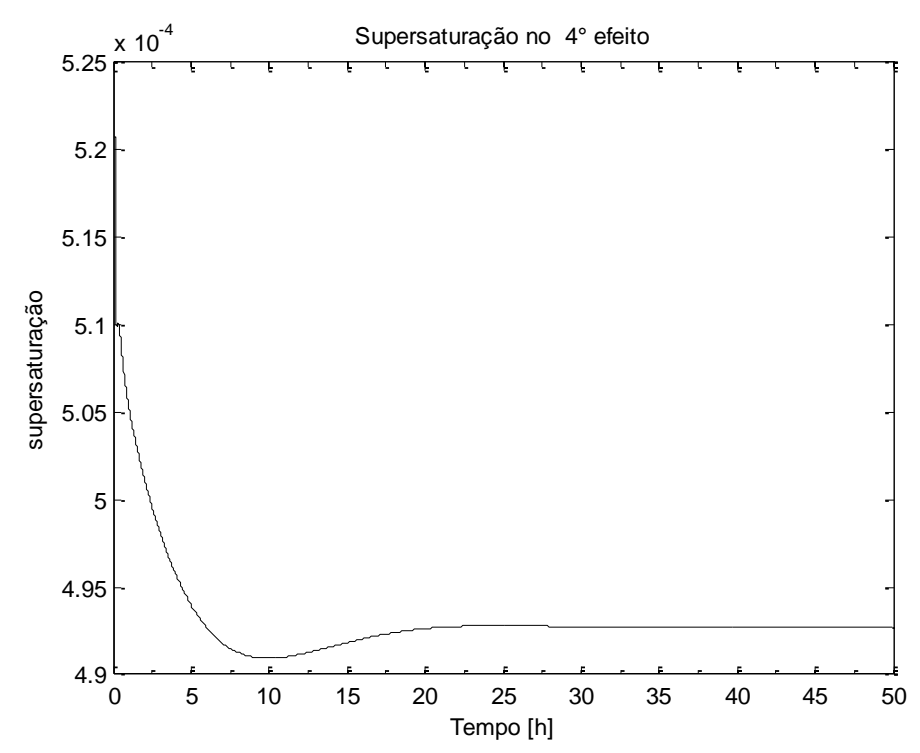

Figura 48 - Supersaturação no quarto efeito para controle IHMPC

\subsubsection{Análise de perturbação}

Uma planta química está sujeita a perturbações durante sua operação, afetando as condições operacionais pré-determinadas. Essas perturbações levam a desvios que devem ser absorvidas pelo controlador.

Nesta seção, foram simuladas perturbações do processo para determinar qual o comportamento da planta controlada pelo controlador PID e pelo controlador preditivo.

A unidade de cristalização por múltiplo-efeito sofre influência de diversas variáveis, entre elas a temperatura da salmoura alimentada e o nível de concentração dessa mesma salmoura alimentada. Supondo que a temperatura absoluta de alimentação do segundo efeito sofra uma queda de $10 \%$, por qualquer motivo, como uma ineficiente troca térmica no trocador de calor de pré-aquecimento de salmoura, a Figura 49 e a Figura 54 mostram as consequências e o comportamento para cada tipo de controlador testado. 

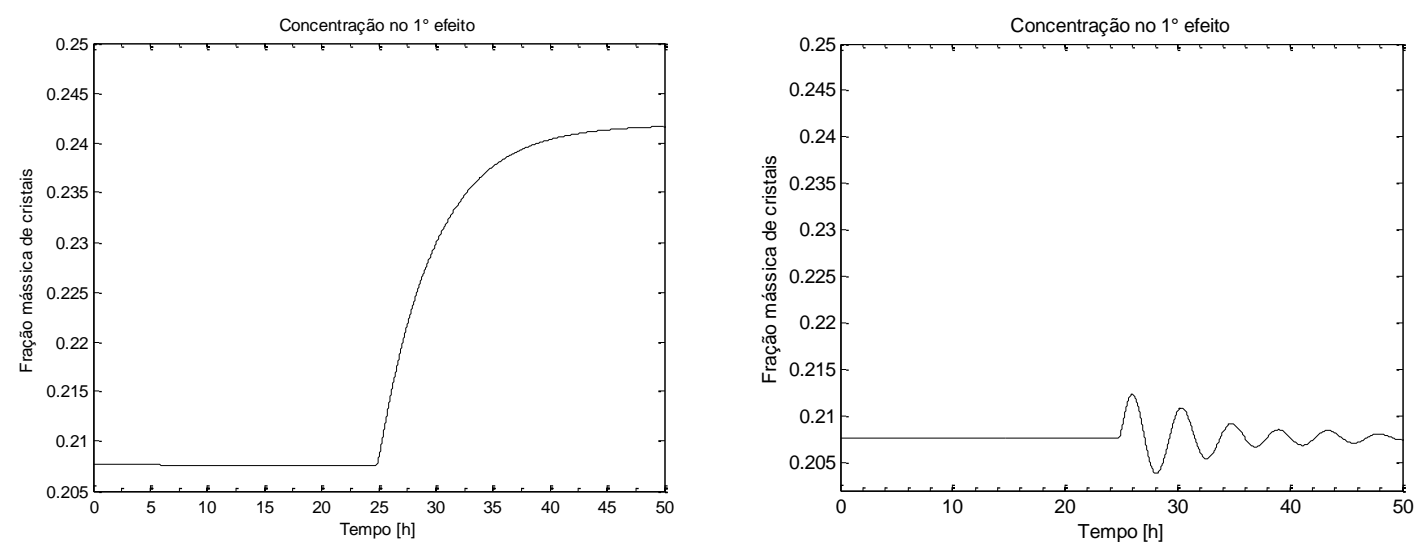

Figura 49 - Fração mássica de cristais para o primeiro efeito: a) IHMPC b) PID
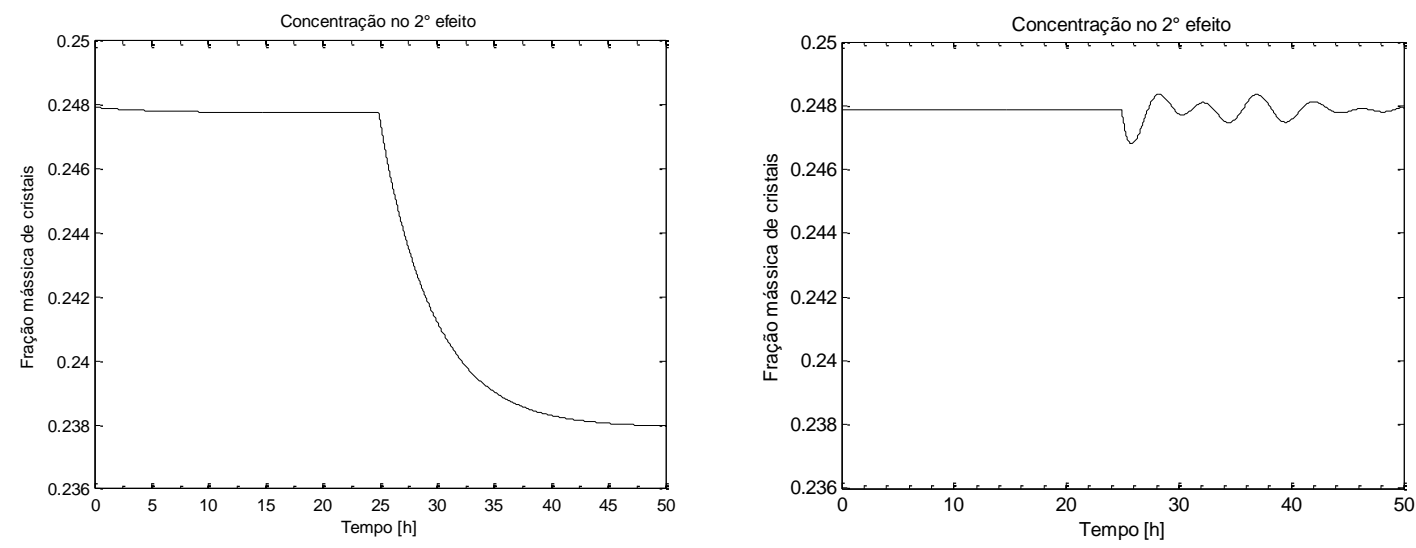

Figura 50 - Fração mássica de cristais para o segundo efeito: a) IHMPC b) PID
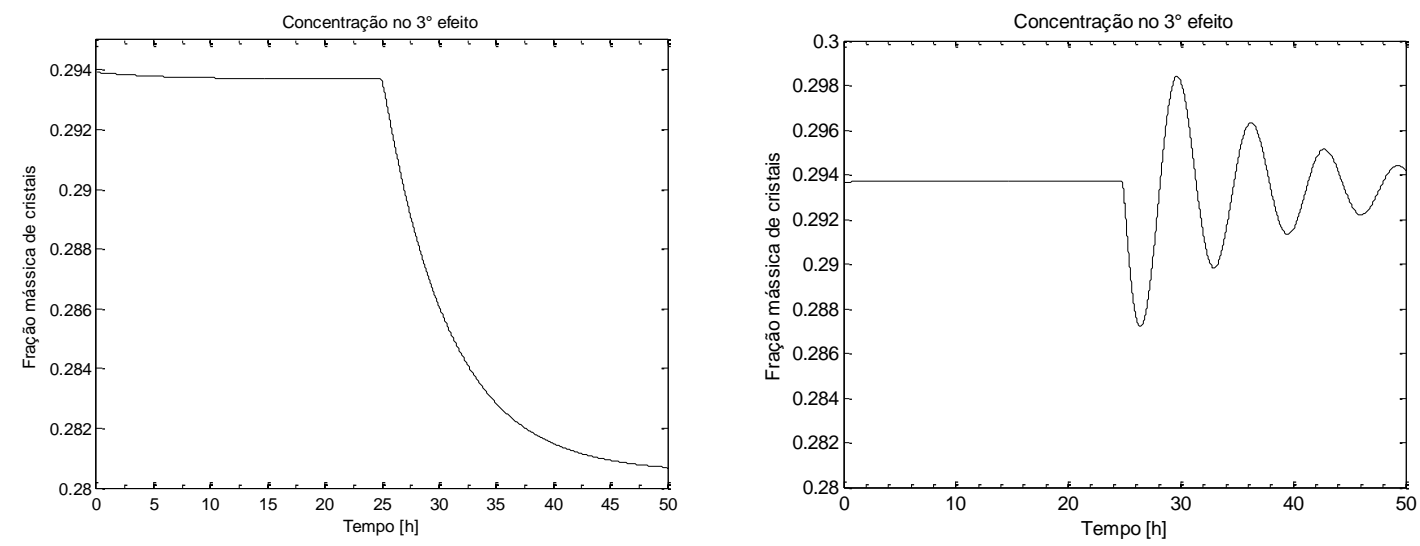

Figura 51 - Fração mássica de cristais para o terceiro efeito: a) IHMPC b) PID 

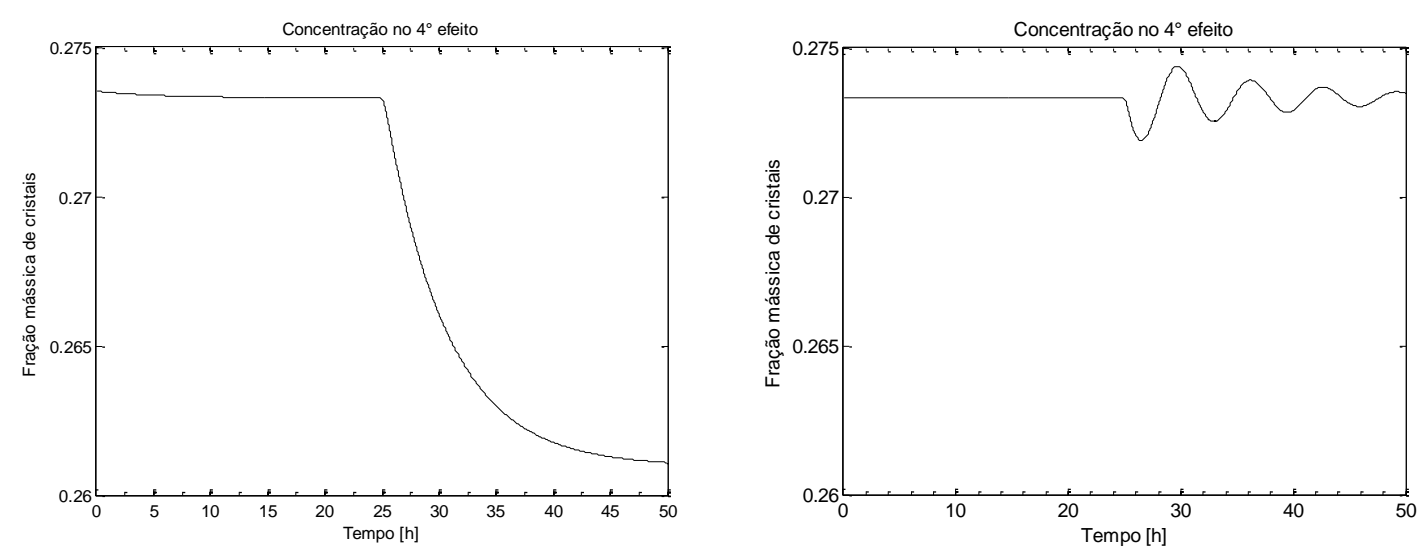

Figura 52 - Fração mássica de cristais para o quarto efeito: a) IHMPC b) PID
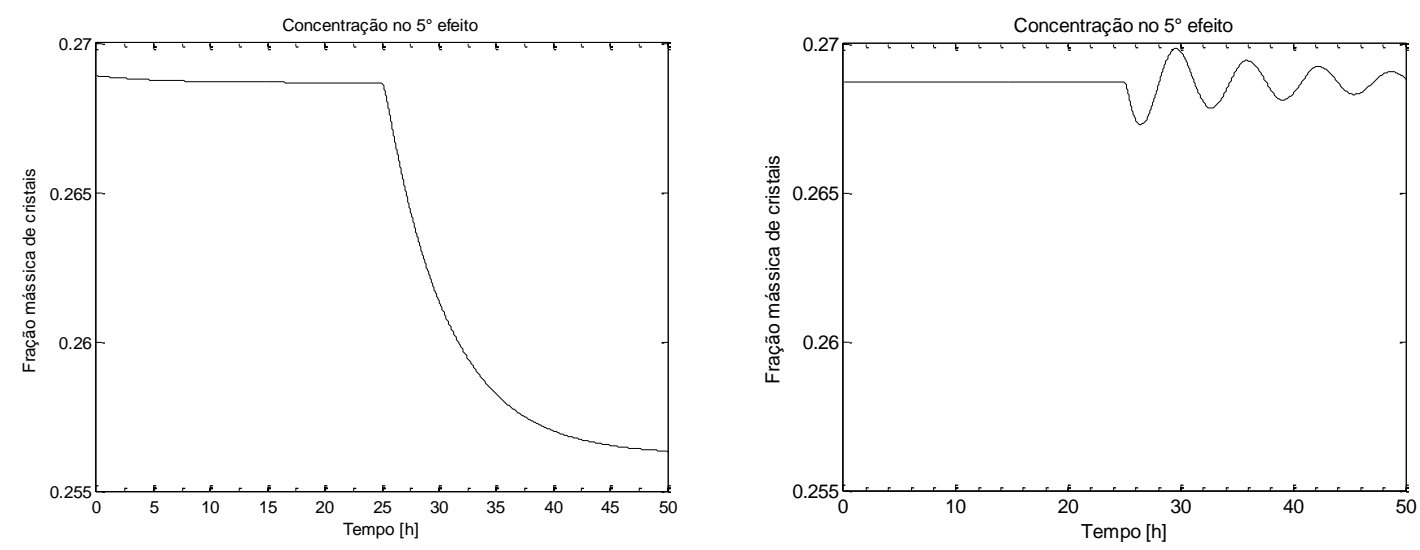

Figura 53 - Fração mássica de cristais para o quinto efeito: a) IHMPC b) PID
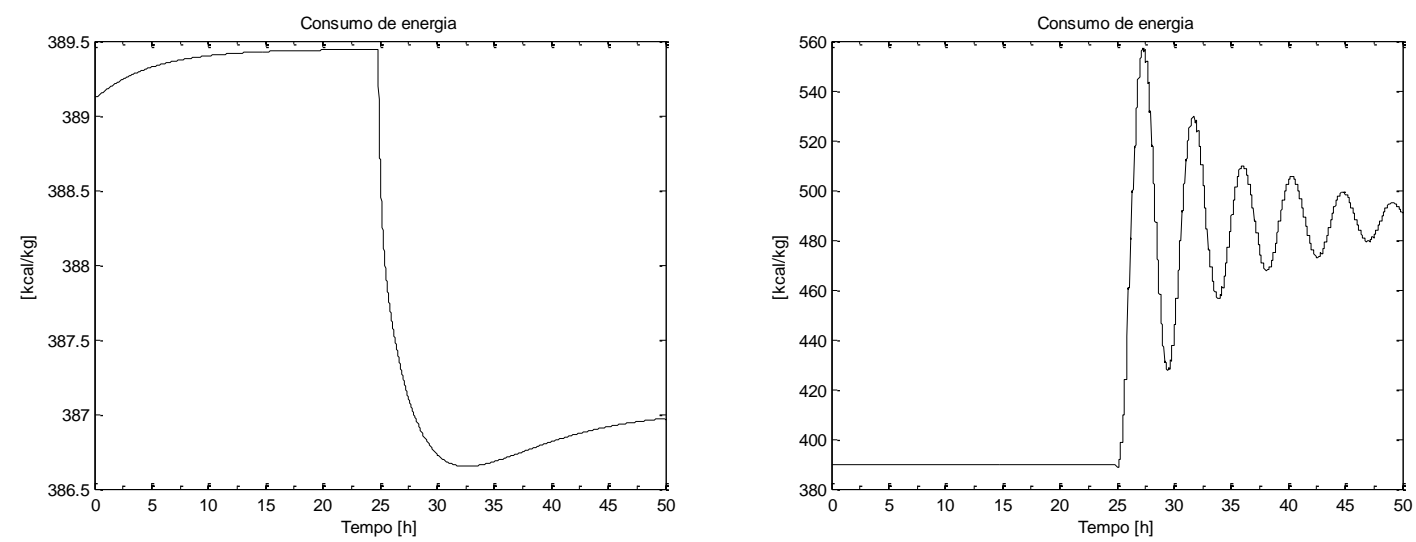

Figura 54 - Consumo energético da planta: a) IHMPC b) PID 
No momento em que há a perturbação na temperatura de alimentação do segundo efeito, o controlador PID corrige o sistema para que ele se mantenha nas condições de operação impostas, ou seja, o controlador tende a assegurar que as variáveis controladas se mantenham no set-point, como se pode ver nas Figura 49b e Figura 53b. Como consequência, houve um aumento de $25 \%$ do consumo energético conforme mostra a Figura 54b.

Em contrapartida, o controlador preditivo tende a controlar o sistema adaptando-se às condições do processo, respeitando as restrições e procurando o ponto ótimo de acordo com a função proposta, nesse caso, a de consumo energético.

Nas Figura 49a a Figura 53a, é possível ver que o controlador levou a planta a um diferente ponto de operação, ou seja, diferentes set-points foram determinados para a nova condição da planta. O controlador encontrou nessa condição um consumo energético levemente menor ao consumo para a condição anterior e com significativa diferença em relação ao consumo da planta operando com o controlador PID (Figura 54a).

Outro ponto importante que as figuras mostram é a estabilidade dos controladores após a perturbação, a oscilação apresentada antes pelo controlador PID se repete, enquanto que o controlador preditivo chega sem oscilação e menor período de tempo à nova condição do processo.

A produção de cristais também se apresentou maior para o controlador preditivo, isso se deve ao fato de que a o consumo ótimo de energia está ligado a uma maior produção, como se pode deduzir analisando o denominador da Equação 82.

A perturbação poderia ocorrer na temperatura de entrada dos outros efeitos, isoladamente ou simultaneamente, produzindo resultados semelhantes para os controladores (não mostrado).

Considerando que possa haver alteração da composição da salmoura alimentada nos cristalizadores, por problemas durante a preparação da solução 
na salina, ou diluição não intencional durante o processo, pode-se notar 0 seguinte comportamento para os dois tipos de controlador (Figura 55).
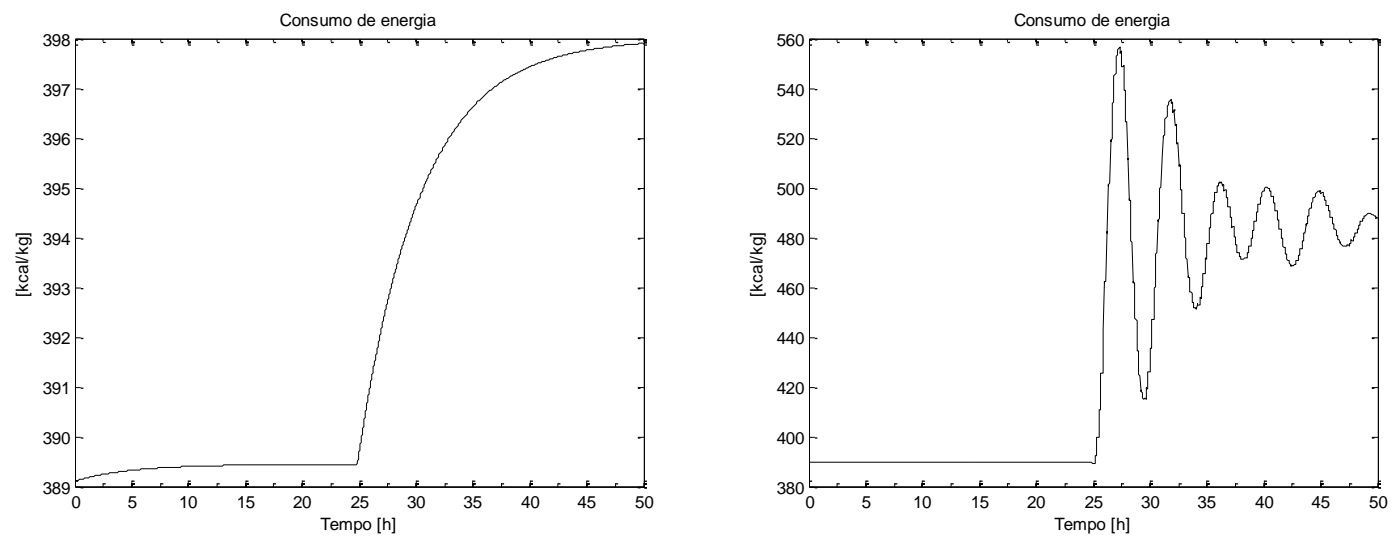

Figura 55 - Consumo energético da planta: a) IHMPC b) PID

Para essa simulação, considerou-se uma queda de $5 \%$ da concentração da salmoura alimentada nos cristalizadores.

Novamente para esse caso o controlador preditivo levou a planta a um estado de menor consumo de energia comparado ao controlador PID, evidenciando a superioridade operacional que o controlador preditivo pode trazer se aplicado à planta de cristalização por evaporação múltiplo-efeito. 


\section{CONCLUSÕES}

Neste trabalho foi desenvolvido um modelo dinâmico de uma unidade de cristalização de sal alimentício por cristalização em um evaporador de cinco efeitos. O modelo se baseia em balanços mássicos e energéticos e apresentou ser uma boa ferramenta para estudos dos fenômenos físicos que acontecem no sistema de cristalização.

Com o modelo proposto foi possível prever a dinâmica de um cristalizador frente à perturbação de um dos efeitos, com possíveis consequências para o desempenho do processo e a qualidade do produto. A partir das respostas dinâmicas, foi possível identificar modelos lineares SISOs discretos que representassem o sistema que serviram de base para o desenvolvimento de um controlador preditivo do processo.

A partir desse modelo criado foi possível testar o controlador avançado do tipo IHMPC com controle de faixas, permitindo que fosse feita comparações com um controlador clássico do tipo PID quanto a estabilidade do processo e principalmente ao consumo energético da planta.

Finalmente, a aplicação do modelo preditivo se mostrou vantajosa comparada a estrutura clássica baseada em controladores tipo PID. Para diferentes distúrbios o controlador avançado foi capaz de levar a planta a um estado de menor consumo energético e a uma maior estabilidade, indicando que seu uso em vez do controlador PID trará benefícios significativos à economia e operação da planta de cristalização por evaporação múltiplo-efeito. 


\section{REFERENCIAS}

AGUIRRE, L. Introdução à Identificação de Sistemas: Técnicas Lineares e NãoLineares Aplicadas a Sistemas Reais. 3a․ ed. Belo Horizonte: Editora UFMG, 2007.

ATUONWU, J. C.; CAO, Y.; RANGAIAH, G. P.; TADE, M. O. Identification and predictive control of a multistage evaporator. Control Engineering Practice, v. 18, n. 12, p. 1418-1428, Dec 2010.

ATUONWU, J. C.; CAO, Y.; RANGAIAH, G. P.; TADÉ, M. O. Nonlinear model predictive control of a multistage evaporator system using recurrent neural networks. 4th IEEE Conference on Industrial Electronics and Applications, ICIEA, p. 1662-1667, 2009.

BADGER, W. L.; STANDIFORD, F. C. Engineering in salt manufacture. Chemical Engineering, v. 62, n. 3/4, p. 173-177, 180-183, 1955.

BAO-CANG, D.; Modern predictive control. CRC Press, 2010.

BILLET, R. Evaporation Technology: Principles aplications, economics. Tradução de FULLARTON, J. W. 1. ed. New York: VCH, 1989.

BUNIN, G. A.; LIMA, F. V.; GEORGAKIS, C.; HUNT, C. M. Model predictive control and dynamic operability studies in a stirred tank: rapid temperature cycling for crystallization. Chemical Engineering Communications, v. 197, n. 5, p. 733-752, 2010.

BURDETT, J. W.; HOLLAND, C. D. Dynamics of a multiple-effect evaporator system. Aiche Journal, v. 17, n. 5, p. 1080-\&, 1971.

CADET, C.; TOURE, Y.; GILLES, G.; CHABRIAT, J. P. Knowledge modeling and nonlinear predictive control of evaporators in cane sugar production plants. Journal of Food Engineering, v. 40, n. 1-2, p. 59-70, Apr-May 1999.

CHRISTOFIDES, P. D.; EI-FARRAC, N.; LI, M.; MHASKAR, P. Model-based control of particulate processes. Chemical Engineering Science, v. 63, n. 5, p. 1156-1172, Mar 2008.

CHRISTOFIDES, P. D.; LI, M. H.; MADLER, L. Control of particulate processes: Recent results and future challenges. Powder Technology, v. 175, n. 1, p. 1-7, 2007.

CHMAERZYNSKI, A; PIEKARSKI, H. Enthalpies of crystallization of $\mathrm{NaCl}, \mathrm{KCl}$, $\mathrm{LiCl} . \mathrm{H}_{2} \mathrm{O}, \mathrm{MgCl}_{2} \cdot 6 \mathrm{H}_{2} \mathrm{O}, \mathrm{CaCl}_{2} \cdot 6 \mathrm{H}_{2} \mathrm{O}$ and $\mathrm{BaCl}_{2} .2 \mathrm{H}_{2} \mathrm{O}$ from aqueous solution at 298.15 K. Journal of Thermal Analysis, v. 38, p.2019-2025, 1992.

CORRIOU, J. P.; ROHANI, S. A New Look at Optimal Control of a Batch Crystallizer. Aiche Journal, v. 54, n. 12, p. 3188-3206, Dec 2008. 
DAMOUR, C.; BENNE, M.; GRONDIN-PEREZ, B.; CHABRIAT, J. P. Nonlinear predictive control based on artificial neural network model for industrial crystallization. Journal of Food Engineering, v. 99, n. 2, p. 225-231, Jul 2010.

FELDER, R. M; ROSSEAU, R. W. Principios Elementares dos processos químicos, 3aㅡ ed. editora LTC, 2005.

GEANKOPLIS, C. J. Transport processes and separation process principles (includes unit operations). 4. ed. New Jersey: Prentice Hall 2003.

GONZALEZ, A. H.; D. Odloak A stable MPC with zone control. Journal of Process Control, 19,110-122, 2009.

GROOTSCHOLTEN, P. A. M. Solid-liquid contacting in industrial crystallizer and its influence on product size distribution. (1982). (Doctor) - Department of Mechanical Enginnering, Delft University of Technology, Delft, 1982.

HENSON, M. A. Nonlinear model predictive control: current status and future directions. Computers \& Chemical Engineering, v. 23, n. 2, p. 187-202, Dec 1998.

HERMANTO, M. W.; CHIU, M. S.; BRAATZ, R. D. Nonlinear model predictive control for the polymorphic transformation of I-glutamic acid crystals. A/ChE Journal, v. 55, n. 10, p. 2631-2645, 2009.

HU, Q.; ROHANI, S.; JUTAN, A. New numerical method for solving the dynamic population balance equations. AIChE Journal, v. 51, n. 11, p. 3000-3006, Nov 2005.

INCROPERA, F. P; WITT, D. P. Fundamentos de transferência de calor e de massa, 3를. ed. Guanabara / Koogan, 1992.

JANCIC, S. J.; GROOTSCHOLTEN, P. A. M. Industrial Crystallization. 1st. ed. Delft: Delft University Press, 1984.

JONES, A. G. Crystallization Process Systems. Oxford: ButterworthHeinemann, 2002.

KAM, K. M.; TADE, M. O. Simulated nonlinear control studies of five-effect evaporator models. Computers \& Chemical Engineering, v. 23, n. 11-12, p. 1795-1810, 2000.

KAUFMANN, D.L. Sodium chloride, the production and properties of salt and brine. New York, USA: Reinhold Publishing Corporation 1960.

KOUVARITAKIS, B.; CANNON, M. Nonlinear predictive control: theory and practice. London: Institution of Engineering and Technology, 2001. (VET Control Engineering Series).

KRAMER, H. J. M.; DIJKSTRA, J. W.; VERHEIJEN, P. J. T.; VAN ROSMALEN, G. M. Modeling of industrial crystallizers for control and design purposes. Powder Technology, v. 108, n. 2-3, p. 185-191, 2000. 
LAERSON, P. A.; PATIENCE, D. B; RAWLINGS, J. B. Industrial crystallization process control, IEEE Control Systems Magazine, p. 70-80, 2006.

LAKATOS, B. G.; SAPUNDZHIEV, T. J.; GARSIDE, J. Stability and dynamics of isothermal CMSMPR crystallizers. Chemical Engineering Science, v. 62, n. 16, p. 4348-4364, 2007.

LEE, J. S.; LEE, K. J. Dynamic simulation of a forced circulation evaporating system. Annals of Nuclear Energy, v. 20, n. 5, p. 347-360, 1993.

LIU, J. F.; DE LA PENA, D. M.; CHRISTOFIDES, P. D.; DAVIS, J. F. Lyapunovbased Model Predictive Control of Particulate Processes Subject to Asynchronous Measurements. Particle \& Particle Systems Characterization, v. 25, n. 4, p. 360-375, Nov 2008.

MATTHEWS, H. B.; RAWLINGS, J. B. Batch crystallization of a photochemical: Modeling, control, and filtration. AIChE Journal, v. 44, n. 5, p. 1119-1127, May 1998.

MESBAH, A.; LANDLUST, J.; HUESMAN, A. E. M.; KRAMER, H. J. M.; JANSENS, P. J.; VAN DEN HOF, P. M. J. A model-based control framework for industrial batch crystallization processes. Chemical Engineering Research \& Design, v. 88, n. 9A, p. 1223-1233, Sep 2010.

MIRANDA, V.; SIMPSON, R. Modelling and simulation of an industrial multiple effect evaporator: tomato concentrate. Journal of Food Engineering, v. 66, n. 2, p. 203-210, Jan 2005.

MULLIN, J. W. Crystallization. 4. ed. Oxford: Butterworth Heinemann, 2001.

MYERSON, A. Handbook of Industrial Crystallization. 2. ed.: ButterworthHeinemann, 2002.

NAGY, Z. K.; CHEW, J. W.; FUJIWARA, M.; BRAATZ, R. D. Comparative performance of concentration and temperature controlled batch crystallizations. Journal of Process Control, v. 18, n. 3-4, p. 399-407, Mar-Apr 2008.

NEVERS, N. Physical and chemical equilibrium for chemical engineers. New York: John Wiley \& Sons, 2002.

OGATA, K. ; "Engenharia de Controle Moderno"; $4^{\text {a }}$ edição Pretice/Hall do Brasil; 2003.

PATRA, D.; JENA, D.; MOHANTY, S. K. Model predictive control. (2007). (Bachelor) - Department of electronics and communication engineering, National Institute of Technology, Roukerla, 2007.

Perry's chemical engineering handbook. $7^{\underline{a}}$ ed. United States: McGraw-Hill, 2007

QIN, S. J.; BADGWELL, T. A. A survey of industrial model predictive control technology. Control Engineering Practice [S.I.], v. 11, n. 7, p. 733-764, 2003. 
RAMKRISHNA, D. Population Balances: Theory and Application to Particulate Systems and Engineering. San Diego: Academic Press, 2000.

RANDOLPH, A. D.; LARSON, M. A. Theory of Particulate Processes: Analysis and Techniques of Continuous Crystallization. 2nd. ed.: Academic Press, 1988.

RAWLINGS, J. B.; MAYNE, D. Q. Model predictive control theory and design. Nob Hill Pub, 2009.

RAWLINGS, J. B.; MILLER, S. M.; WITKOWSKI, W. R. Model identification and control of solution crystallization processes - A review. Industrial \& Engineering Chemistry Research, v. 32, n. 7, p. 1275-1296, 1993.

RAWLINGS, J.B.; MUSKE, K. R. The stability of constrained receding horizon control. IEEE Transactions on Automatic Control, v. 38, n. 10, p. 1512 -1516, 1993

RAWLINGS, J. B.; WITKOWSKI, W. R.; EATON, J. W. Modeling and control of crystallizers. Powder Technology, v. 69, n. 1, p. 3-9, 1992.

RODRIGUES, M. A; ODLOAK, D. An infinite horizon model predictive control for stable and integrating process. Computers and Chemical Engineering, v. 27, p. $1113-1128,2003$

ROHANI, S.; HAERI, M.; WOOD, H. C. Modeling and control of a continuous crystallization process - Part 1. Linear and non-linear modeling. Computers \& Chemical Engineering, v. 23, n. 3, p. 263-277,1999a.

ROHANI, S.; HAERI, M.; WOOD, H. C. Modeling and control of a continuous crystallization process - Part 2. Model predictive control. Computers \& Chemical Engineering [S.I.], v. 23, n. 3, p. 279-286, 1999b.

RUNYON, C. H.; RUMSEY, T. R.; MCCARTHY, K. L. Dynamic simulation of a nonlinear model of a double effect evaporator. Journal of Food Engineering [S.I.], v. 14, n. 3, p. 185-201, 1991.

SANTORO, B. F. Controle Preditivo de Horizone Infinito Para Sistemas Integradores e com Tempo Morto (Mestrado) - Departamento de Engenharia Química, Universidade de São Paulo, São Paulo, 2011

SEBORG, D. E.; THOMA, F.; MELLICHAMP, D. A. Process dynamics and control. 2. ed. New York: John Wiley \& Sons, 2004.

SHI, D.; EL-FARRA, N. H.; LI, M. H.; MHASKAR, P.; CHRISTOFIDES, P. D. Predictive control of particle size distribution in particulate processes. Chemical Engineering Science [S.I.], v. 61, n. 1, p. 268-281, Jan 2006.

SINNOT, R. K. Chemical Enginnering Design. 4. ed. Oxford: Elsevier, 2005. (Coulson \& Richardson's chemical engineering series).

SUÁREZ, L. A. P.; GEORGIEVA, P.; AZEVEDO, S. F. D. Error Tolerant MPC versus $\mathrm{PI}$ Control - a Crystallization Case Study. Budapest, Hungary: Proceeding in the European Control Conference, 2009. p. 2899-2904. 
TAVARE, N. Industrial Crystallization: Process Simulation Analysis and Design. 1st. ed. New York: Plenum Press, 1995. (The Plenum Chemical Engineering Series).

WANG, L. Predictive control system, design and implementation with Matlab. London, Springer, 2009.

WOLF, S. Modelling, System Identification and Control of an Evaporative Continuous Crystallizer. (1990). (PHD) - Faculty of Mechanical Engineering and Maritime Technology, Delf University of technology, 1990.

YADAV, P.; JANA, A. K. Simulation and control of a commercial double effect evaporator: Tomato juice. Chemical Product and Process Modeling, v. 5, n. 1, 2010.

YU, Z. Q.; CHEW, J. W.; CHOW, P. S.; TAN, R. B. H. Recent Advances in Crystallization control: An Industrial Perspective. Chemical Engineering Research and Design, v. 85, n. 7, p. 893-905, 2007. 


\section{ANEXO - Propriedades físicas}

Tabela A. 1- Coeficientes para a equação de Antoine para salmoura saturada e água pura (Kaufmann, 1960)

\begin{tabular}{|c|c|c|c|}
\hline Coeficiente & $\mathbf{A}_{\mathbf{p}}$ & $\mathbf{B}_{\mathbf{p}}$ & $\mathbf{C}_{\mathbf{p}}$ \\
\hline Salmoura & 7,8783 & 1701,1 & 231,78 \\
\hline Água & 5,1156 & 1687,4 & 230,17 \\
\hline
\end{tabular}

Tabela A. 2 - Poder calorífico de soluções saturadas de $\mathrm{NaCl}$ (Kaufmann, 1960).

\begin{tabular}{|c|c|}
\hline $\mathrm{T}\left({ }^{\circ} \mathrm{C}\right)$ & $\mathrm{Cp}(\mathrm{cal} / \mathrm{g} . \mathrm{K})$ \\
\hline 21,1 & 0,786 \\
\hline 26,7 & 0,789 \\
\hline 32,2 & 0,792 \\
\hline 37,8 & 0,795 \\
\hline 43,3 & 0,798 \\
\hline 48,9 & 0,802 \\
\hline 54,4 & 0,806 \\
\hline 60 & 0,81 \\
\hline 65,6 & 0,814 \\
\hline 71,1 & 0,819 \\
\hline 76,7 & 0,824 \\
\hline 82,2 & 0,828 \\
\hline 87,8 & 0,834 \\
\hline 93,3 & 0,838 \\
\hline 98,9 & 0,844 \\
\hline 104,4 & 0,848 \\
\hline 110 & 0,854 \\
\hline 115,6 & 0,858 \\
\hline 121,1 & 0,864 \\
\hline
\end{tabular}

Esses dados foram aproximados para $\mathrm{Cp}(\mathrm{cal} / \mathrm{g} \cdot \mathrm{K})=0,0008 \mathrm{~T}\left({ }^{\circ} \mathrm{C}\right)+0,7648$, sendo $R^{2}=0,9926$ 
Tabela A. 3 - Solubilidade da salmoura em função da temperatura (Kaufmann, 1960).

\begin{tabular}{|c|c|}
\hline $\mathrm{T}\left({ }^{\circ} \mathrm{C}\right)$ & g soluto/100g $2 \mathrm{O})$ \\
\hline 0 & 35,8 \\
\hline 10 & 35,8 \\
\hline 20 & 35,9 \\
\hline 30 & 36,2 \\
\hline 40 & 36,4 \\
\hline 50 & 36,8 \\
\hline 60 & 37,2 \\
\hline 70 & 37,6 \\
\hline 80 & 38,0 \\
\hline 90 & 38,5 \\
\hline 100 & 39,1 \\
\hline 107 & 39,6 \\
\hline
\end{tabular}

Esses dados foram aproximados para $C_{s}=0,000000114 T^{3}+0,0002572 T^{2}+$ $0,00745 T+35,715$, sendo $R^{2}=0,99924$. Dados entre 107 e $122{ }^{\circ} \mathrm{C}$ foram extrapolados a partir dessa curva. A fração de soluto pode ser calculada por $_{w}=C_{s} /\left(C_{s}+100\right)$.

Tabela A. 4 - Densidade de Salmoura saturada (Mullin, 2001)

\begin{tabular}{|c|c|}
\hline $\mathrm{T}$ & $\mathrm{kg} / \mathrm{m}^{3}$ \\
\hline 0 & 1209 \\
\hline 10 & 1204 \\
\hline 20 & 1199,9 \\
\hline 30 & 1195,7 \\
\hline 40 & 1191,4 \\
\hline 50 & 1187,2 \\
\hline 60 & 1183 \\
\hline 70 & 1178,7 \\
\hline 80 & 1174,5 \\
\hline 90 & 1170,3 \\
\hline 100 & 1166 \\
\hline
\end{tabular}


Esses dados foram aproximados para Csat $=-0,42534652^{*} T+1208,52105533$ sendo $R^{2}=0,99986$. Dados entre 107 e $122{ }^{\circ} \mathrm{C}$ foram extrapolados a partir dessa curva.

Tabela A. 5 - Propriedades do cristal de $\mathrm{NaCl}$

\begin{tabular}{|l|r|l|}
\hline Densidade (Perry, 2007) & 2163 & $\mathrm{~kg} / \mathrm{m}^{3}$ \\
\hline Poder calorífico (Perry, 2007 [range 273-1074K]) & $10,79+0,00042 \mathrm{~K}(\mathrm{~K})$ & $\mathrm{cal} / \mathrm{mol} . \mathrm{K}$ \\
\hline Entalpia de Cristalização (Chmarzynski e Piekarsi, 1992) & 1500 & $\mathrm{~J} / \mathrm{gmol}$ \\
\hline Massa molar & 58,5 & \\
\hline
\end{tabular}

Tabela A. 6 - Propriedades da água pura (Incropera e Witt, 1992).

\begin{tabular}{|l|l|l|}
\hline Entalpia de vaporização & $-0,00268 \mathrm{~T}^{2}-2,13004 \mathrm{~T}+2496,31683$ & $\mathrm{~kJ} / \mathrm{kg}$ \\
\hline Entalpia do líquido & $4,20245 \mathrm{~T}-0,836059$ & $\mathrm{~kJ} / \mathrm{kg}$ \\
\hline Entalpia do vapor & $-0.002262 \mathrm{~T}^{2}+2,007473 \mathrm{~T}+2497,525967$ & $\mathrm{~kJ} / \mathrm{kg}$ \\
\hline
\end{tabular}

Tabela A. 7- Constantes e expoentes da taxa de crescimento e nucleação

\begin{tabular}{|c|c|c|}
\hline $\mathrm{kg}$ & $12,63 \times 10-6$ & $\mathrm{~m} / \mathrm{h}$ \\
\hline $\mathrm{g}$ & 1 & \\
\hline $\mathrm{kb}$ & $2 \times 1016$ & $\# / \mathrm{m}$ \\
\hline $\mathrm{b}$ & 1,4 & \\
\hline
\end{tabular}




\section{Modelagem}

Na seção 3.2.1 discutiu-se sobre o efeito da variação de densidade no balanço de massa global, aqui é apresentado um gráfico que exemplifica os baixos efeitos dessa variação na modelagem do processo.

A Figura A. 1 foi gerada para uma perturbação na concentração e temperatura de alimentação do terceiro efeito da unidade de cristalização por evaporação múltiplo-efeito. Porém, a baixa influencia da variação de densidade foi sempre observada para variações de concentração de cristais entre 15 a $30 \%$ em massa.

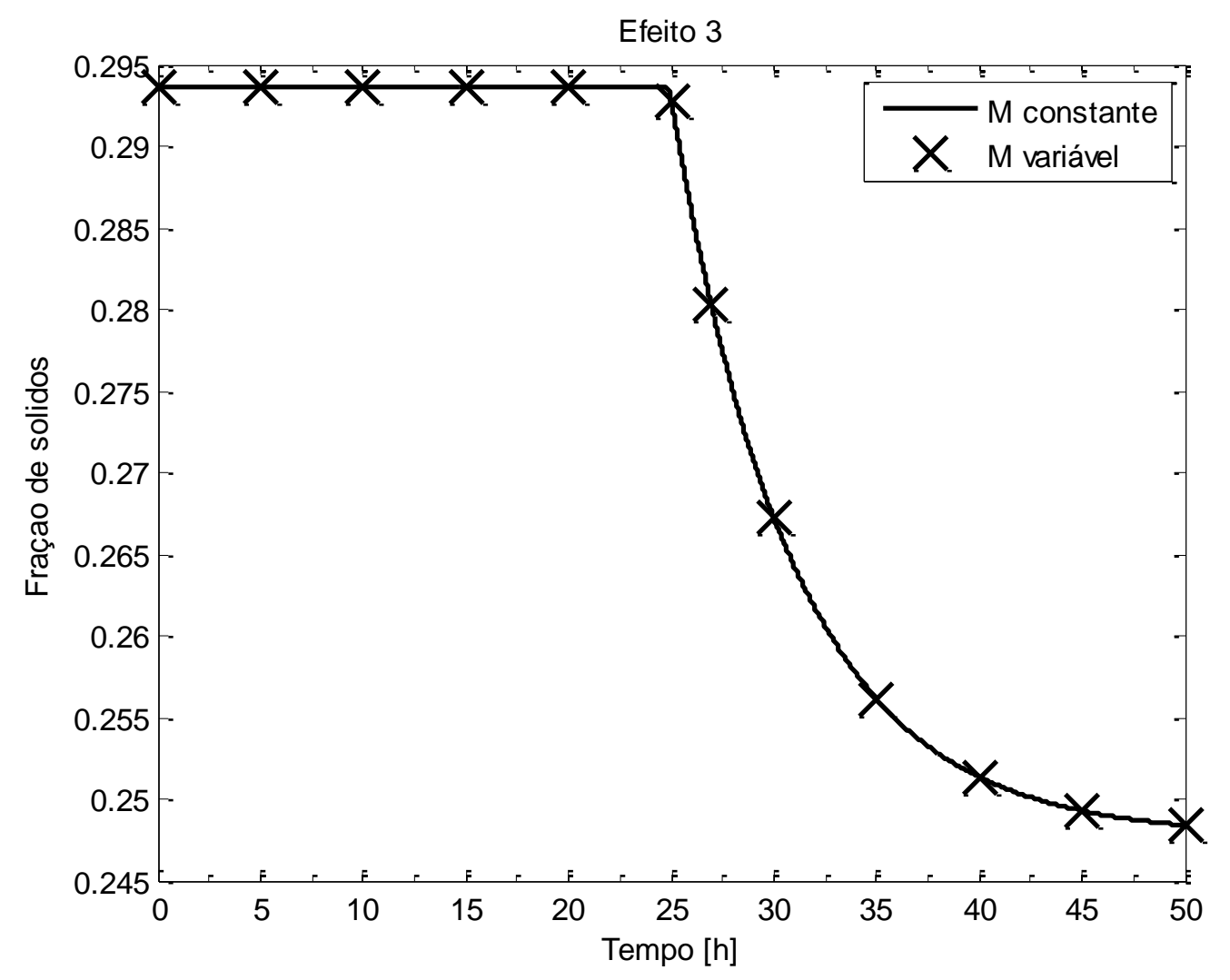

Figura A. 1 - Comparação entre o modelo com massa total do cristalizador constante e massa do cristalizador variável com a densidade. 